The Psychological Effects of 60 days in Administrative Segregation ${ }^{\odot}$

by

\title{
Ivan Zinger
}

\author{
A thesis submitted to \\ the Faculty of Graduate Studies and Research \\ in partial fulfillment of the requirements \\ for the degree of \\ (Doctor of Philosophy) \\ Department of Psychology
}

Carleton University

Ottawa, Ontario

December 1998 
Acquisitions and Bibliographic Services

395 Wellington Street Ottawa ON K1A ON4 Canada

\section{du Canada}

Acquisitions et

services bibliographiques

395, rue Wellington

Ottawa ON K1A ON4

Canada
The author has granted a nonexclusive licence allowing the National Library of Canada to reproduce, loan, distribute or sell copies of this thesis in microform, paper or electronic formats.

The author retains ownership of the copyright in this thesis. Neither the thesis nor substantial extracts from it may be printed or otherwise reproduced without the author's permission.
L'auteur a accordé une licence non exclusive permettant à la Bibliothèque nationale du Canada de reproduire, prêter, distribuer ou vendre des copies de cette thèse sous la forme de microfiche/film, de reproduction sur papier ou sur format électronique.

L'auteur conserve la propriété du droit d'auteur qui protège cette thèse. $\mathrm{Ni}$ la thèse ni des extraits substantiels de celle-ci ne doivent être imprimés ou autrement reproduits sans son autorisation.

\section{Canadä}


Acknowledgments

This research project could not have been conducted without the full support of the Correctional Service of Canada (CSC). Larry Motiuk, Director General of the CSC Research Branch, was instrumental in facilitating the implementation of this national research project. He taught me, inter alia, how to effectively address the many administrative obstacles confronting anyone conducting correctional field research. Moreover, many dedicated CSC psychologists provided assistance to this project. Without the support of Daryl Kroner, Wagdy Loza, Jeremy Mills, Ralph Serin, and David Simourd, this project would not have being possible. I must also thank the three research assistants, Petrina Lemieux, Erin McCormick, and Jennifer van de Ven, who diligently collected the data and displayed a great deal of flexibility in working around the daily operational priorities of segregation units. Finally, the technical assistance and hard work of Cherami Wichmann undoubtedly facilitated the completion of this research project. I am therefore extremely grateful to all these individuals who exhibited impeccable professionalism and provided me with assistance, guidance, and most important, friendship. 


\section{Abstract}

Participants in this longitudinal study included 60 inmates from Kingston, Collins Bay and Millhaven Penitentiaries who had either been (a) voluntarily or involuntarily placed in administrative segregation and remained in segregation for 60 days (quasi-experimental group; $\underline{n}=23$ ), or $(b)$ randomly selected from the general inmate population and remained in the general inmate population for 60 days (comparison group; $\underline{n}=37$ ). Participants initially completed written psychological tests and took part in a structured interview that assessed their overall mental health and psychological functioning. The same procedure was undertaken 30 days later, and again 60 days later. Segregated offenders had similar education, offence history and criminogenic needs than non-segregated offenders. However, segregated offenders had distinct personalities (NEO) and were higher risk cases (SIR Scale) than non-segregated offenders. Overall, segregated offenders had poorer mental health and psychological functioning. However, there was no evidence that over a period of 60 days the mental health and psychological functioning of segregated offenders significantly deteriorated. 
Table of Contents

Acknowledgments.

ii

Abstact....................................................... ii

Tables of Content.................................................. iv

List of Tables......................................................... vii

List of Figures.................................................. $\quad x$

List of Appendices............................................ xi

Introduction........................................................... 1

Negative Effects Versus No Negative Effects.................. 2

Negative Effects...................................... 2

No Negative Effects................................. 7

Evaluation of Existing Research on Segregation

A Review of Methodological Shortcomings...................... 9

1. Reliance on Qualitative Data........................ $\quad 10$

2. Conditions of Confinement.......................... 11

3. Relevance of Field and Laboratory Experiments on Sensory Deprivation................................. 13

4. Selection of Subjects.............................. 15

4.1 Use of Volunteers............................ 15

4.2 Use of Inmates Involved in Human Rights

Violation Litigation................................ 17

4.3 Screening-out Subjects with

Psychiatric History.............................. 18

5. Reasons for Segregation........................... 20

6. Attrition............................................. 20

7. Reliance on Cross-sectional and

Longitudinal Research................................. 21

8. Duration and Indeterminate Nature of Stay.......... 22

9. Lack of Comparison Group.......................... 23

10. Inmate/Staff Interaction and the Punitive

Reality of Segregation................................... 23

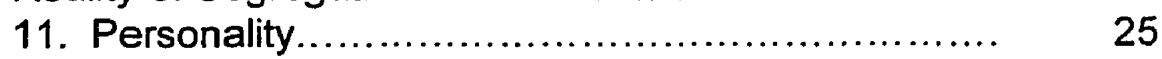

12. Other Factors.................................... 26

Addressing Methodological and Theoretical Shortcomings.... 26 
Study on the Effects of Administrative Segregation.

Hypotheses................................................... 34

Method........................................................ 34

Design and Procedures........................................ 36

Participants ....................................... $\quad 36$

Testing and Procedures.............................. $\quad 36$

Measures.............................................. 37

Aggression Questionnaire....................... $\quad 38$

Balanced Inventory of Desirable.................. $\quad 40$

Beck Depression Inventory - Short Form........... 41

Brief Symptom Inventory........................ 42

Holden Psychological Screening Inventory........ 43

Hopelessness Scale............................... 44

Interview Assessment............................. $\quad 45$

NEO Personality Inventory....................... 45

Shipley Institute of Living Scale-Revised.......... $\quad 46$

State-trait Anxiety Inventory....................... 47

Additional Data Collection................................ 48

Physical Conditions.................................... 48

Offender Intake Assessment............................ 48

Results.................................................. 49

Conditions of Confinement............................ 49

Participation and Attrition............................... 50

Age.................................................... 52

Race................................................. 52

Education............................................ 53

Criminal History........................................ 53

Case Needs......................................... 54

SIR Scale............................................. 55

I.Q. ................................................... 56

Personality............................................ 56

Mental Health and Psychological Functioning............ 57

Balanced Inventory of Desirable Responding..... 59

Repeated Measures Analyses on the

Four Mental Health and psychological

Functioning Composite Variables................. $\quad 60$

MANOVA................................... 61

ANOVAs................................. 62

Externalizing/Aggression............ 62

Internalizing/interpersonal

Distress............................ 63

Psychiatric Symtomatology........... $\quad 65$

Cognitive Ability ..................... 66 
Repeated Measures Analyses on the Eight Measures for Offenders Who

Completed Three Sessions......................... 67

Aggression Questionnaire................... 68

Beck Depression Inventory.................. 69

Brief Symptom Inventory.................... $\quad 70$

Holden Psychological

Screening Inventory........................ $\quad 71$

Hopelessness Scale....................... 73

State-trait Anxiety Inventory................. $\quad 74$

WAIS (Digit Span) ........................ $\quad 76$

WAIS (Digit Symbol)....................... 78

Segregated Offenders Who Completed

Three Sessions Versus Segregated Offenders

Who Completed One or Two Sessions............ $\quad 79$

Voluntary Versus Involuntary Cases..................... 81

Interview Assessment................................... 81

Ten-point Rating Scales............................... 81

Suicide Ideation.......................................... 83

Segregation Experience ............................... 83

Individual Case Review................................ 84

Discussion...................................................... 86

Generalization Issues..................................... 86

Personality............................................ 90

Psychological Effects................................. 92

Policy Issues............................................ 96

Future Direction and Conclusion.......................... 100

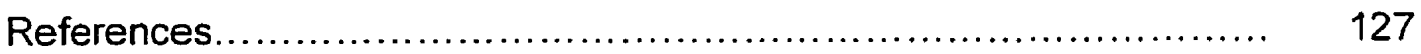


List of Tables

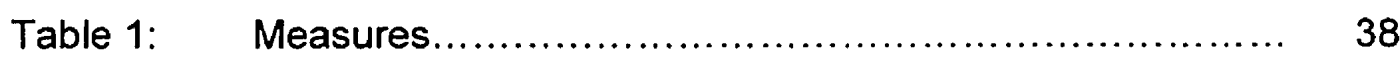

Table 2: $\quad$ Conditions of Confinement in Segregation at Collins Bay, Kingston and Millhaven Penitentiaries...................... 50

Table 3: $\quad$ Number of Completed Sessions Broken down by Group and Institutions

Table 4: $\quad$ Breakdown of Institutions and Reason for Segregation by Type of Segregation.

Table 5: $\quad$ Education OIA Indicators for Segregated and Non-segregated Offenders

Table 6: $\quad$ Offence History (Past and Current) of Segregated and Non-Segregated Offenders.

Table 7: $\quad$ Need Domains at OIA for Segregated and Non-Segregated Offenders.

Table 8: $\quad$ Percentage Distribution of SIR Risk Groups for Segregated and Non-Segregated Offenders.

Table 9: $\quad$ NEO-FFI Sub-scores for Segregated and Non-Segregated Offenders.

Table 10: Four Composite Mental Health and Psychological Functioning Variables.

Table 11: $\quad$ ANOVA for the 13 item BIDR for Segregated $(n=23)$ and Non-segregated $(n=37)$ Offenders who Completed All Three Sessions.

Table 12: $\quad$ Session Means and Respective Standard Deviations of Four Composite Variables for Segregated $(n=23)$ and Non-Segregated $(n=37)$ Offenders Who Completed All Three Sessions.

Table 13: ANOVA on the Externalizing/Aggression Composite Variable for Segregated $(n=23)$ and Non-segregated $(n=37)$ Offenders who Completed All Three Sessions. 
Table 14: ANOVA on the Internalizing/interpersonal

Distress Composite Variable for Segregated $(n=23)$

and Non-segregated $(n=37)$ Offenders who

Completed All Three Sessions..

64

Table 15: $\quad$ ANOVA on the Psychiatric Symtomatology Composite variable for Segregated $(n=23)$ and

Non-segregated ( $n=37$ ) Offenders who Completed

All Three Sessions.

Table 16: ANOVA on the Cognitive Ability Composite Variable for Segregated $(n=23)$ and Non-segregated $(n=37)$

Offenders who Completed All Three Sessions

Table 17: $\quad$ Session Means of Measures for Segregated $(n=23)$

and Non-Segregated $(n=37)$ Offenders Who

Completed All Three Sessions.

Table 18: $\quad$ ANOVA for the Aggression Questionnaire for

Segregated $(n=23)$ and Non-segregated $(n=37)$

Offenders who Completed All Three Sessions

Table 19: $\quad$ ANOVA for the Beck Depression Inventory

(Short Form) for Segregated $(n=23)$ and

Non-segregated $(n=37$ ) Offenders who Completed

All Three Sessions.

Table 20: $\quad$ ANOVA for the Brief Symptom Inventory for

Segregated $(n=23)$ and Non-segregated $(n=37)$

Offenders who Completed All Three Sessions.

Table 21: $\quad$ ANOVA for the Holden Psychological Screening

Inventory for Segregated $(n=23)$ and

Non-segregated $(n=37)$ Offenders who Completed

All Three Sessions

Table 22: $\quad$ ANOVA for the Hopelessness Scale for

Segregated $(n=23)$ and Non-segregated $(n=37)$

Offenders who Completed All Three Sessions.

Table 23: $\quad$ ANOVA for the State-trait Anxiety Inventory for

Segregated $(n=23)$ and Non-segregated $(n=37)$

Offenders who Completed All Three Sessions. 75 
Table 24: $\quad$ ANOVA for the WAIS (Digit Span) for Segregated $(n=23)$ and Non-segregated $(n=37)$ Offenders who Completed All Three Sessions

Table 25: $\quad$ ANOVA for the WAIS (Digit Symbol) for Segregated $(n=23)$ and Non-segregated $(n=37)$ Offenders who Completed All Three Sessions.

Table 26: T-tests on the Four Composite Variables and the Eight Original Measures for Segregated Offenders Who Completed Three Sessions $(n=23)$ Versus Segregated Offenders Who Completed Only Session One or Two $(n=51)$.

Table 27: T-tests on the Four Composite Variables and the Eights Original Measures for Voluntary $(n=32)$ and Involuntary $(n=51)$.

Table 28: $\quad$ Session Means and Respective Standard Deviations of Interview Assessment Questions for Segregated $(n=23)$ and Non-Segregated $(n=37)$ Offenders Who Completed All Three Sessions 


\section{List of Figures}

Figure 1: $\quad$ Between and Within Person by Situation Interaction Model... 32

Figure 2: $\quad$ Mean Score on the Internalizing/Interpersonal Variable Across Time...............................................6 65

Figure 3: $\quad$ Mean Scores on the HPSI Across Time.................... 73

Figure 4: Mean Scores on the State-trait Anxiety Inventory Across Time............................................. 76

Figure 5: $\quad$ Mean Scores on the WAIS Digit Span Across Time......... 78 


\section{List of Appendices}

Appendix 1: Consent Form .................................... 104

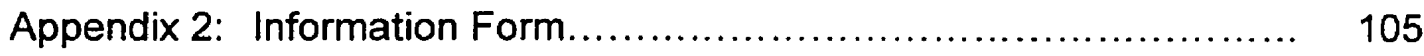

Appendix 3: Debriefing ............................................ 106

Appendix 4: Session 1 Interview: Segregated Inmates.............. 107

Appendix 5: Checklist of Physical Conditions of Confinement........... 113

Appendix 6: Individual Case Review: Segregated Offenders........... 115

Appendix 7: Individual Case Review: Non-segregated Offenders........ 120 


\section{Introduction}

The percentage of segregated inmates has more than doubled in the last ten years ${ }^{1}$ (Pierson, 1988), now representing approximately $5.5 \%$ of federally sentenced offenders in Canada (Kane, 1997). However, little research on these offenders has been completed. Moreover, the literature on segregation is sparse, conflicting, rife with speculations, and based upon far-fetched extrapolations and generalizations (Barak-Glantz, 1983; Brodsky \& Scogin, 1988; Suedfeld et al., 1982; Wormith, Tellier, \& Gendreau, 1988).

Controversy surrounding the issue of the effects of segregation on inmates has unfortunately developed based on this inadequate body of research, resulting in two positions which are virtually polar opposites. Some researchers describe segregation as "cruel and unusual punishment" and psychologically damaging, whereas others provide evidence that segregation has little, if any,

\footnotetext{
${ }^{1}$ Gendreau, Tellier, and Wormith (1985) trace increasing reliance on Protective Custody (PC) and administrative segregation to several factors: the diminished authority of prison administrators; increased demands for drugs; increased media coverage of crimes; overcrowding; outmoded classification systems; the increase in first-time federally sentenced offenders; the deinstitutionalization of mental health patients; the relative solitude of PC units compared to the general population; the growth of inmate prison gangs; police and court practices designed to encourage accomplices to testify against each other in exchange for more favorable dispositions; correctional staff's attitudes at the institutional receptions; increased willingness and ability of offenders to sue for damages; the likelihood of prison officials to be held personally liable for injuries by inmates in their care; and the increased public scrutiny of prison administrations and increased public concerns for human rights violations.
} 
negative psychological effect on inmates. The conclusions of these two assessments are strikingly opposed and difficult, if not impossible, to reconcile.

To favour one of the two opposing views concerning the impact of segregation on inmates may have important policy implications in areas such as:

(a) the level and frequency of monitoring and assessment required for inmates in segregation (mandatory vs. upon request); (b) programming to reduce mental health deterioration (need for, and type of, intervention programs); and (c) the adequacy of current assessment strategies (what aspects of psychosocial functioning are important to assess, and which are less impacted by segregation).

This document contains three sections: 1) a review of the literature concerning the psychological effects of segregation highlighting the two opposing positions; 2 ) a review of the methodological and theoretical issues with respect to segregation research; and 3) the findings of a research project which addressed the shortcomings of the existing literature.

\section{Negative Effects Versus No Negative Effects}

\section{Negative Effects}

Several authors argue that segregation has severe negative psychological effects on inmates. These authors, primarily lawyers and clinical psychologists, have mainly relied upon interviews of segregated inmates and anecdotes to draw their conclusions. For example, Jackson (1983) interviewed numerous segregated inmates, and concluded that segregation was "the most individually 
destructive, psychologically crippling and socially alienating experience that could conceivably exist within the borders of the country" (p. 243). He recounted many instances where segregation was, in his opinion, responsible for the development of psychoses (auditory and visual hallucinations, and delusions) and where segregation drove some offenders to self-inflict serious injuries, or to commit suicide.

Toch (1975) relied on excerpts of interviews with segregated inmates and concluded that there are some inmates whose tolerance for isolation is low. These inmates react to segregation with "surges of panic, despair, or rage. They lose control, break down, regress" (Toch, 1975; p.38).

Grassian (1983) also utilized interviews to assess the effects of segregation on fourteen inmates who were involved in a "cruel and unusual punishment" civil action. Grassian (1983) observed similar symptoms as those reported in the American and German correctional literature of the 18th and early 19th centuries. He reported the following damaging effects of segregation:

1) sensory disturbances: perceptual distortions and loss of perceptual constancy, in some cases without hallucinations; 2) ideas of reference and paranoid ideation short of overt delusions; 3 ) emergence of primitive aggressive fantasies, which remained ego-dystonic and with reality-testing preserved; 4) disturbances of memory and attention short of overt disorientation and confusional state; and 5) derealization experiences without massive dissociative regression. (p. 1453) 
Haney (1993) assessed the mental health of Pelican Bay Special Handling Unit inmates whose conditions of confinement are very similar to those found in traditional segregation. Interviews revealed that inmates were "deprived of human contact, touch and affection for years on end" (p. 4), and that the operational procedures employed by correctional staff are designed to reinforce and maintain these deprivations. Haney (1993) argues that these deprivations can precipitate various forms of psychopathology, and worsen pre-existing psychiatric conditions. Moreover, although inmates' coping skills in segregation vary, few escape unscathed by the experience.

Korn (1988) argues that conditions of confinement in the High Security Unit (HSU) at Lexington (Kentucky) amounted to an "egregious violation of the rights of citizens and a massive abuse of power by the state" (p. 8). He also describes the conditions of confinement in this unit as similar in many respects to conditions found in traditional segregation. Korn (1988) contends that women inmates confined in this unit are depersonalized, denied individuality, denied personal autonomy, sexually abused, humiliated, and forced into hopelessness. He suggests that the conditions of confinement at the HSU at Lexington elicit claustrophobia, rage, severe depression, hallucination, withdrawal, blunting of affect, and apathy. Moreover, his research reports that women inmates housed in this unit experienced physical reactions, such as loss of appetite and weight, exacerbation of pre-existing medical problems, visual disturbances, dizziness, and heart palpitations. 
Benjamin and Lux (1975) reviewed testimony of segregated adult and young offenders and concluded that emotional illness and aggression are byproducts of segregation. Two years later, they stated that there is "overwhelming evidence that solitary confinement alone, even in the absence of physical brutality or unhygienic conditions, can produce emotional damage, decline in mental functioning and even the most extreme forms of psychopathology, such as depersonalization, hallucination and delusions" (Benjamin and Lux, 1977, p. 268). They take the position that placing an inmate in solitary confinement for a substantial length of time (e.g., anything more than a few "cooling off" hours) amounts to "a criminal act far worse than the original crime the prisoner committed in society, and worse than the wide variety of disciplinary breaches which the prisoner may commit while in prison" (p. 296). They argue that the devastating effects of long-term solitary are so severe that the practice should be abolished. They affirm that solitary confinement: (1) causes severe and possibly permanent mental deterioration and emotional damage; (2) results in anger, hostility, and further violence; and (3) is implicated (in some cases) in death by suicide.

Zubek, Bayer, and Shephard (1969) found that solitary confinement affects physiological and psychological health. They assigned 66 university students for one week to three conditions: (1) confinement, (2) confinement and social isolation, and (3) control. Although the majority remained unaffected on standardized measures, differences were found on a self-reported retrospective 
questionnaire, including visual experiences of a hallucinatory-like nature, inefficient thought processes, subjective restlessness, and anxiety. The authors concluded that "it is clear that the various experimental conditions become increasingly less tolerable as one proceeds from confinement, to social isolation, and finally to perceptual deprivation" (p. 629).

Similar findings were reported by Brodsky and Scogin (1988). They interviewed 45 segregated inmates about their confinement in solitary confinement, and reported alarming negative psychological and physiological harm on the Omnibus Stress Questionnaire (Jones, 1976) and an isolation effects checklist. Inmates reported a high prevalence of symptoms, such as feelings of nervousness (84\%), headaches (61\%), talking to self $(68 \%)$, hallucinations and delusions (42\%), confusion (65\%), irrational anger (71\%), nightmares (42\%), and sleeping problems (61\%).

Miller and Young (1997) administered the Brief Symptom Inventory (Derogatis, 1975) to a group of ten offenders who were segregated for administrative reasons and another group of ten offenders who were segregated for disciplinary reasons. They compared the two groups to ten offenders who were incarcerated in the general inmate population. They concluded that as inmates' living restrictions increase, their level of psychological distress also increases. 


\section{No Negative Effects}

There is a small body of empirical literature which provides evidence that segregation produces few, if any, negative psychological effects on inmates. Support for this view stems primarily from the research of Gendreau and his colleagues. For example, Gendreau et al. (1968a) undertook a study to examine whether sensory deprived individuals attempt to seek increased stimulation. They assigned 10 inmates for seven days to a severe sensory deprived condition and 10 inmates to a control condition. They found that the deprived inmates did not desire a greater amount of sensory input subsequent to the perceptual deprivation compared to the control group. The authors concluded that inmates can easily adapt to the deprived situation.

In another study, Gendreau et al. (1968b) randomly assigned 16 students to either an isolation or a non-isolation condition for seven days. They found no significant changes on visual and auditory skill tests. Gendreau et al. (1970) found that monotonous confinement for two days did not result in differences in discriminatory conditioning among inmates. Gendreau et al. (1972) found that solitary confinement of inmates for seven days produced significant changes in their EEG frequency and visually evoked potentials. Although they did not hypothesize as to whether these changes were harmful, the authors argue that physiological changes are simply related to inmates' good ability to adapt to sensory deprivation. Ecclestone, Gendreau, and Knox (1974) found that inmates' personality constructs in solitary confinement for ten days increased in 
stability compared with non-confined inmates. The effect was stronger for "good" connotation constructs (e.g., understanding, honesty, successful, easy going, like me) than "bad" ones (e.g., stubborn, violent, unstable, pessimistic, insecure). Measures of plasma cortisol levels failed to show that solitary confinement was more stressful than normal institutional life.

Gendreau and Bonta (1984) responded to Jackson's (1983) accusations that segregation amounted to "cruel and unusual punishment", calling them grossly inflammatory and unfounded. They reviewed the empirical literature on sensory deprivation, and concluded that "experimental studies examining the effects of solitary confinement on inmates for up to 10 days and retrospective studies have found little debilitating effects upon inmates" (p. 471). Eleven years later, they reexamined the effects of incarceration with special attention to conditions of confinement (Bonta \& Gendreau, 1995). They again concluded that the psychological empirical literature on sensory deprivation reveals no deleterious effects of solitary confinement.

Other researchers who have investigated the effects of segregation have reported similar findings to Gendreau and his colleagues. For example, Suedfeld et al. (1982) assessed 26 inmates who experienced segregation and compared them with 17 inmates who did not. Although they reported that increased time or increased number of times in segregation were associated with inhibition, anxiety, lack of self-insight, submissiveness, depression, hostility, suspicion, distrustfuiness, self-centeredness, and immaturity, they concluded 
that their data did not support the claim that solitary confinement is "overwhelmingly aversive, stressful, or damaging to the inmates" (p. 335).

A further study by Walters et al. (1963) randomly assigned 40 inmates to either a segregation condition or the general inmate population for four days. They found that the isolation produced some changes in subjective feelings (e.g., increased anxiety), but did not result in mental or psychomotor deterioration or increased susceptibility to social influence. They concluded that "the deleterious consequences of social isolation have been too greatly emphasized" (p. 772).

\section{Evaluation of Existing Research on Segregation:}

\section{A Review of Methodological Shortcomings}

The above review of the literature on the effects of segregation illustrates the difficulty in reconciling the two opposing views of this debate. However, it appears that supporters of one view often fail to appreciate the findings of the opposing view, as well as to recognize the limitations of their own findings when drawing their conclusions. The following review of methodological issues highlights the current unsatisfactory state of the literature on the effects of segregation. As the review notes, the ability to generalize the results of these studies is affected to varying degrees by improper attention to their methodological shortcomings. 


\section{Reliance on Qualitative Data (e.g., Casual Observations. Interviews and}

\section{Anecdotes)}

Many authors use anecdotal evidence to support their claims (Benjamin \& Lux, 1975, 1977; Brodsky \& Scogin, 1988; Grassian, 1983; Jackson, 1983; Korn, 1988). These authors often take selected powerful excerpts of interviews or testimony of segregated inmates or mental health professionals who had contacts with segregated inmates to provide general evidence of the harmful effects of segregation. Some rely on testimony on the use of isolation in the 19th century to produce corroborative evidence of the harmful effects of segregation in today's North American correctional context (Grassian, 1983; Immarigeon, 1992; Luise, 1989). Others use case law of successful, and at times unsuccessful, human rights litigation to depict the general conditions of confinement and treatment of segregated inmates, as well as the ensuing psychological and physical harm (Benjamin \& Lux, 1977; Birkinshaw, 1981; Jackson, 1983; Luise, 1989).

The evidence of the damaging effects of segregation on inmates brought forward by these authors is very disturbing, and cannot be ignored. However, because of the nature of the methodology relied upon by these authors, it is often unclear whether the pathologies displayed by some segregated inmates were directly attributable to the conditions of confinement in segregation or whether prior to their segregation these inmates displayed similar pathologies in the general inmate population or in the community (Gendreau \& Bonta, 1984). 
In addition, Suedfeld (1982) found that some authors inappropriately use findings from case studies of persons who experienced severe abuse and sensory deprivation to illustrate the damaging effects of segregation. Testimony of tortured political and war prisoners who were denied food, clothing, medical assistance and procedural fairness are at times relied upon to provide corroborative evidence of damaging effects of segregation in contemporary North American correctional settings (Benjamin \& Lux, 1975; Korn, 1988). Such comparisons have been judged to be absurd, and the generalization of the findings of these case studies questioned (Gendreau \& Bonta, 1984; Suedfeld et al., 1982). Isolation in a political or war camp is not comparable to the highly regulated and formalized procedures for imposing segregation on inmates in North American penitentiaries. Conditions of confinement, procedural safeguards, and security provided to the prisoners differ to such an extent that a comparison is clearly inappropriate (Gendreau \& Bonta, 1984; Suedfeld et al., 1982).

\section{Conditions of Confinement}

One of the problems with segregation research stems from a difficulty in defining the constructs being evaluated. Many terms, such as administrative segregation, dissociation, isolation, seclusion, protective custody and solitary confinement are used, often interchangeably, to described various restrictive environments. These correctional terms encompass a wide range of conditions of confinement in which restrictions on freedom of association and freedom of 
movement may vary, and in which levels of perceptual deprivation, sensory deprivation and social isolation may also vary. There is such a diversity in the nature of conditions of confinement used in segregation research that lumping all studies together under the same "solitary confinement" label has been judged to be inappropriate (Suedfeld et al., 1982).

Many authors recognize the importance of the institutional correctional environment with respect to its impact upon the segregation experience and the difficulty associated with generalizing results (Grassian, 1983). Conditions of confinement and daily routine vary so greatly among institutions (Kane, 1997; Vantour, 1975) that results derived from one institutional setting may not be applicable to others. For example, the frequency and quality of interactions with staff or other inmates, the physical layout of segregation cells (e.g., solid doors, cell size, etc.), the size of the exercise yard, the availability of recreational equipment and hobby items, and the access to personal effects, programs and services, may all impact on the segregation experience. As a result, the majority of studies describe, at great length, the conditions of confinement and the daily routine of segregated inmates being studied.

Many authors have reviewed the proliferation of control units in the United States and abroad in an attempt to determine their effects on inmates' mental and physical health (Birkinshaw, 1981; Coyle, 1987; Dowker \& Good, 1993; Korn, 1988; Immarigeon, 1992). The establishment of control units in the United States originated in 1963 when a penitentiary in Marion (Illinois) was built to 
replace Alcatraz (Coyle, 1987). Since then, more than 33 States have comparable Marion-like facilities (Immarigeon, 1992). Control units provide a good illustration of the difficulty in defining the constructs being evaluated. Although control units are not formally recognized by correctional authorities as segregation units, and although they sometimes impose fewer restrictions on inmates than in traditional segregation units, they often impose many similar conditions of confinement (Coyle, 1987; Dowker \& Good, 1993; Immarigeon, 1992; Korn, 1988). For example, Dowker and Gienn (1993) describe some of the defining features of these institutions. Inmates are confined in small cells for 22 or 23 hours per day. The cells are often equipped with solid steel doors, which prevent any communication between inmates. Further, often these institutions are equipped with remote electronic sliding doors, which minimize, if not eliminate, most contact with correctional staff. There are no congregate dining, exercise, or religious services, and few, if any, work opportunities.

\section{Relevance of Field and Laboratory Experiments on Sensory Deprivation} Most of the experimental studies on segregation come from the field of sensory deprivation. Gendreau and his colleagues have generated and evaluated many theories and hypotheses on sensory deprivation in the correctional context. For example, Gendreau and colleagues examined whether: isolated prisoners show higher arousal potential because of a lower arousal level induced by solitary confinement (Gendreau et al., 1972); segregation enhances learning (Gendreau et al., 1970); isolated subjects desire a lower level of 
stimulation (visual and auditory sensory input) after a deprivation experience (Gendreau et al., 1968a); and stress levels, as indicated by adrenocortical activity, can detect whether solitary confinement is harmful (Ecclestone, Gendreau, \& Knox, 1974).

Others have commented upon or tested theories and hypotheses of sensory deprivation in the correctional context as well. For example, Benjamin and Lux (1977) argue that segregation is harmful because it dramatically reduces levels of needed stimulation. Dowker and Good (1993) believe that inmates who are segregated for long periods of time may be deprived of necessary meaningful human contacts, and, as a result, these inmates have difficulties in coping with normal social situations again.

Suedfeld et al. (1982) argue that the comparison between field or laboratory experiments on isolation and stimulus reduction and today's typical North American segregation environment is inappropriate. They contend that it is highly questionable whether the typical segregation unit in fact imposes much reduction in stimulus input. They state that most segregated inmates can communicate with guards and other inmates and have access to reading material, mail, lawyers, other visitors, and frequently possess radios and television sets. Further, Gendreau and Bonta (1984) argue that the conditions of confinement in many of the sensory deprivation and isolation experiments are more severe than those found in today's segregation units. They argue that, since these field and laboratory experiments show little support for the position 
that sensory deprivation and isolation are damaging, the conclusions drawn from these studies are especially informative and relevant.

Zubek, Bayer, and Shephard (1969) define the concept of segregation in a more detailed manner, arguing that it is comprised of three main components: social isolation, sensory deprivation, and confinement. They believe that the nature and the extent of all three components can vary significantly. Moreover, they contend that it is often unclear whether and how one component or a combination of components affect inmates' health. The nature and the extent of (1) the contacts with staff and other inmates, (2) the level of sensory deprivation (e.g., television, adequate reading material, programs and service, etc.), and (3) the overall conditions of confinement, may all affect inmates differently. Zubek, Bayer, and Shephard (1969) suggest that typical perceptual deprivation experiments inappropriately encompass social isolation and confinement. As a result, these studies cannot provide answers as to which component affects inmates' mental health and functioning (i.e., the dependent variable). On the other hand, Scott and Gendreau (1969) argue that "sensory deprivation (absolute), perceptual deprivation (relative) and social isolation are three degrees of the same issue" (p. 337).

\section{Selection of Subjects}

\subsection{Use of Volunteers. Experimental studies on segregation rely} primarily on volunteers who agree to be segregated for a fixed period of time. Some authors have been reluctant to accept results of studies which have relied 
on volunteers (Arbour, 1996; Jackson, 1983; Vantour, 1975). Walters et al. (1963) believe that the problem with using volunteers is that they are apparently not too frightened by the prospect of facing a few days of isolation, and they may have personality characteristics and past experiences which enable them to cope with, and remain unaffected by, segregation.

Approximately half of all inmates placed in segregation are confined against their will (Kane, 1997). In addition, it is questionable whether "voluntary" segregation is truly voluntary. Arguably, most inmates would prefer to remain in the general inmate population if the threat to their personal safety was to be removed. Nonetheless, some authors claim that, based on their "clinical experience", inmates who initially strongly object to being placed in segregation appear to adapt as well as inmates who voluntarily request it (Ecclestone, Gendreau, \& Knox, 1974; Gendreau et al., 1972).

In addition to the issue of using volunteers, the use of alternative populations may also lead to limited generalization of findings. For example, the use of university students who, in general, exhibit good adjustment, stable personality, and higher levels of intelligence, education, and socioeconomic status may not lead to accurate comparisons with the segregated inmate population. Suedfeld et al. (1982) argue that attempting to use findings from these sources as an indication of what one can expect from inmates in segregation is inappropriate because it is not relevant to the phenomenon being evaluated. The high prevalence of severe mental disorders among segregated 
inmates (Hodgins \& Cote, 1991) makes any comparison with university student samples somewhat questionable.

\subsection{Use of Inmates Involved in Human Rights Violation Litigation.}

Some studies on the negative effects of segregation have relied on segregated inmates who were involved in lawsuits alleging violations of their constitutional rights (Brodsky \& Scogin, 1988; Grassian, 1983). Brodsky and Scogin (1988) conducted a study on the effects of segregation in a unit which was under litigation for human rights violations. They found high rates of reported anger (86\%), physical symptoms $(79 \%)$, sleep disturbance $(64 \%)$, anxiety $(45 \%)$, and depression (36\%) among segregated inmates. Grassian (1983) interviewed 15 inmates who were involved in a class action suit against the Department of Corrections for alleged violation of their Eighth Amendment provisions protecting them against "cruel and unusual punishment". Although his study argued that no inmate knowingly exaggerated negative symptoms, he found severe perceptual changes, affective disturbances, and rapid subsidence of symptoms on termination of isolation in the majority of the inmates, and disturbances of thought content and problems of impulse control in a minority of cases.

Subjects involved in human rights violation litigation may have a special interest in demonstrating that their conditions of confinement have negative psychological and physiological effects. Therefore, the results of studies which rely on such inmates will always remain questionable. Further, Suedfeld et al. (1982) suggest that inmates engaged in litigation are perhaps not representative 
of average inmates; their reactions to segregation may not be the norm. Similarly, Gendreau and Bonta (1984) question the reliability of information of case studies performed by Jackson (1983). They suggest that many of Jackson's interviewed inmates were notorious (e.g., Andy Bruce and Don Oag), far from representative, and had filed an inordinately large numbers of grievances, legitimate or otherwise, against the prison system.

\subsection{Screening-out Subjects with Psychiatric History. A significant} proportion of segregated inmates have a psychiatric history (Hodgins \& Cote, 1991; Motiuk \& Blanchette, 1997). However, some studies purporting to examine the impact of segregation have screened-out such subjects (Ecclestone, Gendreau, \& Knox, 1974; Gendreau et al., 1972). As a result, findings from these studies may be difficult to apply to the population of segregated inmates.

Hodgins and Cote (1991) report that in their sample of 32 long term segregated inmates, $31 \%$ suffered from some kind of severe lifetime mental disorder (25\% schizophrenia, 3.1\% major depression, and 3.1\% bipolar disorder). The rate of schizophrenia among this sample was more than three times the rate of the disorder among non-segregated inmates. However, the rate of major depression in their sample was lower than the rate in the general inmate population. This suggests that non-disruptive mentally-ill inmates may remain in the general inmate population, whereas inmates who are "disturbed and disruptive" are isolated from the general inmate population. 
Wormith, Tellier, and Gendreau (1988) evaluated the attributes of inmates in protective custody (PC) in a provincial institution. PC inmates typically can associate between themselves but do not have access to the same level of programs, services, and privileges offered to the general inmate population. They found that PC inmates were more likely to have a history of psychiatric problems. They suggest that PC inmates' psychological weaknesses and idiosyncratic behaviours may not be well tolerated by the general inmate population, and it appears that inappropriate behaviours are often punished regardless of the underlying basis for the conduct (Carriere, 1989; Gendreau, Tellier, \& Wormith, 1985; Rold, 1992). Consequently, numerous inmates with mental disorders are segregated (Gendreau, Tellier, \& Wormith, 1985; Rold, 1992).

Little research has focused on the effects of segregation on inmates with psychiatric conditions. Many authors argue that segregation can exacerbate some existing psychiatric conditions (Haney, 1993; Hodgins \& Cote, 1991; Wadeson \& Carpenter, 1976). For example, Wadeson and Carpenter (1976) concluded that segregation stimulates hallucinatory activity and provokes paranoia among some mental health patients.

The existence of psychiatric disturbance may very well be a defining characteristic of the population of segregated inmates. Moreover, findings from the studies reviewed above underline the importance of not restricting research samples to those without a history of psychiatric disorders. 


\section{Reasons for Segregation}

Inmates may voluntarily request segregation or be involuntarily segregated for a multitude of reasons (Kane, 1997; Gendreau, Tellier, \& Wormith, 1985; Wormith, Tellier, \& Gendreau, 1988). The most common reasons given by inmates for seeking various forms of $\mathrm{PC}$ and segregation include: conflicts in the general population (e.g., gambling and drug debts); the nature of the inmate's offense (e.g., sexual offender); suspected of being an informant; personality problems; phobias (including fear of gays); being the target of sexual aggression; and escaping the crowded and often violent atmosphere of maximum security (Gendreau, Tellier, \& Wormith, 1985).

Approximately fifty percent of segregation placements are involuntary (Kane, 1997). Research on segregation thus far has failed to assess the effects of long term segregation on these inmates. Such an omission has rendered generalization of findings even more difficult. For example, the underlying reasons for segregating inmates may influence their abilities to cope with the experience (Weinberg, 1967). Whether they view their placement in segregation as a result of their own behaviour or as the result of being an innocent victim of circumstances beyond their control may influence their ability to cope with the more restrictive regime of segregation.

\section{Attrition}

Some segregation studies reported attrition among subjects participating in the experimental condition (i.e., segregation), and provided little, if any, 
explanations (Ecclestone, Gendreau, \& Knox, 1974; Walters et al., 1963;

Weinberg, 1967; Zubek, Bayer, \& Shephard, 1969). For example, Ecclestone, Gendreau, and Knox (1974) reported a 32\% attrition rate, and Weinberg (1967) reported a $68 \%$ attrition rate. Even when more than adequate monetary incentives are provided, attrition has been reported (Bexton, Heron, \& Scott, 1954; Zubek, Bayer, \& Shephard, 1969).

Attrition is a major drawback to psychological research in general. However, the problem with attrition is especially relevant to the evaluation of the psychological effects of segregation. Subjects who decide to no longer participate in the experiment may be the same individuals who would not cope well with the conditions of segregation and would be negatively affected by them.

\section{Reliance on Cross-sectional and Longitudinal Research}

Cross-sectional research is inadequate for evaluating the effects of segregation. Results of cross-sectional segregation research are limited to the identification of differences between groups (segregated and non-segregated). The results of this type of research do not allow for inferences concerning the causes of these differences (Suedfeld et al., 1982). Nevertheless, after conducting a cross-sectional study and observing poorer mental and physical health among segregated inmates than among non-segregated inmates, some authors have quickly attributed the cause of such poorer health to segregation (Brodsky \& Scogin, 1988; Miller \& Young, 1997). The possibility that segregated inmates already were of poorer mental and physical health prior to their 
segregation must at least be considered as an alternative explanation in crosssectional studies.

\section{Duration and Indeterminate Nature of Stay}

Another problem with current experimental studies on segregation surrounds the issue of the length and indeterminate nature of the stay (Jackson, 1983; Suedfeld et al., 1982). In previous experimental research, the length of stay is limited to ten days or less (e.g., 2 days: Gendreau et al., 1970; 4 days: Walters et al., 1963; 5 days: Weinberg, 1967; 7 days: Gendreau et al., 1972; Gendreau et al., 1968a; 1968b; Zubek, Bayer, \& Shephard, 1969; 10 days: Ecclestone, Gendreau, \& Knox, 1974). Moreover, volunteers for these studies know exactly when the experiment will end, and that they can end their participation at will.

The reality of segregation is that the length of stay is always unknown, and more than $80 \%$ of inmates spend more than 10 days in segregation at any one time (Kane, 1997). Suedfeld et al. (1982) argue that making general statements on the effects of segregation without qualifying the length of stay is inappropriate. Bonta and Gendreau (1995) specifically state that their conclusion that segregation is not detrimental only applies to periods of segregation of 10 days or less. As these studies confirm, generalizing the results of experimental studies beyond 10 days is questionable. 


\section{Lack of Comparison Group}

Some studies utilizing structured and non-structured interviews with segregated inmates have failed to include a comparison group of nonsegregated inmates (Brodsky \& Scogin, 1988; Grassian, 1983). Brodsky and Scogin (1988) interviewed 45 segregated inmates about their confinement in solitary confinement but did not include a control group. Although they reported disturbing negative psychological and physiological effects, since no comparison group was included, the results are of little value because it remains undetermined whether inmates in the general inmate population would have reported similar effects about their confinement in the general inmate population. 10. Inmate/Staff Interaction and the Punitive Reality of Segregation Several authors have suggested that the relationship between staff and inmates is an important factor which may affect how inmates cope with segregation (Benjamin \& Lux, 1977; Bonta \& Gendreau, 1995; Carriere, 1989; Ellis, 1993; Gendreau \& Bonta, 1984; Korn, 1988; Suedfeld et al., 1982; Vantour, 1975; Wormith, Tellier, \& Gendreau, 1988). Inmates may be more affected by the way they are treated by correctional staff than by the conditions of confinement typically found in North American segregation units (Bonta \& Gendreau, 1995; Gendreau \& Bonta, 1984; Vantour, 1975). For example, Vantour (1975) argues that negative psychological impacts of segregation are attributable not so much to the physical environment per se, but to events surrounding the confinement, including: 
the reason for being segregated; the process by which the prisoner is segregated; the physical facilities and routine; the lack of contact with staff and other prisoners; the length of the period of segregation; the uncertainty as to when a prisoner will be released; and the process by which the prisoner is returned to the population. (p. 65)

Similarly, Gendreau and Bonta (1984) argue that negative effects of solitary confinement may be more the result of:

the fact [offenders] were not given clear criteria as to why they were placed in solitary, their review process was amorphous, and they were not certain as to how they could improve behaviorally so as to eventually leave. They claimed they were also gratuitously harassed in petty ways by the guards. (p.474)

Bonta and Gendreau (1995) argue that there is some evidence that when inmates are treated capriciously by management or correctional staff, psychological stress can result even in the most humane of prison environments. Harassment, physical roughness, enforcement and non-enforcement of rules, and unpredictable withholding of privileges may play a greater role than complaints about physical conditions, the social isolation and the sensory deprivation associated with segregation (Suedfeld et al., 1982).

Many authors have found that contrary to legislative and policy provisions, the management of administrative segregation is based on a punitive philosophy, and that segregated inmates have fewer rights, privileges, and 
access to programs and services than inmates in the general inmate population (Arbour, 1996; Carriere, 1989; Gendreau, Tellier, Wormith, 1985; Kane, 1997; Tellier, Wormith, \& Gendreau, 1984; Vantour, 1975). For example, Arbour (1996) concluded that CSC's management of administrative segregation was not in accordance with the law and its policies, and demonstrated a systemic "prison culture which did not value individual rights" (p. xiii).

Wormith, Tellier, and Gendreau (1988) reported that correctional employees often have negative views towards, and discriminate against, segregated inmates. They found that PC inmates complained about the attitudes of correctional staff towards them and the adverse psychological effects of being in $\mathrm{PC}$, whereas inmates in the general population were more likely to complain about institutional living conditions, rules, and regulations. Similarly, Carriere (1989) states that PC inmates are often treated in a demeaning manner by correctional staff. Further, he contends that segregated inmates are treated as maximum security inmates regardless of the security risk they pose.

For generalization purposes, the evaluation of the effects of segregation must include real interactions between staff and inmates, and should not be limited to courteous interactions typically found in laboratory experiments.

\section{Personality}

The inmates' personality or temperament may play a role in how they will be affected by segregation. Some personality characteristics may reduce tolerance for segregation, while other characteristics may enhance it (Suedfeld et 
al., 1982; Walters et al., 1963). Little, if any, research on the effects of segregation has focused on personality. Assessment of personality must be included in segregation research in order to identify inmates' abilities and predispositions to cope with segregation.

\section{Other Factors}

Segregation may have detrimental parole consequences, reduce an inmate's chances of being admitted to a half-way house, and affect an inmate's security classification (Carriere, 1989; Gendreau, Tellier, \& Wormith, 1985; Tellier, Wormith, \& Gendreau, 1984). Knowledge of these consequences may negatively affect how inmates adapt to segregation. Further, an inmate who was housed in a single cell prior to segregation may be reassigned to a "doublebunked" cell after a placement in segregation. This future loss of privacy may also affect how inmates cope with the experience of segregation.

Other complaints may also influence the segregation experience such as cold food and delayed response to requests for assistance (e.g., medication, telephone calls, counselors, reading material, etc.) (Suedfeld et al., 1982). In the segregation environment, these complaints cannot be viewed as trivial because they are often the only distractions available to break the monotony of the segregation experience.

\section{Addressing Methodological and Theoretical Shortcomings}

The preceding review confirms that the literature on segregation is sparse, conflicting, rife with speculations, and based upon far-fetched extrapolations and 
generalizations (Barak-Glantz, 1983; Brodsky \& Scogin, 1988; Suedfeld et al., 1982; Wormith, Tellier, \& Gendreau, 1988). The numerous methodological shortcomings highlighted above are partly attributable to a general lack of theoretical underpinning for understanding the experiences of segregated offenders. There is a clear need for a framework for studying the effects of segregation that is derived from contemporary psychological theory on adaptation and coping.

It is also clear from the preceding review of the current literature that there is no shortage of explanations of the detrimental effects of segregation. The factors that are thought to contribute to segregation's harmful impact include: partial isolation; partial sensory and perceptual deprivation; reasons for segregation (voluntary and involuntary); fairness of the segregation process; indeterminate nature of the stay; inmate/staff interactions; personal attributes of segregated inmates (e.g., personality, history of mental disorders, previous segregation experiences); uncertainty of future; uncertainty of behaviour required to leave segregation; and, perceptions of effects of placement into segregation (e.g., classification, chance of parole). However, few authors examining such factors have framed these explanations in theoretical terms.

Most theorization on the effects of segregation has been examined through sensory deprivation constructs (Benjamin \& Lux, 1977; Bexton, Heron, \& Scott, 1954; Ecclestone, Gendreau, \& Knox, 1974; Gendreau et al., 1968a, 1968b, 1970, 1972; Zubek, Bayer, \& Shepard). However, sensory deprivation 
theories may be too narrow or restricted for a comprehensive understanding of the psychological effects of today's administrative segregation. Although an important factor, sensory deprivation is only one of many components outlined above which may affect the mental health and psychological functioning of segregated offenders. A more all-encompassing theory is required to evaluate the effects of the overall segregation experience.

Early studies and theories which evaluated the effects of long-term imprisonment are perhaps of value in providing a theoretical framework for understanding the psychological effects of administrative segregation. Unlike studies on segregation, these early studies on the effects of long-term imprisonment appear to start from a strong theoretical underpinning. Most of the early studies concerned with inmates' behaviour in prisons have been framed using the sociological concept of "institutionalization" (Zamble, Porporino \& Kalotay, 1984). Pursuant to this perspective, inmates' behaviours can be interpreted as the central collective solution to adapting and coping with the pains of imprisonment, and segregation can make those pains more acute (Toch, 1975).

Clemmer (1940) referred to the process of assimilation into the prison subculture as "prisonization". Administrative segregation is described as either an adaptation or a failure to adapt to the prison environment. On one hand, inmates (often victimized offenders) are either voluntarily seeking refuge into segregation units because they cannot cope with prison life in the general inmate 
population. On the other hand, inmates (often aggressors) are involuntarily placed in segregation for attempting to position themselves higher within the inmate's own social-class hierarchy.

Two complementary models have been advanced to explain factors influencing this process of "prisonization": the deprivation and importation models (Alpert, 1979; Thomas, 1977). The deprivation model emphasizes prisonspecific factors, such as length of incarceration, time remaining, organizational structure (Akers, Hayner, \& Gruinger, 1977), and interpersonal involvement and social roles assumed by inmates (Sykes \& Messinger, 1960), whereas the importation model focuses on pre-prison factors, such as socioeconomic background, employment and educational history, offence and incarceration history (Alpert, 1979; Thomas, 1977), and identification with criminal values (Thomas \& Poole, 1975).

Prisonization studies testing these two models have been criticized on both methodological and conceptual grounds (Zamble \& Porporino, 1990; Zamble, Porporino, \& Kalotay, 1984). Firstly, methodologically, limitations of cross-sectional designs (Zamble, 1992; Zamble \& Porporino, 1990) and the use of insensitive measures of behaviours, cognitions and emotional experiences have been reported (Zamble, 1992). Secondly, conceptually, prisonization has been found to be "too general and too crude a concept" as a criterion measure of adaptation (Zamble, Porporino, \& Kalotay, 1984; p. 8). Zamble and his colleagues have suggested that instead behavioral indices and measures of 
emotional states must be examined as criteria of adaptational outcome in prison (Zamble, Porporino, \& Kalotay, 1984; Zamble \& Porporino, 1990; Zamble, 1992). Moreover, they have argued that prisonization theory fails to consider "how particular aspects of the environment will affect individual inmates, or how individuals with different personal characteristics will react to particular conditions and situations" (Zamble, Porporino, \& Kalotay, 1984; p. 9). Prisonization theory may be a good explanation for why offenders may end up in administrative segregation, but the criticisms expressed by Zamble and his colleagues are also applicable to research attempting to understand the psychological effects of administrative segregation. Therefore, these criticisms have to be taken into account in developing a theoretical framework for understanding the effects of administrative segregation.

Zamble and his colleagues have recognized that the interactionist model of the causes of human behaviour (Lazarus \& Folkman, 1983; Magnussen \& Endler, 1977) provides the most appropriate theoretical framework for studying coping and adaptation of inmates serving long prison terms. In addition, others have also recognized the value of the interactionist model for understanding individual differences in adaptation and coping in prison (Toch, 1992). It is therefore not surprising that this theoretical approach may also provide the most promising framework for understanding how inmates who are placed in administrative segregation cope and adapt to their environment. 
Simply stated, the interactionist model is based on the premise that emotions and behaviours are outcomes of the interaction between external situation characteristics and personal characteristics (Lazarus \& Folkman, 1983; Magnussen \& Endler, 1977; Zamble, Porporino, \& Kalotay, 1984). The interaction between "person factors" and "environmental factors" (i.e., person by situation interaction) is the main determinant of behaviour (Manussen \& Endler, 1977). Pursuant to the interactionist model, the individual's evaluation of stressors (physical and social environmental conditions that an average person would perceive as actually or potentially threatening) are stress appraisals, and psychological and biological responses to stressors are stress reactions (Lazarus \& Folkman, 1984). Coping responses are behaviours and cognitions that a person uses to adjust to a stressor and are aimed at ameliorating its negative emotional or physical effects (Lepore \& Evans, 1996). Finally, coping resources are properties of individuals, their social environment, and physical environmental resources that enable a person to respond to stressors (Lepore \& Evans, 1996). It is important to note that the concept of "appraisal" is central in accounting for individual, as well as group, differences in adaptation and coping. Lazarus and Folkman (1984) have said that "people and groups differ in their sensitivity and vulnerability to certain types of events, as well as in their interpretations and reactions" (p. 22). 
Figure 1: Between and Within Person by Situation Interaction Model

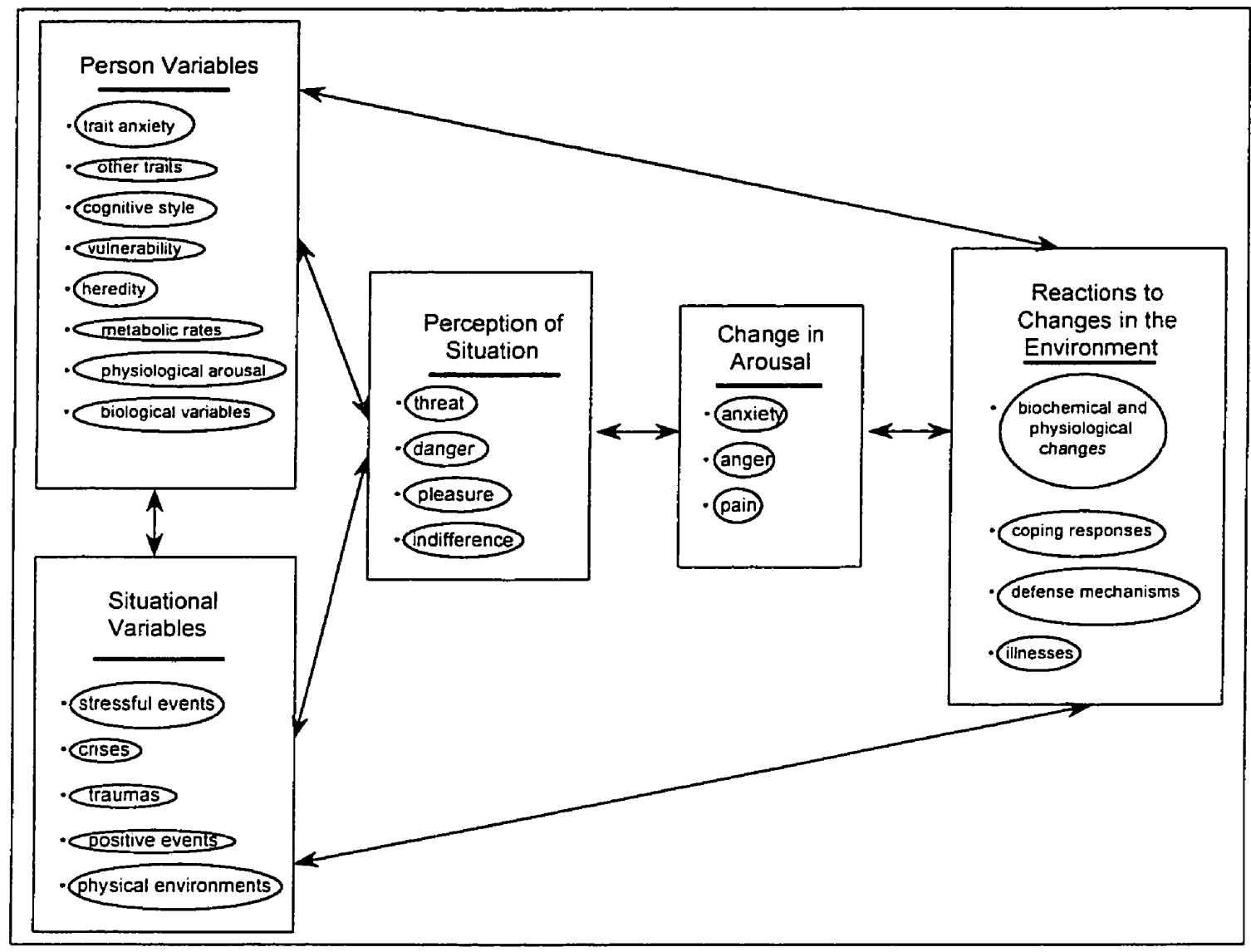

Endler $(1993,1997)$ provided a graphic portrayal of the interactionist model (see Figure 1) and described it as follows:

Note that this "between" and "within" person by situation interaction model focusses on sub categories within each basic construct. The squares refer to "between" variables (e.g., persons and situations) and the circles to "within" variables (e.g., cognitive styles, traits, biological variables). Note that phase $A$ refers to person and situation variables, phase $B$ to perception of situation variables, phase $C$ to changes in arousal, and 
phase $D$ to reactions to changes in arousal. Each phase has subcategories which dynamically interact with one another.

Applying this interactionist model to understanding the detrimental effects of administrative segregation results in the following analysis. Phase A: vulnerable offenders, including many with serious mental health problems, are confronted with the stressful event of being placed in an austere segregation cell managed by staff who may have a punitive correctional philosophy (stressors). This new environment includes partial isolation and partial sensory and perceptual deprivation. This environment is also surrounded with a great number of uncertainties (stressors), such as the indeterminate nature of the stay, the behaviour required to leave segregation, and the potential effects of placement into segregation (e.g., classification, chance of parole). Phase B: this new environment and all those uncertainties will be perceived negatively by inmates (stress appraisals), especially the vulnerable ones. Phase $\mathrm{C}$ and $\mathrm{D}$ : arousal changes will occur and the segregated offenders, poorly equipped to cope with this new situation (coping resources), will react negatively (coping responses) by (a) displaying various forms of aggression, (b) internalizing their emotions and revealing interpersonal distress, (c) showing new, or aggravating existing, psychiatric symptoms, and (d) displaying poorer cognitive abilities (stress reactions) over time. 
Study on the Effects of Administrative Segregation

Unlike existing experimental studies, the purpose of this study was not to test whether social isolation, sensory or perceptual deprivation was harmful to inmates' mental health and psychological functioning. The focus instead was to discern whether exposure to up to 60 days to a "real" segregation environment, with all it encompasses, was harmful to inmates' mental health or psychological functioning. Contrary to existing experimental studies on segregation which limit their evaluations of the effects of segregation on one or two factors (i.e., partial isolation, partial sensory and perceptual deprivation, and conditions of confinement), this study evaluated all factors associated with the segregation experience. It is only by assessing all factors that impact an inmate that we can have a comprehensive understanding of the harmful effects of administrative segregation in today's correctional context.

\section{Hypotheses}

1. Segregation for up to 60 days will negatively affect the mental health and psychological functioning of inmates.

a. It will lead to increased internalizing symptoms (e.g., depression, anxiety, hopelessness, and suicide ideation).

b. It will lead to increased externalizing symptoms (e.g., hostility, aggression, and anger).

2. Segregation for up to 60 days will negatively affect inmates' physical functioning. That is, it will lead to increased reporting of somatic symptoms 
(e.g., sleep patterns, heart palpitations, and loss of appetite and weight), and decreased vigor-activity.

3. Segregation for up to 60 days will impact on inmates' perception and cognitive functioning. It will have a negative effect on specific cognitive processes (e.g., memory disturbances and problems with attention).

4. The experience of segregation will lead to a devaluation of interpersonal relationships.

5. Involuntarily segregated inmates will be more affected by segregation than voluntarily segregated inmates. 
Method

\section{Design and Procedures}

Participants. Participants included inmates from Kingston, Collins Bay and Millhaven Penitentiaries who have either been (a) placed in administrative segregation and remained in segregation for 60 days (quasi-experimental group), or (b) randomly selected from the general inmate population and remained in the general inmate population for 60 days (comparison group). Data were collected over an eight month period beginning in October 1997.

Testing and Procedures. Senior psychologists at the selected institutions supervised the data collection. The Psychologists selected and trained/oriented three research assistants (RAs) concerning institutional security protocols and the use of the psychological testing instruments. The RAs were graduates or students of psychology (one $4^{\text {th }}$ year student, one M.A. candidate, and one M.A.).

Inmates who were just placed in administrative segregation (voluntary and involuntary) and provided their informed consent (see Appendixes $1 \& 2$ ), were asked to complete written psychological tests and take part in a structured interview. After each session, participants were debriefed (see Appendix 3). The same procedure was undertaken 30 days later and again 60 days later if the inmates remained segregated. Non-segregated offenders were selected at random and underwent the same testing procedures at the same intervals. 


\section{Measures}

The initial testing session (session one) lasted approximately two hours. In addition to the battery of tests which were utilized at each session, the initial session included a general measure of intelligence and a short personality inventory. Because performance on these additional instruments was not expected to fluctuate over 60 days, these measures were administered only once. The follow-up assessments conducted at 30 days (session two) and 60 days (session three) were therefore shorter, each lasting approximately one hour. The comparison group underwent the same testing procedure as the segregated group.

The measures which were selected for use in this study were chosen based on several criteria. Measures were selected which possessed acceptable psychometric properties, had a short administration time, and had been previously used with inmate samples. Consideration was also given to measures which had been used in previous segregation research. Table 1 illustrates the list of measures which were selected for use in this study and their respective alphas. 
Table 1

Measures

Measures (All Three Sessions)

Alpha

Aggression Questionnaire

Balanced Inventory of Desirable Responding (short form)

Beck Depression (abbreviated)

Brief Symptom Inventory

Somatization

Obsessive-compulsive

Interpersonal

Depression

.84

Anxiety

.83

Hostility

.85

Phobic Anxiety

.80

Paranoid Ideation

.80

Psychoticism

.66

Holden Psychological Screening inventory $\quad .84$

Hopelessness Scale

Interview Assessment

NA

State-trait Anxiety Inventory (State-short form)

WAIS Sub-test: Digit Span

NA

WAIS Sub-test: Digit Symbol

NA

Measures (Initial Assessment Only)

Interview Assessment

NA

NEO Personality Inventory (Short Form)

Neuroticism

Extraversion

.70

Openness

.61

Agreeableness

.71

Conscientiousness

.80

Shipley

Note. ${ }^{*}$ Items 4, 7 \& 9 were removed to improve psychometric properties.

Aggression Questionnaire (AQ; Buss \& Perry, 1992). The Aggression

Questionnaire is a widely used self-report measure of externalizing behaviours 
and feelings. This 29-item instrument is rated on a 5 point scale of least to most characteristic. There are four subscales: Physical Aggression; Verbal Aggression; Anger; and Hostility. This scale has been used with offender samples (e.g., Williams et al., 1996).

Although this measure is relatively new, there is strong evidence for its reliability. The alpha coefficients of internal consistency for the subscales have been reported to rarıge from .72 to .89 (Buss \& Perry, 1992; Archer, Kilpatrick, \& Bramwell, 1995). Test-retest reliability over a nine week period has been reported to range from .72 to .80 (Buss \& Perry, 1992). Although there is a relatively small number of items per scale, the coefficients indicate that the stability over time is adequate.

Convergent validity has been reported. Aspects of temperament and other traits have been found to correlate strongly with relevant subscales, as well as with perceptions of others (Buss \& Perry, 1992). In addition, the Verbal, Anger, and Physical Scales of the AQ have been reported to be highly correlated with similar scales on the Aggression Inventory (Archer et al., 1995). The validity of the measure has been supported by the ability of the Physical Aggression subscale to predict enjoyment of fights and willingness to join in a fight, but not to perceptions of others' hostility (Russell, 1995; Russell \& Arms, 1995). The Anger subscale was able to predict those who would expect a riot to ensue due to insults (Russell \& Arms, 1995). 
Balanced Inventory of Desirable Responding (BIDR; Paulhus, 1984). The BIDR is composed of 40 items which are rated on a 7 point scale. This instrument has two subscales: Self-Deception and Impression Management. The Self-Deception Scale assesses self-motivated biased responding that portrays the respondent more positively. The Impression Management Scale assesses other-motivated responding, that is, attempting to present a favourable impression on others. This measure has been used with offender samples (e.g., Kroner \& Weekes, 1995).

Convergent validity of this scale has been supported by the report of a significant relationship between the subscales of this instrument and the Marlowe-Crowne Social Desirability Scale (Dutton \& Hemphill, 1992). Socially desirable responding as measured by this scale has also been negatively associated with reports of committing violence and verbal aggression on the Conflict Tactics scale, as well as reported feelings of anger on the Multidimensional Anger Inventory (Dutton \& Hemphill, 1992). Discriminant validity has been suggested by the finding that those with different personal ideals (i.e., ingratiators, exemplifiers, and intimidators) scored differently on the Impression Management subscale (Verkasalo, \& Lindeman, 1994).

The psychometric properties of this measure have been examined with offender samples. Kroner and Weekes (1996) reported the existence of three factors within an offender sample: Impression Management (IM); Denial of the Negative (DN; unwillingness to admit undesirable characteristic to the self), and; 
Over-Confident Rigidity (OCR; self-perception of infallibility and rigidity). The internal consistency of the three-factor solution ranged from .58 (OCR, 9 items) to .84 (IM, 17 items). The DN and the OCR scales have been found to discriminate between offenders who admit and those who deny or partially deny committing their offences. Moreover, the IM and OCR scales have been found to differentiate between intake and upcoming release offenders. The five items which loaded most strongly on these three scales were selected, creating a 15 item short form of the BIDR.

\section{Beck Depression Inventory - Short Form (BDI-S; Beck \& Beck, 1972).}

The BDI is a widely used instrument, designed to measure the severity of cognitive, behavioural and physiological symtomatology in depression over the last week. For each item, four alternative statements which reflect differential severity regarding functioning are provided. This measure has been used with offender samples (e.g., Coleman et al., 1992; Day, 1993; Gudjonsson, 1984; Eyestone \& Howell, 1994; McGuire et al., 1995; Smyth, Ivanoff, \& Jang, 1994). Although the full version has 21 items, there is a short form available which is composed of 13 items (BDS-S; Beck \& Beck, 1972). The BDI-S was selected for use in the present study.

The psychometric properties of this instrument (both forms) are strong, and there is a high concordance between the BDI and the BDI-S. Beck and colleagues (Beck \& Beck, 1972; Beck, Rial, \& Rickles, 1974) reported correlations of .89 to .97 between the two forms. The short form has also been 
found to be correlated well with clinician's ratings of depression (Beck \& Beck, 1972; Beck et al., 1974; Scogin et al., 1988; Stukenberg et al., 1990).

The internal consistency of this instrument is good as alpha coefficients have been reported to range from .74 to .90 (Beck \& Beamesdorfer, 1974; Foelker et al., 1987; Gould, 1982; Leahy, 1992; Scogin et al., 1988; Vredenberg et al., 1985). Although the initial use of the BDI-S dictated a uni-dimensional solution, others have reported the existence of two factors (Leahy, 1992; Foelker et al., 1987; Reynolds \& Gould, 1981; Volk et al., 1993).

However, there is some indication that the BDI-S suffers from poor accuracy, identifying a high number of false positives (poor specificity; Volk, Pace, \& Parchman, 1993). Using a cut-off point of 8 , the sensitivity and specificity of the BDI-S have been reported at .71 to .79 and .77 to .83 respectively (Nielson \& Williams, 1980; Stukenberg et al., 1990).

Brief Symptom Inventory (BSI: Derogatis, 1992). This 53-item inventory was designed to screen for psychological symptom status in the last week. This measure is essentially a short form of the Symptom Checklist - 90 - Revised (SCL-90-R), and correlations between the two forms are reported to be high (e.g., .92 to .98; Derogatis, 1992). This instrument takes about 10 minutes to complete, and yields 9 primary dimension scores (Somatization; ObsessiveCompulsive; interpersonal Sensitivity; Depression; Anxiety; Hostility; Phobic Anxiety; Paranoid Ideation; and Psychoticism). In addition there are three global indices (Global Severity; Positive Symptom Distress Index; and Positive 
Symptom Total). This measure has been used with offender samples (e.g., Boulet \& Boss, 1991; Singer et al., 1995), and in segregation research (e.g., Miller, 1994).

Internal consistency of the scales is good, with alpha coefficients reported to range from .71 to .89 for the subscales (Boulet \& Boss, 1991; Broday \& Mason, 1991; Derogatis \& Melisaratos, 1983). Test-retest reliability is also excellent with a range from .68 to .91 for the subscales (Derogatis \& Melisaratos, 1983).

This scale has demonstrated concurrent validity with (1) assessments of negative affect, life satisfaction, and affect intensity (Sheldon, 1994), (2) the Beck Anxiety Inventory (Osman et al., 1993), (3) the Cognition Checklist (Osman et al., 1995), and (4) the MMPI (Boulet \& Boss, 1991). Discriminant validity has also been demonstrated for normative groups compared to: those with Hoarding problems (Frost, Krause, \& Steketee, 1996); sexually dysfunctional patients (Derogatis \& Meyer, 1979); and violent men in relationships (Gavazzi, Julian, \& McKenry, 1996). Moreover, this measure is sensitive to treatment effects (Piersma, Reaume, \& Boes, 1994).

Holden Psychological Screening Inventory (HPSI; Holden, Mendonca, Mazmanian, \& Reddon, 1992). This 36-item inventory, which measures psychosocial adjustment, is rated on a 5 point scale. In addition to providing a total score, this scale assesses three higher order components of psychopathology: Psychiatric Symtomatology (psychotic processes, anxiety and 
somatic concerns), Social Symtomatology (inadequate or deviant socialization and impulse expression) and Depression Symtomatology (feelings of pessimism, poor self-esteem, and social introversion). This instrument has been used with offender samples (e.g., Holden \& Grigoriadis, 1995; Reddon et al., 1996).

The alpha coefficients of internal consistency have been reported to range from .66 to .90 for the subscales and total score (Holden, 1991; Holden et al., 1992). This scale has also been found to have convergent validity with staff ratings (Holden et al., 1992). Moreover, the HPSI has been found to be sensitive to the effects of psychological interventions (Reddon et al., 1995). The subscales of the HPSI have also shown concurrent validity with the MMPI-2 and the BPI (Holden \& Grigoriadis, 1995), and the NEO Five Factor Inventory (Costa \& McCrae, 1989; Holden, 1992).

Hopelessness Scale (BHS; Beck \& Steer, 1988). This 20 item T/F scale measures negative experiences and pessimism concerning the future. Hopelessness is thought to be interrelated with the constructs of depression, and to be a good predictor of suicidal ideation (Steer et al., 1993; Ivanoff \& Jang, 1991). This measure has been used with offender samples (e.g., Ivanoff \& Jang, 1991; Power \& Beveridge, 1990; Smyth et al., 1994).

The internal consistency of this scale is good. Alpha coefficients have been reported to be between .82 and .93 (Beck \& Steer, 1988), and item-total correlations ranged from .39 to .76 (Beck et al., 1974). The construct of hopelessness has been hypothesized to be state-like (as opposed to a trait), and 
thus, unstable. Due to this factor, test-retest reliabilities have been relatively low, ranging from .66 to .94 (Beck \& Steer, 1988; Holden \& Fekken, 1988).

Concurrent validity has been reported between this measure and indicators of suicide risk (Lennings, 1992). Concurrent validity has been shown with clinical ratings of hopelessness (Beck et al., 1974) and with other tests which measure negative attitudes about the future (Beck et al., 1974). Evidence for discriminant validity has been presented (e.g., differentiating heroin-addicted from alcoholic women; Beck, Steer \& Shaw, 1984). Finally, this measure is sensitive to treatment effects (Beck et al., 1974).

Interview Assessment. A structured interview was developed (see Appendix 4) and was administered at each testing session. The initial interview was more comprehensive and required an additional five minutes of testing time. Aspects of the interview have been taken from existing scales and interviews, and cover the following areas which were not assessed by the other psychological measures: present feelings; history of segregation (e.g., priors, reasons); significant events happening over the last week - stressors; time allotment; social relationships; suicidal ideation; and social and interpersonal skilis.

NEO Personality Inventory (NEO-FFl; Costa \& McCrae, 1992). The NEO was designed to assess the "big five" personality constructs: Neuroticism; Extroversion; Openness; Agreeableness; and Conscientiousness. The NEO has been used previously with offender samples (e.g., Lehne, 1994). The long form 
of this inventory is composed of 181 items. However, for this investigation the short form was selected. This version is composed of 60 items rated on a 5 point scale.

The NEO (short form) is relatively new and few studies of the psychometric properties of this measure have been reported. The manual, however, presents adequate evidence of the psychometric properties. Internal consistency is reported to be acceptable, with alpha coefficients ranging from .73 to .95 (Costa \& McCrae, 1992; Holden \& Fekken, 1994) for the subscales. Support for the construct validity of this scale has been reported with the HPSI (Holden, 1992).

Shipley Institute of Living Scale-Revised (Shipley, 1940). The Shipley, also known as the Shipley-Hartford Retreat Scale, is a widely used screening measure of overall intellectual ability. This instrument consists of a 40 item (multiple choice) Vocabulary subtest and 20 item (open-ended) Abstract Reasoning subtest. The Shipley yields six summary scores: vocabulary; abstraction; total test; conceptual quotient; abstraction quotient; and an estimate of IQ. This instrument has been used with offender samples (e.g., Hooper \& Evans, 1984; Fowles \& Tunick, 1986; Ingram et al., 1985; Wood, Conn, \& Harrison, 1977; Sutker \& Moan, 1973), and in segregation research (Walters, Callagan, \& Newman, 1963; Weinberg, 1967).

Shipley (1940) provided evidence for the internal consistency of the scales ( .87 for Abstractions to .92 for Total test). Test retest reliability for periods 
of three months have been reported to range from .57 to .88 for the factors (Ruiz \& Krauss, 1967; Shipley 1940).

Validity has been examined in terms of the relationship of the Shipley with the WAIS (entire test as well as subscales), and the Wechsler-Bellevue Intelligence Test (Fowles \& Tunick, 1986; Frisch \& Jessop, 1989; Heinemann et al., 1985; Retzlaff, Slicner, \& Gibertini, 1986; Shipley, 1940; Weiss \& Schell, 1991). Concurrent validity has also been supported with this scale and the Hemmon-Nelson Tests of Mental Ability (Watson et al., 1992). The discriminant validity of the Shipley has also been presented (identifying disruptive youths; Hooper \& Evans, 1984).

State-trait Anxiety Inventory (Spielberger, 1983). This measure is composed of 40 items which assess two distinct but related aspects of anxiety: (a) state anxiety: transitory, subjective (nervousness, worry, high arousal), and a function of situational stress; and (b) trait anxiety: relatively stable differences in anxiety proneness (how one perceives or approaches stressful situations). Respondents indicate how they feel "right now" based on a four point scale. This measure has been used extensively in research with clinical populations and with offender samples (e.g., Lutz, 1990; Segal, Hobfoll \& Cromer, 1984).

The internal consistency of this measure is high; coefficient alphas have been reported at .87 (Knight, Waal-Manning, \& Spears, 1983; Spielberger, 1983), and Kuder-Richardson (KR-20) correlations (split-half and odd-even) have been reported to range from .45 to .85 (Metzger, 1976). As would be expected, 
the test-retest correlation coefficients are low $(r=.16$ to .62$)$ for the State scale, indicating that this measure is sensitive to fluctuations due to situational variations (Metzger, 1976; Nixon \& Steffeck, 1977; Spielberger, 1983).

The state scale has been found to differentiate persons who were facing a stressful situation from those who were not (Metzger, 1976). Convergent validity has been reported with measures of depression (MMPI, BHS, and the BDI; Novy et al., 1993).

For this study a six-item short form was used. This short form has been found to display acceptable reliability and validity. In fact, the scores provided by the short form in previous research are similar to those of the long form (Matreau \& Bekker, 1992).

\section{Additional Data Collection}

Physical Conditions. Research assistants gathered information on the physical layout of the segregation units (see Appendix 5).

Offender Intake Assessment. All offenders sentenced to penitentiaries (i.e., for prison terms exceeding two years) must complete the Offender Intake Assessment (OIA) prior to their penitentiary placement. In most instances, the OIA lasts eight weeks, and allows CSC to render informed decisions with respect to placement, classification, and programming. During the OIA, information on inmates is collected and stored on the computerized Offender Management System (OMS). 
OIA information was retrieved on inmates' current and past criminal history and the seven need domains (Employment, Marital/Family, Associates, Substance Abuse, Community Functioning, Personal/Emotional and Attitude). Offenders' scores on the Statistical Information on Recidivism (SIR) was also retrieved. The SIR score provides an estimate of the probability that an individual will re-offend within three years after release. Each offender's total score on the SIR scale can range from -30 (very poor risk) to +27 (very good risk). There is evidence that the SIR Scale possess good reliability and validity (Bonta, Harman, Hann, \& Cormier, 1996; Bonta, Pang, \& Wallace-Capretta, 1995; Hann \& Harman, 1989). Further, this scale has shown a good ability to predict release outcome (Hann \& Harman, 1988; Motiuk \& Porporino, 1989). It should be noted that sex offenders and homicide offenders, as a group, score favourably on this scale as they are considerably older than the general prison population and typically have less exposure to the Criminal Justice System (Motiuk and Blanchette, 1997).

Results

Conditions of Confinement. Information on the conditions of confinement of segregation units at Collins Bay, Kingston and Millhaven penitentiaries was collected. Table 2 describes the physical conditions at each penitentiary. Conditions of confinement at Kingston Penitentiary are divided into two sections because one of the segregation units is noticeably different from the others. 
Table 2

Conditions of Confinement in Segregation at Collins Bay, Kingston and Millhaven Penitentiaries

\begin{tabular}{|c|c|c|c|c|}
\hline \multicolumn{5}{|c|}{ Institution } \\
\hline & Collins Bay & Millhaven & K.P. 1 & K.P.2 \\
\hline Cell size (sq.ft) & 80.6 & 57.2 & 56 & 46 \\
\hline Ceiling height (ft./in.) & $7 ' 10 "$ & $11^{\prime} 8 "$ & $9^{\prime}$ & $11^{\prime} 5^{\prime \prime}$ \\
\hline Number of cells per range & 19 & 16 & 20 & 37 \\
\hline Solid door & Yes & Yes & Yes & No \\
\hline Yard size (sq.ft.) & 750 & 1200 & 1500 & 1500 \\
\hline Concrete wall around yard & Yes & Yes & Yes & Yes \\
\hline $\begin{array}{l}\text { Yard covered overhead } \\
\text { with wired fence }\end{array}$ & Yes & Yes & Yes & Yes \\
\hline
\end{tabular}

Participation and Attrition. The refusal rate for participating in this study was $44 \%$ for segregated and $40 \%$ for non-segregated offenders. Table 3 illustrates the number of completed sessions broken down by Group (i.e., segregated vs. non-segregated) and institutions. It shows that 83 segregated offenders and 53 non-segregated offenders participated in this study. However, complete data for all three sessions (60 days) were only available for 23 segregated and 37 nonsegregated offenders.

The loss of participants from the segregated group was primarily due to releases to the general inmate population or transitional units (i.e., protective custody), or transfers to other institutions. True attrition, the refusal to participate in a subsequent session, occurred in nine cases $(10.8 \%)$. It should be noted that true attrition included cases in which offenders expressed their intent to 
participate in the study but their conduct jeopardized the personal safety of the RAs (e.g., threats, and one incident in which an offender attempted to grab a RA). The average elapsed time after placement in segregation for session one, two and three was $3.6,29.8$ and 57.8 days respectively.

For non-segregated offenders, the loss of participation was mainly due to transfers to other institutions and placement in segregation. True attrition occurred in only two cases (3.8\%).

Table 3

Number of Completed Sessions Broken down by Group and Institutions

\begin{tabular}{lllllll} 
& & \multicolumn{3}{c}{ Segregated $(n=83)$} & Non-Segregated $(n=53)$ \\
\hline Institutions & S. 1 & S. 2 & S. 3 & S.1 & S.2 & S.3 \\
\hline Collins Bay & 31 & 8 & 7 & 19 & 16 & 16 \\
Kingston & 19 & 12 & 11 & 20 & 17 & 14 \\
Millhaven & 33 & 12 & 5 & 14 & 13 & 7 \\
\hdashline Total & 83 & 32 & $\underline{23}$ & 53 & 46 & $\underline{37}$ \\
\hline
\end{tabular}

Table 4 shows a breakdown of institutions and the legal reasons for placement in administrative segregation. Initially (i.e., upon placement), $39 \%$ (n $=32)$ of segregated offenders were voluntary cases whereas $61 \%(\underline{n}=51)$ were involuntary cases. Moreover, voluntary cases were all seeking protection, whereas the majority of involuntary cases $(71 \%, \underline{n}=36)$ were legally placed in administrative segregation for jeopardizing the safety of other inmates, staff, or the security of the institution. Noteworthy, after 60 days the percentage of 
voluntary cases increased to $57 \%(\underline{n}=13)$ and the percentage of involuntary cases decreased to $43 \%(\underline{n}=10)$.

Table 4

Breakdown of Institutions and Reason for Segregation by Type of Segregation

\begin{tabular}{|c|c|c|c|c|c|c|c|c|}
\hline & \multicolumn{3}{|c|}{ Voluntary } & \multicolumn{5}{|c|}{ Involuntary } \\
\hline & \multicolumn{3}{|c|}{ Section $31^{\star}$} & \multicolumn{5}{|c|}{ Section $31^{*}$} \\
\hline & (1) & $(2$ & (3) & & (1) & (2) & (3) & \\
\hline Institutions & & & & Total & & & & Total \\
\hline Collins Bay & 4 & 0 & 0 & 4 & 6 & 17 & 4 & 27 \\
\hline Kingston & 15 & 0 & 0 & 15 & 1 & 3 & 0 & 4 \\
\hline Millhaven & 13 & 0 & 0 & 12 & 2 & 16 & 2 & 2 \\
\hline Total & 32 & 0 & 0 & $\underline{32}(39 \%)$ & 9 & 36 & 6 & $\underline{51}(61 \%)$ \\
\hline
\end{tabular}

Note. * Section 31 of the CCRA provides the reasons for placement in administrative segregation: (1) an inmate's own safety is in danger; (2) an inmate may jeopardize the safety of others or the safety of the penitentiary; and (3) an inmate may interfere with a criminal investigation or with a serious disciplinary matter.

Age. Using t-tests, segregated offenders were found to be younger $(\underline{M}=28.9)$ than non-segregated inmates $(\underline{M}=32.20, \underline{t}(134)=2.66, \underline{p}<.01)$. The age of segregated and non-segregated offenders ranged from 20 to 54 years old. Bivariate correlation analyses showed that Age was not significantly correlated with any measure (i.e., dependent variable).

Race. The Offender Intake Assessment (OIA) was used to provide background information on the offenders. OIA information on race was available on 119 offenders: $66 \%$ of offenders were Caucasian; $25 \%$ black; $7 \%$ aboriginal, and; $3 \%$ from other visible minority groups. Among segregated offenders $(\underline{n}=73)$, the 
percentage of Caucasians, blacks, aboriginal and other visible minority groups was $64 \%, 27 \%, 7 \%$ and $1 \%$ respectively.

Education. OIA information was used to assess the educational background of offenders. Using chi-square analyses, Table 5 indicates that segregated and non-segregated offenders did not significantly differ in educational background.

Table 5

Education OIA Indicators for Segregated and Non-segregated Offenders

\begin{tabular}{|c|c|c|c|c|}
\hline & Non-Seg. & Seg. & $\chi^{2}$ & Sign \\
\hline OIA Indicator & $\%(\underline{n}=39)$ & $\%(\underline{n}=54)$ & & \\
\hline Under grade 8 & 23.1 & 27.8 & 0.26 & $\underline{\mathrm{ns}}$ \\
\hline Under Grade 9 & 51.3 & 56.6 & 0.26 & $\underline{\mathrm{ns}}$ \\
\hline No high school diploma & 84.6 & 83.0 & 0.04 & $\underline{\mathrm{ns}}$ \\
\hline Learning difficulty & 26.3 & 33.3 & 0.52 & $\underline{\mathrm{ns}}$ \\
\hline Learning disability & 21.1 & 22.6 & 0.03 & ns \\
\hline
\end{tabular}

Criminal History. OIA data also provided criminal history information for 131 offenders. As table 6 shows, chi-square analyses reveal no significant difference between segregated and non-segregated offenders on past and current offence history. Similar non-significant findings were obtained on history of disciplinary infractions $\left(\chi^{2}(1, \underline{N}=84)=1.93, \underline{p}=0.17\right)$, escape/UAL $\left(\chi^{2}(1, \underline{N}=91)=0.95, \underline{p}\right.$ $=0.33)$ and failure on conditional releases $\left(\chi^{2}(1, \underline{N}=91)=0.95, \underline{p}=0.39\right)$. 
Table 6

Offence History (Past and Current) of Segregated and Non-Segregated

Offenders

$$
\text { Non-Seg. }(\underline{n}=49) \quad \text { Seg. }(\underline{n}=82) \quad \chi^{2} \quad \text { Sign. }
$$

Offences

$\begin{array}{lllll}\text { Homicide } & 5(10.2) & 13(15.9) & 0.83 & \underline{\mathrm{ns}} \\ \text { Robbery/Assault } & 29(76.3) & 47(82.5) & 0.54 & \underline{\mathrm{ns}} \\ \text { Sexual assault } & 6(15.8) & 9(15.8) & 0.00 & \underline{\mathrm{ns}} \\ \text { Property } & 11(31.4) & 19(33.3) & 0.04 & \underline{\mathrm{ns}} \\ \text { Drugs } & 8(16.3) & 12(14.6) & 0.07 & \underline{\mathrm{ns}} \\ \text { Other * } & 13(34.2) & 26(45.6) & 1.23 & \underline{\mathrm{ns}}\end{array}$

Note. * e.g., arson, weapon and forcible confinement.

With respect to session one segregated offenders $(\underline{n}=83$ ), nine were serving life sentences (11\%). The average sentence length (excluding life sentences; $\underline{n}=74$ ) imposed by the Courts for their index offence was 6.97 years.

Of the 53 session one non-segregated offenders, 13 offenders were serving life sentences (25\%). The average sentence length (excluding life sentences; $\underline{n}=40$ ) imposed by the Courts for their index offence was 5.98 years. Case Needs. T-tests were conducted to determine whether segregated offenders $(\underline{n}=83)$ differed significantly from non-segregated offenders $(\underline{n}=53)$ in terms of need domains identified by the OIA. By assigning a value of one for the presence of each OIA indicator, Table 7 shows that segregated and nonsegregated offenders did not significantly differ on any of the OIA need domains. 
Table 7

Need Domains at OIA for Segregated and Non-Segregated Offenders

\begin{tabular}{|c|c|c|c|c|}
\hline & Non-Seg. $(\underline{n}=53)$ & Seg. $(\underline{n}=83)$ & $\underline{t}$ & Sign. \\
\hline Need Domains* & $\underline{M}$ & $\underline{M}$ & & \\
\hline Employment & 9.89 & 9.22 & 0.49 & $\underline{\mathrm{ns}}$ \\
\hline Marital/Family & 5.43 & 5.87 & 0.45 & $\underline{\mathrm{ns}}$ \\
\hline Associates & 3.30 & 3.37 & 0.14 & $\underline{\mathrm{ns}}$ \\
\hline Substance Abuse & 7.68 & 7.69 & 0.01 & $\overline{\mathrm{ns}}$ \\
\hline Community Funct. & 5.21 & 4.80 & 0.56 & $\overline{\mathrm{ns}}$ \\
\hline Personal/Emotional & 11.25 & 11.57 & 0.18 & $\overline{\mathrm{ns}}$ \\
\hline Attitude & 5.75 & 5.55 & 0.21 & $\overline{\mathrm{ns}}$ \\
\hline
\end{tabular}

Note. * A value of one was assigned to each OIA indicator present within each need domain. The means represent the average number of indicators per need domain.

SIR Scale. Using t-tests, segregated offenders were found to be higher risk of recidivism $(\underline{M}=-8.26)$ than non-segregated offenders $(\underline{M}=-1.07, \underline{t}(110)=4.70$, $\underline{p}<.001)$. SIR scores of segregated and non-segregated offenders were clustered into the five typically reported risk categories: very poor risk (-30 to -9$)$, poor risk $(-8$ to -5$)$, fair risk $(-4$ to 0$)$, good risk $(+1$ to +5$)$, and very good risk $(+6$ to +27 ). Table 8 illustrates the percentage of segregated and non-segregated offenders within each of the five risk categories. It shows that $80.9 \%(\underline{n}=55)$ of segregated offenders were grouped in the poor and very poor risk categories compared to only $45.4 \%(\underline{n}=20)$ for non-segregated offenders. Conversely, $54.6 \%(\underline{n}=24)$ of non-segregated offenders were grouped in the fair, good, and very good risk categories compared to only $19.1 \%(\underline{n}=13)$ of segregated offenders. 
Table 8

Percentage Distribution of SIR Risk Groups for Segregated and Non-Segregated Offenders

\begin{tabular}{|c|c|c|}
\hline & Non-Segregated & Segregated \\
\hline Risk Grouping & $\underline{n}(\%)$ & $\underline{\mathrm{n}}(\%)$ \\
\hline $\begin{array}{l}\text { Very Poor } \\
\text { Poor } \\
\text { Fair } \\
\text { Good } \\
\text { Very Good }\end{array}$ & $\begin{array}{l}10(22.7) \\
10(22.7) \\
9(20.5) \\
4(9.1) \\
11(25.0)\end{array}$ & $\begin{array}{l}41(60.3) \\
14(20.6) \\
2(2.9) \\
8(11.8) \\
3(4.4)\end{array}$ \\
\hline Total & $44(100)$ & $\underline{68}(100)$ \\
\hline
\end{tabular}

1.Q. Estimates of I.Q. from the Shipley Institute of Living Scale-Revised (Shipley, 1940) were compared for segregated and non-segregated offenders. Nonsegregated offenders $(\underline{M}=97.25)$ possessed higher estimates of $I . Q$. than segregated offenders $(\underline{M}=89.70, \underline{t}(131)=2.93, \underline{p}<.01)$. Bivariate correlation analyses revealed that the estimate of I.Q. was significantly correlated with the WAIS Digit Symbol $(\underline{r}=.27, \underline{p}<.01)$ and Digit Span $(\underline{r}=.48, \underline{p}<.01)$ but unrelated to other measures.

Personality. Table 9 shows the differences between segregated and nonsegregated offenders on the "big five" personality constructs as assessed by the NEO Personality Inventory (NEO-FFI; Costa \& McCrae, 1992). Segregated offenders scored higher on Neuroticism $(\underline{t}(125)=3.73, \underline{p}<.001)$, and lower on Extraversion $(\underline{t}(129)=2.26, \underline{p}<.05)$, Openness $(\underline{t}(127)=3.09, \underline{p}<.01)$, 
Agreeableness $(\underline{t}(121)=2.99, \underline{p}<.01)$ and Conscientiousness $(\underline{t}(127)=3.54, \underline{p}$ $<.001)$ than non-segregated offenders.

Table 9

NEO-FFI Sub-scores for Segregated and Non-Segregated Offenders

\begin{tabular}{|c|c|c|c|}
\hline & Seg. $(\underline{n}=83)$ & Non-Seg. $(\underline{n}=53)$ & $\underline{t}(\underline{d f})$ \\
\hline Factors (T-Scores) & $\underline{M}$ & $\underline{M}$ & \\
\hline Neuroticism ${ }^{\star \star \star \star}$ & 54.9 & 48.4 & $3.73(125)$ \\
\hline Extraversion* & 45.9 & 50.0 & $2.26(129)$ \\
\hline Openness ${ }^{\star \star}$ & 49.0 & 53.5 & 3.09 (127) \\
\hline Agreeableness ${ }^{\star \star}$ & 41.6 & 47.4 & $2.99(121)$ \\
\hline Conscientiousness $^{\star \star \star}$ & 45.2 & 51.2 & $3.54(127)$ \\
\hline
\end{tabular}

Note. ${ }^{\star} \mathrm{p}<.05,{ }^{\star \star} \mathrm{p}<.01,{ }^{\star \star \star} \underline{\mathrm{p}}<.001$

\section{Mental Health and Psychological Functioning.}

Two strategies were used to analyse the mental health and psychological functioning of the 60 offenders who completed all three sessions (segregated ( $\underline{n}$ $=23$ ) and non-segregated offenders $(\underline{n}=37)$ ). First, due to the relatively small sample size $(\underline{n}=60)$, a between/within-subject MANOVA (repeated measures) could not be performed on the eight psychological instruments used to assess changes in mental health and psychological functioning.

Therefore, selected psychological measures and subscales were merged to create four composite variables: Externalizing/Aggression, Internalizing/Interpersonnel Distress, Psychiatric Symtomatology, and Cognitive Ability (see Table 10). To create these composite variables, the measures and subscales were standardized (z-scores) across all three sessions. 
Consequently, a MANOVA with the four composite variables as dependent

variables was performed. This analysis was followed by univariate and trend

analyses.

Table 10

Four Composite Mental Health and Psychological Functioning Variables

Externalizing/Aggression

Aggression Questionnaire - Anger

Aggression Questionnaire - Hostility

Aggression Questionnaire - Physical

Aggression Questionnaire - Verbal

Brief Symptom Inventory - Hostility

Internalizing/Interpersonal Distress

Beck Depression (abbreviated)

Brief Symptom Inventory - Anxiety

Brief Symptom Inventory - Depression

Brief Symptom Inventory - Interpersonel Sensitivity

Holden Psychological Screening Inventory - Depression

Holden Psychological Screening Inventory - Social Symtomatology

Hopelessness Scale

State-trait Anxiety Inventory (State-short form)

Psychiatric Symtomatology

Brief Symptom Inventory - Obsessive-compulsive

Brief Symptom Inventory - Phobic Anxiety

Brief Symptom Inventory - Paranoid Ideation

Brief Symptom Inventory - Positive Symptom

Holden Psychological Screening Inventory - Psychiatric Symtomatology

Cognitive Ability

WAIS Digit Span

WAIS Digit Symbol 
As a second strategy, repeated measures univariate analyses and trend analyses were conducted with the original eight measures as dependent variables.

Both strategies used to analyse the mental health and psychological functioning of the 60 offenders who completed all three sessions resulted in similar findings. Overall, both analyses indicated that: segregated offenders reported poorer mental health and psychological functioning than nonsegregated offenders; both segregated and non-segregated offenders reported fewer problems across time (i.e., sixty days); and there is no evidence that across time (i.e., sixty days) the mental health and psychological functioning of segregated offenders significantly deteriorated.

Because impression management affects both strategies, an analysis of the Balanced Inventory of Desirable Responding (BIDR; Paulhus, 1984) will be presented at the onset.

Balanced Inventory of Desirable Responding (BIDR; Paulhus, 1984). Table 11 indicates that non-segregated offenders showed significant higher scores of impression management than segregated offenders $(\underline{F}(1,58)=11.36, \underline{p}<.001$, $\left.\eta^{2}=.16\right)$. Although the BIDR was significantly correlated with all dependent variables, due to the relationship between the BIDR and the independent variable Group (i.e., segregated versus non-segregated offenders), the BIDR was not used as a covariate for subsequent analyses. 
Segregated and non-segregated offenders displayed significantly increased scores on impression management across time $(\underline{F}(2,116)=3.68, \underline{p}<$ $.05, \eta^{2}=.06$ ). However, the ANOVA and a follow-up trend analysis revealed no significant Time (i.e., session 1, 2 \& 3) by Group interaction.

Table 11

ANOVA for the 13 item BIDR for Segregated $(n=23)$ and Non-segregated ( $n$ =37) Offenders who Completed All Three Sessions

$\begin{array}{llllll}\text { Sources } & \underline{\mathrm{df}} & \text { MS } & \mathrm{F} & \text { Sig. }\end{array}$

Between

$\begin{array}{lclll}\text { Group (G) } & 1 & 2389.3 & 11.36 & \underline{\text { sig }}^{\star \star \star} \\ \text { s within-group error } & 58 & 210.3 & & \end{array}$

Within

$\begin{array}{lllll}\text { Time }(T) & 2 & 119.5 & 3.68 & \text { sig* }^{*} \\ \text { GXT } & 2 & 11.1 & 0.34 & \underline{\mathrm{ns}} \\ \text { s within-group error } & 116 & 32.5 & & \end{array}$

Total 179

Note. ${ }^{\star} \mathrm{p}<.05,{ }^{\star \star} \underline{\mathrm{p}}<.01,{ }^{\star \star \star} \mathrm{p}<.001$

Repeated Measures Analyses on the Four Mental Health and Psychological Functioning Composite Variables.

Table 12 presents the means and respective standard deviations for each of the four composite mental health and psychological functioning variables for all three sessions. 
Table 12

Session Means and Respective Standard Deviations of Four Composite Variables for Segregated $(n=23)$ and Non-Segregated $(n=37)$ Offenders Who Completed All Three Sessions

\begin{tabular}{|c|c|c|c|c|}
\hline \multicolumn{5}{|c|}{ Means (모) } \\
\hline DV & Group & S1 & $\mathrm{S} 2$ & S3 \\
\hline $\begin{array}{l}\text { Externalizing/ } \\
\text { Aggression }\end{array}$ & $\begin{array}{l}\text { Seg. } \\
\text { Non-seg. }\end{array}$ & $\begin{array}{l}1.3(3.5) \\
-0.7(2.8)\end{array}$ & $\begin{array}{l}-0.2(3.3) \\
-1.1(3.4)\end{array}$ & $\begin{array}{l}-0.1(3.8) \\
-1.3(3.8)\end{array}$ \\
\hline $\begin{array}{l}\text { Internalizing/ } \\
\text { Interpersonal }\end{array}$ & $\begin{array}{l}\text { Seg. } \\
\text { Non-seg. }\end{array}$ & $\begin{array}{l}3.5(6.5) \\
-0.8(4.8)\end{array}$ & $\begin{array}{l}0.1(4.8) \\
-2.5(4.6)\end{array}$ & $\begin{array}{l}0.9(4.4) \\
-3.2(4.4)\end{array}$ \\
\hline $\begin{array}{l}\text { Psychiatric } \\
\text { Symtomatology }\end{array}$ & $\begin{array}{l}\text { Seg. } \\
\text { Non-seg. }\end{array}$ & $\begin{array}{l}2.2(5.1) \\
-0.3(3.6)\end{array}$ & $\begin{array}{l}0.3(3.4) \\
-1.4(3.3)\end{array}$ & $\begin{array}{l}0.0(4.0) \\
-1.7(3.5)\end{array}$ \\
\hline $\begin{array}{l}\text { Cognitive } \\
\text { Ability }\end{array}$ & $\begin{array}{l}\text { Seg. } \\
\text { Non-seg. }\end{array}$ & $\begin{array}{l}-0.5(1.7) \\
0.0(1.2)\end{array}$ & $\begin{array}{l}0.2(1.7) \\
0.5(1.4)\end{array}$ & $\begin{array}{l}0.3(1.8) \\
0.9(1.4)\end{array}$ \\
\hline
\end{tabular}

MANOVA. Using the sample comprised of 60 offenders who completed all three sessions (segregated $(\underline{n}=23)$ and non-segregated offenders $(\underline{n}=37)$ ), a $2 \times 3$ between/within-subject repeated measures multivariate analysis was performed using the four composite variables as DVs: Externalizing/Aggression, Internalizing/Interpersonal Distress, Psychiatric Symptomatology, and Cognitive Ability. Using Wilks' Lambda criterion, segregated offenders were found to be significantly different from non-segregated offenders on the combined four DVs $(\underline{F}(4,55)=2.69, \underline{p}<.05)$. Moreover, segregated and non-segregated offenders differed on the combined four DVs across time $(\underline{F}(8,51)=12.91, \underline{p}<.001)$. 
Although approaching significance, the MANOVA revealed no significant Time (i.e., sessions $1,2 \& 3$ ) $\times$ Group (i.e., segregated versus non-segregated offenders) interaction $(\underline{E}(8,51)=2.01, \underline{p}=.06)$.

ANOVAs. Between/within-subject repeated measures univariate analyses were performed on the four composite variables. Follow-up trend analyses were also performed to test the a priori planned comparison assessing whether across time the mental health and psychological functioning of segregated offenders deteriorated at a faster rate than that of non-segregated offenders (i.e., Time by Group interaction).

Externalizing/Aggression. Table 13 shows that segregated and nonsegregated offenders displayed significantly fewer aggressive thoughts and behaviours across time $\left(\underline{F}(2,116)=5.26, \underline{p}<.01, \eta^{2}=.08\right)$. The ANOVA and a follow-up trend analysis revealed no significant Time by Group interaction. 
Table 13

ANOVA on the Externalizing/Aggression Composite Variable for Segregated ( $n=$ 23) and Non-segregated $(n=37)$ Offenders who Completed All Three Sessions

Sources $\quad \underline{\mathrm{df}} \quad \underline{M S} \quad \underline{F} \quad$ Sig.

\section{Between}

Group (G)

86.5

2.99

ns

s within-group error

58

28.9

Within

$\begin{array}{lllll}\text { Time }(\mathrm{T}) & 2 & 18.1 & 5.26 & \text { sig }^{\star \star} \\ \mathrm{G} \times \mathrm{T} & 2 & 4.3 & 1.25 & \underline{\mathrm{ns}} \\ \text { s within-group error } & 116 & 3.5 & & \end{array}$

Total 179

Note. ${ }^{\star} \mathrm{p}<.05,{ }^{\star \star} \mathrm{p}<.01,{ }^{\star \star \star} \mathrm{p}<.001$.

Internalizing/interpersonal Distress. Table 14 reveals that segregated offenders reported significantly more internalizing problems and interpersonal distress than non-segregated offenders $\left(\underline{F}(1,58)=9.20, \underline{p}<.01, \eta^{2}=.14\right)$. Moreover, segregated and non-segregated offenders showed significantly fewer such problems across time $\left(\underline{F}(2,116)=24.7, \underline{p}<.001, \eta^{2}=.30\right)$. Although the ANOVA showed no Time by Group interaction, a follow-up analysis found a significant quadratic trend $\left(\underline{F}(1,58)=6.32, \underline{p}<.05, \eta^{2}=.10\right)$. Figure 2 illustrates this interaction. It shows that non-segregated offenders gradually reported fewer 
internalizing problems and interpersonal distress across time, whereas segregated offenders reported a decrease of such problems between session one and session two, but a subsequent modest increase between session two and session three.

Table 14

ANOVA on the Internalizing/interpersonal Distress Composite Variable for Segregated $(n=23)$ and Non-segregated $(n=37)$ Offenders who Completed All Three Sessions

$\begin{array}{llllll}\text { Sources } & \underline{\mathrm{df}} & \underline{M S} & \underline{F} & \text { Sig. }\end{array}$

\section{Between}

$\begin{array}{lclll}\text { Group (G) } & 1 & 573.4 & 9.20 & \text { sig }^{\star \star} \\ \text { s within-group error } & 58 & 62.3 & & \end{array}$

Within

$\begin{array}{lllll}\text { Time }(T) & 2 & 119.3 & 24.7 & {\underline{\text { ig }^{\star \star \star}}}_{\text {GXT }} \\ \text { S within-group error } & 2 & 11.1 & 2.3 & \text { ns } \\ \end{array}$

Total 179

Note. ${ }^{\star} \underline{p}<.05,{ }^{\star *} \mathrm{p}<.01,{ }^{\star \star \star} \mathrm{p}<.001$. 


\section{Figure 2: Mean Score on the Internalizing/lnterpersonal Variable Across Time}
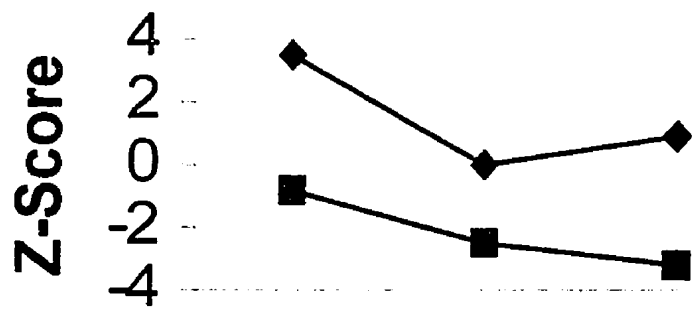

$\rightarrow$ Seg.

1

2

3

$\rightarrow-$ Non-seg.

Session

Psychiatric Symtomatology. Table 15 shows that segregated offenders reported significantly more psychiatric symptoms than non-segregated offenders $\left(F(1,58)=4.67, p<.05, \eta^{2}=.08\right)$. In addition, segregated and non-segregated offenders reported significantly fewer psychiatric symptoms across time ( $F(2$, 116) $=15.57, p<.001, \eta^{2}=.21$ ). The ANOVA and a follow-up trend analysis revealed no significant Time by Group interaction. 
Table 15

ANOVA on the Psychiatric Symtomatology Composite variable for Segregated ( $\mathrm{n}$ $=23$ ) and Non-segregated ( $n=37$ ) Offenders who Completed All Three Sessions

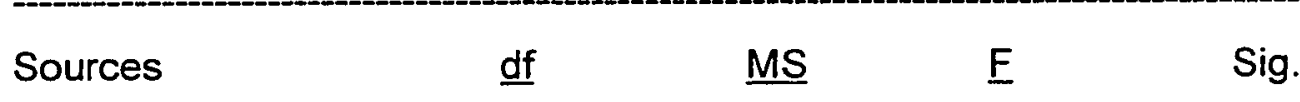

\section{Between}

Group (G)

1

167.8

4.67

sig* $^{*}$

s within-group error

58

35.9

Within

Time (T)

2

50.6

15.57

sig $^{\star \star \star}$

$G \times T$

2

2.8

0.85

ns

s within-group error

116

3.2

Total

179

Note. ${ }^{\star} \mathrm{p}<.05,{ }^{\star \star} \mathrm{p}<.01,{ }^{\star \star \star} \mathrm{p}<.001$.

Cognitive Ability. Table 16 indicates that the performance of segregated and non-segregated offenders significantly improved across time $(F(2,116)=$ 28.54, $p<.001, \eta^{2}=.33$ ). The ANOVA and a follow-up trend analysis revealed no significant Time by Group interaction. 
Table 16

ANOVA on the Cognitive Ability Composite Variable for Segregated $(n=23)$ and Non-segregated $(n=37$ ) Offenders who Completed All Three Sessions

Sources

Between

Group (G)

s within-group error $\underline{\text { df }}$

1

58
MS

10.9

6.2

Within

$\begin{array}{lllll}\text { Time (T) } & 2 & 9.7 & 28.54 & \text { sig }^{\star \star *} \\ \text { GXT } & 2 & 0.4 & 1.20 & \underline{\mathrm{ns}} \\ \underline{\text { s within-group error }} & 116 & 0.34 & & \end{array}$

Total 179

Note. ${ }^{\star} \underline{p}<.05,{ }^{\star \star} \underline{p}<.01,{ }^{\star \star \star} \underline{p}<.001$.

Repeated Measures Analyses on the Eight Measures for Offenders Who Completed Three Sessions.

Between/within-subject repeated measures univariate analyses were performed on the sample of 60 offenders who completed all three sessions (segregated $(\underline{n}=23)$ and non-segregated offenders $(\underline{n}=37)$ ) using the eight measures as dependent variables (DVs). Follow-up trend analysis were performed to test the a priori planned comparison assessing whether the mental health and psychological functioning of segregated offenders deteriorated at a faster rate than that of non-segregated offenders across time (i.e., Time by 
Group interaction). Table 17 presents the means and respective standard deviations for each of the eight measures for all three sessions.

Table 17

Session Means of Measures for Segregated $(n=23)$ and Non-Segregated ( $n$ =37) Offenders Who Completed All Three Sessions

Means $(\underline{S D})$

\begin{tabular}{|c|c|c|c|c|}
\hline DV & Group & $\mathrm{s1}$ & $\mathrm{S} 2$ & S3 \\
\hline Aggression & Seg. & $77.6(14.2)$ & $71.5(17.7)$ & $72.1(21.2)$ \\
\hline Questionnaire & Non-seg. & $68.2(14.2)$ & $66.9(18.6)$ & $65.5(20.0)$ \\
\hline \multirow[t]{2}{*}{ Beck Depression } & Seg. & $8.8(7.3)$ & $6.3(6.0)$ & $6.6(5.5)$ \\
\hline & Non-seg. & $5.5(5.6)$ & $4.6(5.8)$ & $3.9(5.0)$ \\
\hline Brief Symptom & Seg. & $0.92(0.18)$ & $0.62(0.39)$ & $0.62(0.44)$ \\
\hline Inventory & Non-seg. & $0.58(0.46)$ & $0.44(0.42)$ & $0.38(0.40)$ \\
\hline \multirow[t]{2}{*}{ HPSI } & Seg. & $62.3(13.9)$ & $57.3(10.3)$ & $59.5(9.9)$ \\
\hline & Non-seg. & $52.1(10.8)$ & $50.6(9.3)$ & $49.6(11.1)$ \\
\hline Hopelessness & Seg. & $5.3(4.6)$ & $3.6(3.6)$ & $4.3(4.3)$ \\
\hline Scale & Non-seg. & $4.3(4.3)$ & $3.1(4.4)$ & $2.8(4.3)$ \\
\hline State- trait & Seg. & $13.4(4.4)$ & $12.1(4.0)$ & $13.1(4.5)$ \\
\hline Anxiety Inventory & Non-seg. & $12.0(3.4)$ & $9.8(3.5)$ & $9.6(3.3)$ \\
\hline WAIS & Seg. & $8.7(2.9)$ & $9.5(2.8)$ & $9.5(3.1)$ \\
\hline Digit Span & Non-seg. & $9.6(2.5)$ & $9.5(2.6)$ & $10.1(2.3)$ \\
\hline WAIS & Seg. & $7.8(2.4)$ & $9.0(3.1)$ & $9.4(3.3)$ \\
\hline Digit Symbol & Non-seg. & $8.7(2.3)$ & $9.9(3.0)$ & $10.5(2.9)$ \\
\hline
\end{tabular}

Aggression Questionnaire (AQ; Buss \& Perry, 1992). As Table 18 reveals, the ANOVA on the $A Q$ revealed no significant main effect or interaction. 
Table 18

ANOVA for the Aggression Questionnaire for Segregated $(n=23)$ and Nonsegregated $(n=37)$ Offenders who Completed All Three Sessions

$\begin{array}{lllll}\text { Sources } & \underline{\text { df }} & \underline{M S} & \underline{F} & \text { Sig. }\end{array}$

Between

Group (G)

1

1997.5

2.48

$\underline{\text { nS }}$

$\underline{s}$ within-group error

58

803.8

Within

Time ( $T$ )

2

2

291.3

2.83

ns

$G \times T$

116

81.3

0.79

$\underline{\text { nS }}$

$\underline{s}$ within-group error

116

102.9

Total 179

Note. ${ }^{\star} \mathrm{p}<.05,{ }^{\star \star} \mathrm{p}<.01,{ }^{\star \star \star} \mathrm{p}<.001$

Beck Depression Inventory - Short Form (BDI-S; Beck \& Beck, 1972).

Table 19 indicates that both segregated and non-segregated offenders reported significantly fewer depressive symptoms across time $(\underline{E}(2,116)=8.3, \underline{p}<.001$, $\left.\eta^{2}=.13\right)$. The ANOVA and a follow-up trend analysis revealed no significant Time by Group interaction. 
Table 19

ANOVA for the Beck Depression Inventory (Short Form) for Segregated ( $n=23$ ) and Non-segregated ( $n=37$ ) Offenders who Completed All Three Sessions

Sources

df

$\underline{\mathrm{MS}}$

$\underline{F}$

Sig.

Between

Group (G)

1

281.8

3.29

$\underline{\text { ns }}$

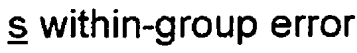

58

85.6

Within

$\begin{array}{lllll}\text { Time (T) } & 2 & 64.0 & 8.30 & \underline{\text { sig }}^{\star \star \star} \\ \text { GX T } & 2 & 9.0 & 1.17 & \text { ns } \\ \text { s within-group error } & 116 & 7.7 & & \end{array}$

Total 179

Note. ${ }^{*} \underline{p}<.05,{ }^{\star *} \underline{p}<.01,{ }^{\star * *} \underline{p}<.001$.

Brief Symptom Inventory (BSI: Derogatis, 1992). Table 20 shows that segregated offenders reported significantly more depressive symptoms than non-segregated offenders $\left(\underline{F}(1,58)=5.67, \underline{p}<.05, \eta^{2}=.09\right)$. In addition, both segregated and non-segregated offenders reported significantly fewer depressive symptoms across time $\left(\underline{F}(2,116)=19.57, \underline{p}<.001, \eta^{2}=.25\right)$. The ANOVA and a follow-up trend analysis revealed no significant interaction. 
Table 20

ANOVA for the Brief Symptom Inventory for Segregated $(n=23)$ and Nonsegregated $(n=37)$ Offenders who Completed All Three Sessions

Sources

Between

Group (G)

s within-group error df

1

58
$\underline{\mathrm{MS}}$

2.86

0.50

Within

$\begin{array}{lllll}\text { Time (T) } & 2 & 1.1 & 19.57 & \text { sig }^{\star \star \star} \\ \mathrm{GXT} & 2 & .09 & 1.74 & \underline{\mathrm{ns}} \\ \underline{\mathrm{s}} \text { within-group error } & 116 & .06 & & \end{array}$

Total 179

Note. ${ }^{\star} \mathrm{p}<.05,{ }^{\star \star} \mathrm{p}<.01,{ }^{\star \star \star} \mathrm{p}<.001$

Holden Psychological Screening Inventory (HPSI; Holden, Mendonca, Mazmanian, \& Reddon, 1992). As Table 21 shows, segregated offenders reported significantly more problems in psychosocial adjustment than nonsegregated offenders $\left(\underline{E}(1,58)=11.40, \underline{p}<.001, \eta^{2}=.16\right)$. As well, segregated and non-segregated offenders reported significantly fewer problems in psychosocial adjustment across time $\left(\underline{E}(2,116)=6.27, \underline{p}<.01, \eta^{2}=.10\right)$. Although the ANOVA showed no Time by Group interaction, a follow-up analysis found a significant quadratic trend $\left(\underline{F}(1,58)=5.90, \underline{p}<.05, \eta^{2}=.09\right)$. Figure 3 
illustrates this interaction. It shows that non-segregated offenders gradually reported fewer psychosocial adjustment problems across time, whereas segregated offenders reported a net decrease of psychosocial adjustment problems between session one and session two, but a subsequent modest increase between session two and session three.

Table 21

ANOVA for the Holden Psychological Screening Inventory for Segregated ( $\mathrm{n}=$ 23) and Non-segregated ( $n=37$ ) Offenders who Completed All Three Sessions

$\begin{array}{llllll}\text { Sources } & \underline{\mathrm{df}} & \underline{M S} & \underline{F} & \text { Sig. }\end{array}$

Between

Group (G)

1

3393.1

11.40

$\underline{\operatorname{sig}}^{\star \star \star}$

s within-group error

58

297.8

Within

Time (T)

2

173.0

6.27

$\underline{\operatorname{sig}}^{\star \star}$

$\mathrm{G} \times \mathrm{T}$

2

52.7

1.91

ns

s within-group error

116

27.6

Total 179

Note. ${ }^{\star} \underline{p}<.05,{ }^{\star \star} \underline{p}<.01,{ }^{\star \star \star} \underline{p}<.001$. 


\section{Figure 3: Mean Scores on the HPSI Across Time}
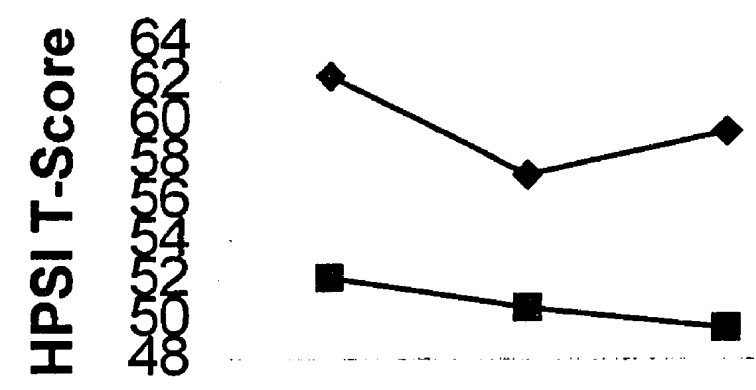

$\multimap-$ Seg.

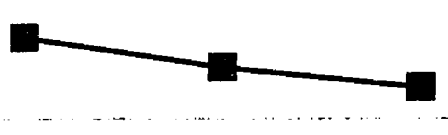

$\rightarrow-$ Non-seg.

1

2

3

Session

Hopelessness Scale (BHS; Beck \& Steer, 1988). Table 22 shows that segregated and non-segregated offenders did not significantly differ on this measure. However, segregated and non-segregated offenders indicated significantly less hopelessness across time $\left(\underline{F}(2,116)=10.19, \underline{p}<.001, \eta^{2}=\right.$ .15). The ANOVA and follow-up trend analysis revealed no Time by Group interaction. 
Table 22

ANOVA for the Hopelessness Scale for Segregated $(n=23)$ and Nonsegregated ( $n=37$ ) Offenders who Completed All Three Sessions

$\begin{array}{llllll}\text { Sources } & \underline{\mathrm{df}} & \underline{\mathrm{MS}} & \underline{\mathrm{F}} & \text { Sig. }\end{array}$

\section{Between}

$\begin{array}{lcccc}\text { Group (G) } & 1 & 44.4 & 0.92 & \text { ns } \\ \text { s within-group error } & 58 & 48.4 & & \end{array}$

\section{Within}

Time (T)

2

34.8

10.19

$\underline{\operatorname{sig}}^{\star \star \star}$

$G \times T$

2

3.29

0.96

ns

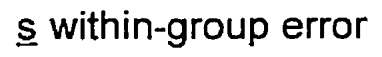

116

3.42

Total 179

Note. ${ }^{*} \underline{p}<.05,{ }^{\star \star} \underline{p}<.01,{ }^{\star \star \star} \underline{p}<.001$.

State-trait Anxiety Inventory (Spielberger, 1983). As Table 23 indicates, segregated offender displayed significantly more state anxiety than nonsegregated offenders $\left(E(1,58)=8.09, \underline{p}<.01, \eta^{2}=.12\right)$. Further, segregated and non-segregated offenders displayed significantly less state anxiety across time $\left(\underline{E}(2,116)=7.63, \underline{p}<.001, \eta^{2}=.11\right)$. Although the ANOVA showed no interaction between Time by Group, a follow-up analysis found a significant linear trend $\left(E(1,58)=4.77, \underline{p}<.05, \eta^{2}=.08\right)$. Figure 4 illustrates this interaction. It shows that non-segregated offenders gradually reported less state 
anxiety across time, whereas segregated offenders reported a decrease of state anxiety between session one and session two, but return to the their initial higher levels of state anxiety at session three.

Table 23

ANOVA for the State-trait Anxiety Inventory for Segregated $(n=23)$ and Nonsegregated ( $n=37$ ) Offenders who Completed All Three Sessions

$\begin{array}{lllll}\text { Sources } & \text { df } & \text { MS } & \underline{F} & \text { Sig. }\end{array}$

Between

$\begin{array}{lclll}\text { Group }(G) & 1 & 243.5 & 8.09 & \text { sig }^{\star \star} \\ \text { s within-group error } & 58 & 30.1 & & \end{array}$

Within

$\begin{array}{lllll}\text { Time }(T) & 2 & 48.9 & 7.63 & \text { sig }^{\star \star *} \\ \text { GXT } & 2 & 15.6 & 2.43 & \text { ns } \\ \text { s within-group error } & 116 & 6.42 & & \end{array}$

Total 179

Note. ${ }^{\star} \underline{p}<.05,{ }^{\star \star} \underline{p}<.01,{ }^{\star \star \star} \underline{p}<.001$. 


\section{Figure 4: Mean Scores on the State-trait Anxiety Inventory Across Time}
$\begin{array}{ll} & 13 \\ \text { ఖ } & \\ \text { ऽ } & 11\end{array}$
9

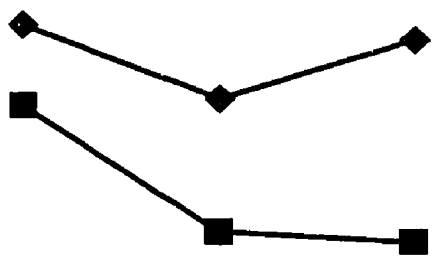

$\neg$ Seg.

1

2

3

Session

WAIS (Digit Span). As Table 24 reveals, performance on the Digit

Symbol improved significantly across time $\left(E(2,116)=5.44, p<.01, \eta^{2}=.09\right)$.

Although the ANOVA showed no Time by Group interaction, a follow-up analysis found a significant quadratic trend $\left(E(1,58)=5.24, \underline{p}<.05, \eta^{2}=.07\right)$. Figure 5 illustrates this interaction. It shows that non-segregated offenders obtained similar scores between session one and session two, but increased their performance between session two and session three. With respect to segregated offenders, they increased their performance between session one and session two, but obtained similar scores between session two and session three. 
Table 24

ANOVA for the WAIS (Digit Span) for Segregated $(n=23)$ and Non-segregated ( $n=37$ ) Offenders who Completed All Three Sessions

$\begin{array}{llllll}\text { Sources } & \underline{\mathrm{df}} & \underline{M} & \underline{F} & \text { Sig. }\end{array}$

Between

Group (G)

1

10.3

0.56

ns

s within-group error

58

18.27

Within

$\begin{array}{lllll}\text { Time (T) } & 2 & 6.8 & 5.44 & \text { sig }^{\star \star} \\ \text { GX T } & 2 & 3.2 & 2.56 & \text { ns } \\ \text { s within-group error } & 116 & 1.3 & & \end{array}$

Total

179

Note. ${ }^{*} \mathrm{p}<.05,{ }^{\star \star} \mathrm{p}<.01,{ }^{\star \star *} \mathrm{p}<.001$. 


\section{Figure 5: Mean Scores on the WAIS Digit Span Across Time}

10.5

0
O
D
1

9.5

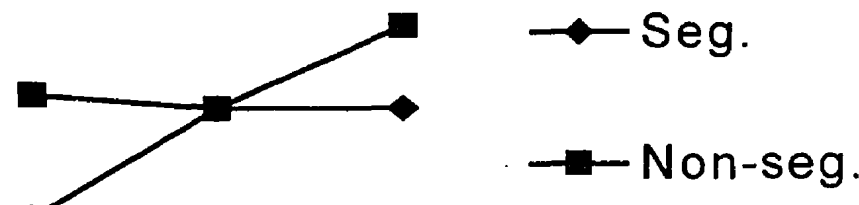

8.5

1

2

3

Session

WAIS (Digit Symbol). Table 25 shows that performance on the Digit

Symbol improved significantly across time $\left(\underline{E}(2,116)=22.56, \underline{p}<.001, \eta^{2}=.28\right)$.

The ANOVA and the follow-up trend analysis showed no significant Time by Group interaction. 
Table 25

ANOVA for the WAIS (Digit Symbol) for Segregated $(n=23)$ and Nonsegregated $(n=37$ ) Offenders who Completed All Three Sessions

Sources

df

MS

F

Sig.

Between

Group (G)

1

40.7

2.00

$\underline{\text { nS }}$

s within-group error

58

20.3

Within

Time ( $T$ )

2

42.7

22.56

$\underline{\mathrm{sig}}^{\star \star \star}$

$G \times T$

2

0.38

0.12

$\underline{\text { nS }}$

$\underline{\text { s within-group error }}$

116

1.89

Total 179

Note. ${ }^{\star} \underline{p}<.05,{ }^{\star \star} \underline{p}<.01,{ }^{\star \star \star} \underline{p}<.001$.

\section{Segregated Offenders Who Completed Three Sessions Versus Segregated}

\section{Offenders Who Completed One or Two Sessions.}

It was hypothesized that offenders who remain in segregation for longer periods of time display more mental health and psychological functioning problems than those who are more quickly reintegrated into the general offender population. Therefore, employing a similar two-strategy approach using (1) the four composite variables and (2) the eight original measures as DVs, t-tests were performed to evaluate whether offenders who stayed in segregation for all three 
sessions $(\underline{n}=23)$ differed from segregated offenders who were released or transferred after session one or two $(\underline{n}=51)$. True attrition cases $(\underline{n}=9)$ were removed from the analyses because they could have been part of the group of offenders who stayed in segregation for all three sessions.

Table 26 shows that regardless of the strategy used, no difference was found between offenders who stayed in segregation for all three sessions $(\underline{n}=$ 23) and segregated offenders who were released or transferred after session one or two $(\underline{n}=51)$.

Table 26

T-tests on the Four Composite Variables and the Eight Original Measures for Segregated Offenders Who Completed Three Sessions $(n=23)$ Versus Segregated Offenders Who Completed Only Session One or Two $(n=51)$.

\begin{tabular}{lll}
\hline Source & $\underline{\mathrm{t}}(72)$ & Sign. \\
\hline Externalizing/Aggression & 0.78 & $\underline{\mathrm{ns}}$ \\
Internaiizing/Interpersonnel & 0.85 & $\underline{\mathrm{ns}}$ \\
Psychiatric Symtomatology & 0.01 & $\underline{\mathrm{ns}}$ \\
Cognitive Ability & 0.74 & $\underline{\mathrm{ns}}$ \\
\hline Aggression Questionnaire & 0.56 & $\underline{\mathrm{ns}}$ \\
Beck Depression & 0.95 & $\underline{\mathrm{ns}}$ \\
Brief Symptom Inventory & 0.79 & $\underline{\mathrm{ns}}$ \\
HPSI & 0.05 & $\underline{\mathrm{ns}}$ \\
Hopelessness Scale & 0.20 & $\underline{\mathrm{ns}}$ \\
State-trait Anxiety Inventory & 0.42 & $\underline{\mathrm{ns}}$ \\
WAIS - Digit Span & 0.50 & $\underline{\mathrm{ns}}$ \\
WAIS - Digit Symbol & &
\end{tabular}




\section{Voluntary Versus Involuntary Cases.}

Again, employing a two-strategy approach using (1) the four composite variables and (2) the eight original measures as DVs, t-tests were completed to evaluate whether voluntary $(\underline{n}=32)$ and involuntary $(\underline{n}=51)$ cases differed in mental health and psychological functioning. As Table 27 reveals, no difference was found between voluntary and involuntary cases.

Table 27

T-tests on the Four Composite Variables and the Eights Original Measures for Voluntary $(n=32)$ and Involuntary $(n=51)$.

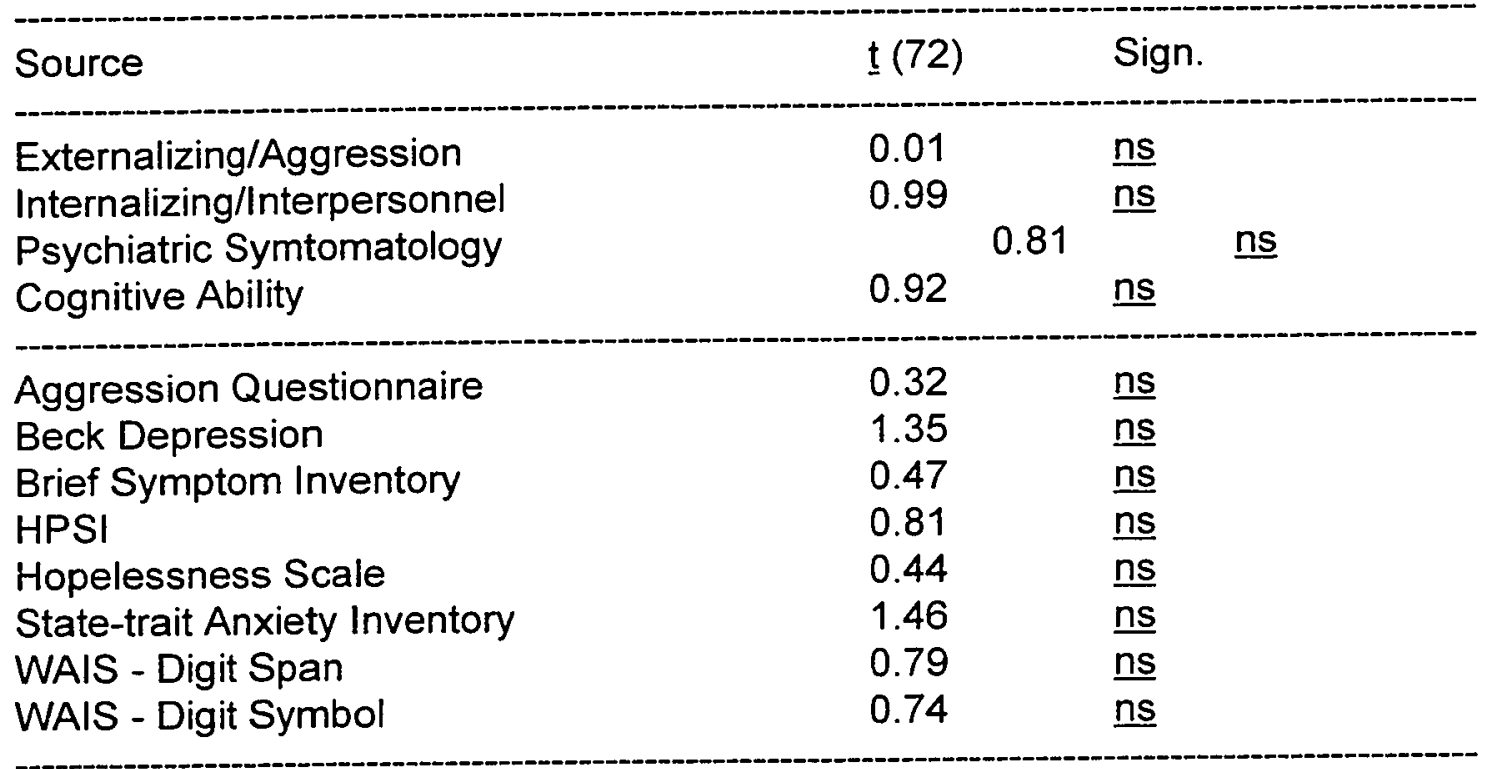

Interview Assessment.

Ten-point Rating Scales. A structured interview was conducted at each session. Table 28 shows the means and respective standard deviations at each session for the five ten-point scale questions. The mean represents the average score on the ten-point scale questions with one being negative and ten being positive. 
Table 28

Session Means and Respective Standard Deviations of Interview Assessment Questions for Segregated $(n=23)$ and Non-Segregated $(n=37)$ Offenders Who Completed All Three Sessions

\begin{tabular}{|c|c|c|c|c|}
\hline \multirow[b]{2}{*}{ Questions } & \multirow[b]{2}{*}{ Group } & \multicolumn{3}{|c|}{ Means ( $\underline{S D})$} \\
\hline & & S1 & $\mathrm{S} 2$ & S3 \\
\hline $\begin{array}{l}\text { How are you } \\
\text { feeling today? }\end{array}$ & $\begin{array}{l}\text { Seg. } \\
\text { Non-seg. }\end{array}$ & $\begin{array}{l}5.5(2.0) \\
6.3(2.2)\end{array}$ & $\begin{array}{l}6.0(2.3) \\
6.4(2.1)\end{array}$ & $\begin{array}{l}5.9(2.3) \\
6.6(1.8)\end{array}$ \\
\hline $\begin{array}{l}\text { How important you } \\
\text { think it is to have friends? }\end{array}$ & $\begin{array}{l}\text { Seg. } \\
\text { Non-seg. }\end{array}$ & $\begin{array}{l}6.4(2.7) \\
7.9(2.4)\end{array}$ & $\begin{array}{l}6.9(2.5) \\
7.9(2.7)\end{array}$ & $\begin{array}{l}6.4(2.7) \\
7.5(2.9)\end{array}$ \\
\hline $\begin{array}{l}\text { Do you have any } \\
\text { problem with sleeping? }\end{array}$ & $\begin{array}{l}\text { Seg. } \\
\text { Non-seg. }\end{array}$ & $\begin{array}{l}6.3(2.5) \\
4.0(3.4)\end{array}$ & $\begin{array}{l}5.0(3.1) \\
3.1(2.8)\end{array}$ & $\begin{array}{l}5.3(2.7) \\
3.1(2.7)\end{array}$ \\
\hline $\begin{array}{l}\text { Do you have any problem } \\
\text { with appetite? }\end{array}$ & $\begin{array}{l}\text { Seg. } \\
\text { Non-seg. }\end{array}$ & $\begin{array}{l}3.1(2.5) \\
2.7(2.7)\end{array}$ & $\begin{array}{l}3.6(3.0) \\
2.6(2.7)\end{array}$ & $\begin{array}{l}3.7(2.9) \\
2.6(2.5)\end{array}$ \\
\hline $\begin{array}{l}\text { Do you have any problem } \\
\text { with concentration? }\end{array}$ & $\begin{array}{l}\text { Seg. } \\
\text { Non-seg. }\end{array}$ & $\begin{array}{l}3.6(2.5) \\
3.0(2.1)\end{array}$ & $\begin{array}{l}3.5(2.8) \\
2.9(2.1)\end{array}$ & $\begin{array}{l}3.9(2.5) \\
3.1(2.4)\end{array}$ \\
\hline
\end{tabular}

For each of the five questions, repeated measures univariate analyses were performed. No main effect or interaction was found on the following four questions: how are you feeling today?; how important you think it is to have friends?; do you have any problem with appetite?, and; do you have any problem with concentration. With respect to the question on sleeping, segregated offenders reported significantly more sleeping problems that non-segregated offenders $\left(E(1,58)=12.64, \underline{p}<.001, \eta^{2}=.18\right)$. Moreover, segregated and nonsegregated offenders reported significantly fewer problems across time ( $\underline{F}$ 
$\left.(2,116)=4.04, \underline{p}<.05, \eta^{2}=.07\right)$. An ANOVA and $a$ follow-up trend analysis showed no significant Time by Group interaction.

Suicide Ideation. Offenders were asked questions on suicide ideation. Offenders who completed all three sessions $(\underline{n}=60)$ were asked if they ever thought of committing suicide. At session one, $40 \%(\underline{n}=9)$ of segregated and $33 \%(\underline{n}=12)$ of non-segregated offenders responded "yes". When asked if they ever attempted suicide, $22 \%(\underline{n}=5)$ of segregated and $29 \%(\underline{n}=11)$ of nonsegregated offenders said "yes".

At each session, offenders were asked if they thought of committing suicide in the last week. $17 \%(\underline{n}=4)$ of segregated offenders answered "yes" at session one, $4 \%(\underline{n}=1)$ at session two, and $4 \%(\underline{n}=1)$ at session three. As for non-segregated offenders, $14 \%(\underline{n}=5), 11 \%(\underline{n}=4)$ and $3 \%(\underline{n}=1)$ answered "yes" respectively.

Segregation Experience. Offenders who completed all three sessions $(\underline{n}=60)$ were asked if they have ever been placed in segregation in the past. The vast majority of segregated $(96 \%, \underline{n}=22)$ and non-segregated offenders $(87 \%, \underline{n}=$ 32) reported having being in segregation before. When asked how many times they have been placed in segregation, segregated offenders $(\underline{M}=11.5)$ reported almost twice as many times than non-segregated offenders $(\underline{M}=6.3)$. 


\section{Individual Case Review}

Both strategies used to analyse the mental health and psychological functioning of the offenders who completed all three sessions $(\underline{n}=60$ ) resulted in similar findings: overall, segregated offenders did not deteriorate at a statistically greater rate than that of non-segregated offenders. Moreover, offenders who remained in segregation for all three sessions $(\underline{n}=23)$ did not significantly differed in mental health and psychological functioning from segregated offenders who were released or transferred after session one or two $(\underline{n}=51)$. As well, voluntary cases $(\underline{n}=32)$ did not significantly differed in mental health and psychological functioning from involuntary cases $(\underline{n}=51)$. However, these findings do not preclude the possibility that for some offenders, the experience of segregation may have had negative effects on their mental health and psychological functioning. Therefore, a case by case review of all offenders who completed all three sessions $(\underline{n}=60)$ was conducted to see whether some segregated offenders showed distinct patterns of deterioration.

Appendix 6 illustrates the overall means at each session for the four composite variables for segregated offenders, as well as each individual scores on the four composite variables for every segregated offenders $(\underline{n}=23)$ at each session. Appendix 7 shows the same information for non-segregated offenders $(\underline{n}=37)$. The Cognitive Ability variable was re-coded so that the degree of deterioration or improvement is on the same scale for all four composite variables: higher scores represent worse mental health and psychological 
functioning, and lower scores represent better mental health and psychological functioning.

A visual examination of appendix 6 indicates that three segregated cases (i.e., 6,12 \& 14) showed a marked deterioration on one or more of the four composite variables, and three segregated offenders (i.e., 9, 20 \& 21) showed marked initial improvements between session one and session two, but subsequently "bounced back" to their initial lower levels of mental health and psychological functioning at session three. However, as illustrated in Appendix 7, similar visual patterns, perhaps less pronounced, were also found among seven non-segregated offenders (i.e., 4, 6, 17, 19, 25, 27 \& 32).

One pattern of improvements among the segregated group is noteworthy. As illustrated in Appendix 6, three segregated offenders (i.e., 9, 16 \& 22) showed marked improvements on the Psychiatric Symtomatology composite variable, whereas only one such marked improvement was found among the nonsegregated offenders (i.e., Appendix $7 ; 30$ ). 


\section{Discussion}

\section{$\underline{\text { Generalization Issues }}$}

For several reasons, this study represents the most comprehensive empirical review of the psychological effects of administrative segregation in today's Canadian federal correctional context. To begin with, this study applied the rigour of an experimental longitudinal design to a "real" segregation environment. Participants were actual inmates and not volunteers who agreed to be segregated for a fixed period of time. As such, the sample included actual inmates (some with existing psychiatric conditions and others who feared for their personal safety) who were voluntarily or involuntarily placed for periods up to 60 days in administrative segregation pursuant to the current administrative segregation process. They were segregated under "real" conditions of confinement, which included partial isolation and sensory deprivation. In addition, the participants were confronted with all of the uncertainties surrounding their segregation, such as (a) when the segregation period will end, (b) whether they will be transferred to another institution or returned to the general inmate population, and (c) whether their stay in segregation will affect their security classification, chances for parole or cell assignment. As well, some offenders may have been confronted with correctional employees who may have a punitive approach to managing segregated inmates. All these factors potentially affect one's experience of segregation and were not considered by 
studies using students or inmates who voluntarily agreed to be segregated for a fixed period if time. This study, therefore, examined the psychological effects of today's administrative segregation in federal corrections, and its results cannot be construed as unrealistic extrapolations of scenarios which are too remote from the "real" experience.

Surprisingly, although various forms of administrative segregation have been used for decades, if not centuries, there has been only one longitudinal study previously conducted using an approximation of the empirical approach used in this study. Weinberg (1967) assessed the effects of segregation on 20 inmates who were involuntary placed in administrative segregation. The study, an unpublished doctorate dissertation, was however limited to a segregation period of only five days, and reported a $68 \%$ attrition rate among the experimental group. Again, no other study has been completed using offenders in a "real" segregation context.

The fact that the current longitudinal study was conducted with offenders who were subjected to "real" segregation conditions of confinement clearly enhance its ability to be generalized. Other factors should also be considered when assessing the issue of generalization of findings. Firstly, this study was conducted at several sites making the findings less subject to undue influence by factors such as the conditions of confinement, the cultural environment of a particular institution, or specific events and incidents. 
Secondly, the penitentiaries selected have historically been perceived as some of the toughest in the country. These penitentiaries have some of the largest segregation units and heavily rely on administrative segregation to manage their difficult and high-risk inmate populations. It was therefore expected that segregated offenders in those penitentiaries would be more likely to be affected by the harsher realities of some of Canada's toughest penitentiaries.

Thirdly, the participation rate in this study was not atypical of studies which rely on inmates for subjects and which do not offer any incentive for participation (e.g., money). The true attrition rate among the segregated group was also relatively low (10.8\%) for a longitudinal study. It is important to note that none of the attrition was attributable to offenders being incapable of participating in the study because of high-risk of attempting to commit suicide or episodes of delusion or hallucination. Although always a concern, the rate and nature of the attrition in this study does not significantly undermine its ability to be generalized.

Fourthly, this study relied on multiple assessments of mental health and psychological functioning of offenders (i.e., externalizing/aggression, internalizing/interpersonal distress, psychiatric symtomatology, and cognitive ability). This approach provided a more comprehensive assessment of potential psychological effects of administrative segregation, and is consistent with preferred contemporary psychological and psychiatric assessment practices 
(DSM-IV, 1994). For example, Zamble (1992) argues that a variety of measures of behaviours, cognitions and emotional experiences are needed to assess coping. Neglecting to rely on such a wide spectrum of measures may result in a failure to detect significant psychological effects.

Finally, non-segregated offenders scored significantly higher on a measure of impression management than segregated offenders. Arguably, since segregated offenders did not show significant signs of mental health and psychological deterioration and were more accurate in their responses than nonsegregated offenders, the results of this study are more convincing.

The above mentioned factors enhance the level of confidence in the results of this research. However, there are clear limitations to this study which may reduce the generalizability of the findings. Firstly, a large number of offenders in both segregated (96\%) and non-segregated (87\%) groups had previously experienced segregation. Secondly, the findings are limited to 60 days in administrative segregation, and any extrapolation to lengthier stays would be inappropriate. It is important to note however that statistical data collected by the Correctional Service of Canada (Laplante, 1998) indicate that during the period of June 1997 to May $1998,93 \%$ of involuntary cases and $69 \%$ of voluntary cases were released prior to the 60 day regional review. This fact suggests that a majority of offenders are segregated for periods of less than 60 days; therefore, the findings of this study are very relevant to the Canadian federal context. Although not examined in this study, it is also relevant to note 
that 60 days in segregation is twice the maximum length of time that can be legally imposed for serious disciplinary infractions in Canadian federal penitentiaries.

Thirdly, as stated above, the three penitentiaries selected in this study are among the toughest medium and maximum-security institutions in the country. These penitentiaries rely heavily on administration segregation to control their inmate populations, which are composed of high-risk and high-need federally sentenced offenders. The results of this study should be limited to such inmate populations. Further, the findings of this study may be less applicable to other jurisdictions, such as the United States, in which segregated offenders typically remain in administrative or disciplinary segregation for much longer periods of time, and often under harsher conditions of confinement (Coyle, 1987; Dowker \& Good, 1993; Immarigeon, 1992; Korn, 1988).

Finally, it would also be inappropriate to extend the findings of this study to aboriginal (Bertrand, 1996) and women offenders (Korn, 1988). The realities and experiences of women and aboriginal offenders may affect their ability to adapt and cope with segregation. It is hoped that current initiatives undertaken by the Correctional Service of Canada will provide information on the psychological effects of segregation with these offenders.

\section{Personality}

It was expected that certain personality types would react to the segregation experience differently. Although no deterioration was found, 
differences in personality between segregated and non-segregated offenders were found. These differences have been suggested in the PC and segregation literature, but have seldom been assessed using standardized measures, such as the NEO Personality Inventory (Gendreau, Tellier, \& Wormith, 1985; Hodgins \& Cote, 1991; Rold, 1992).

The NEO was developed to operationalize the five-factor model of personality, a representation of the structure of traits developed over the last forty years (Digman, 1990). Costa and McRae (1990) found that since 1985, research using the NEO has demonstrated that the five factors can account for the major dimensions in personality questionnaires designed to measure, inter alia, the DSM-III-R personality disorders. Segregated offenders were found to score higher on Neuroticism ( $\mathrm{N}$ ) than non-segregated offenders. Costa and McCrae (1992) explained that "the general tendency to experience negative affects such as fear, sadness, embarrassment, anger, guilt, and disgust is the core of the $\mathrm{N}$ domain" (p. 14). They also suggest that neurotic individuals tend to cope more poorly with stress than others. Although segregated offenders were found to score higher on Neuroticism and may, therefore, be ill equipped to cope with the stress associated with segregation, the findings of this study suggest that they nonetheless adapted and coped well with the segregation experience.

Segregated offenders scored significantly lower on Extraversion (i.e., less sociable, likely to prefer large groups, assertive, active and less talkative), Openness (i.e., less active imagination, sensitivity, attentiveness to inner 
feelings, intellectual curiosity, and independence of judgment), Agreeableness (i.e., less altruistic and sympathetic to others and eager to help them, and more egocentric, skeptical of others' intentions, and competitive rather than cooperative), and Conscientiousness (i.e., less strong-willed and determined) than non-segregated offenders. Arguably, these trait patterns depict individuals which have personalities that may bring them at odds with non-segregated offenders as well as correctional staff. The general inmate population may not tolerate offenders with such personality patterns. Due to their lack of assertiveness, general tendency to experience negative affects, and overall poorer mental health and psychological functioning, segregated offenders may be more easily victimized or less apt at adapting and coping with prison life.

\section{Psychological Effects}

Overall, both segregated and non-segregated offenders reported better mental health and psychological functioning over time. This finding is common in studies which rely on repeated-measures designs and has been primarily attributed to practice effects (Pedhazur, 1982). For example, Zamble (1992) found that offenders' emotional states generally improve over time. Participants lose interest in answering repeatedly to identical questions and tend to report less problems overtime.

Although there is an alternative explanation to account for these overall improvements in mental health and psychological functioning, it is less plausible. It is unlikely that these improvements in both segregated and non-segregated 
groups were attributable to significant events which occurred in all three penitentiaries. During the eight-month data collection phase, research assistants could not identify any event which could have had positively affected prison life for both segregated and non-segregated offenders and account for the overall improvements. Therefore, the improvements in mental health and psychological functioning of both segregated and non-segregated offenders should be viewed as artifacts of repeated testing.

It was hypothesized that as a group segregated offenders overall would report greater mental health and psychological functioning problems than nonsegregated offenders. This hypothesis was supported by the fact that segregated offenders indicated significantly more internalized problems, interpersonal distress and psychiatric symptoms than non-segregated offenders. Segregated offenders also displayed significantly more depressive symptoms, problems in psychosocial adjustment, and transient anxiety than non-segregated offenders. These results are consistent with many cross-sectional and qualitative studies (Brodsky \& Scogin, 1988; Grassian 1983; Hodgins \& Cote, 1991; Wormith, Tellier \& Gendreau, 1988; Rold, 1992). It is important to reaffirm that these between group differences may not be attributed to placement in administrative segregation.

The most important questions raised in this study were whether the poor mental heath of segregated offenders was attributable to segregation or whether 
segregated inmates already were of poorer mental heath prior to their segregation.

The hypothesis that the mental health and psychological functioning of segregated inmates would deteriorate over a period of 60 days in segregation was not supported. The MANOVA performed on the four composite variables and the ANOVAs conducted on each of those variables revealed no such deterioration. Further, the ANOVAs performed on each of the eight measures also did not reveal any deterioration, nor did an individual review and comparison of all segregated and non-segregated cases. These unequivocal results can be interpreted in two ways: (a) segregated offenders generally adapted and coped well with the conditions of today's Canadian federal administrative segregation; or (b) the segregated inmates did not perceive the conditions of their confinement as threatening or stressful and therefore were not affected by them.

On one hand, there is no shortage of researchers, this author included, who have observed or reacted strongly to the conditions of confinement of segregated inmates (e.g., 23 out of 24 hours of cell confinement, small yard size, lack of programs and services, constant state of idleness, etc.). However, on the other hand, other researchers have commented on all the distractions, programs and services that are available in segregation units in Canadian penitentiaries (e.g., TV, radios, books, computers, exercise period often with the company of other offenders; Suedfeld et al., 1982). Moreover, the Task Force Reviewing Administrative Segregation (Kane, 1997) was confronted with many correctional 
staff who thought segregation units were "too comfortable" for offenders. They often suggested, contrary to current legal and policy provisions, that the conditions of confinement should be made more harsh in order to discourage offenders from requesting segregation and to provide an "incentive" for segregated inmates to reintegrate into the general inmate population.

Another explanation to account for the unequivocal results could be that the environment that offenders were in before segregation was such that it was viewed more negatively than the conditions of confinement in segregation. If that is the case, it suggests that the correctional authorities must take further steps to ensure that the general inmate population is safe and secure.

Nonetheless, regardless of the possible explanations to account for the lack of deterioration, this study is somewhat encouraging because it provides evidence that segregation for 60 days as currently administered in Canadian penitentiaries does not negatively affect offenders' mental health and psychological functioning.

In sum, analogous to the effects of administrative segregation, Zamble and his colleagues have repeatedly found that psychological functioning was remarkably stable over time in prison, and that contrary to the expectations of proponents of the prisonization theory, marked psychological deterioration is not a necessary consequence of long term imprisonment (Zamble, 1992; Zamble \& Porporino, 1988, 1990; Zamble, Porporino, \& Kalotay, 1984). Perhaps what Zamble and his colleagues have characterized as "the deep freeze" (Zamble 
1992; Zamble \& Porporino, 1988, 1990) is also an appropriate description of what typically happens to inmates placed in administrative segregation for periods of up to 60 days.

\section{Policy Issues}

It was anticipated that this research would have important policy implications in areas such as: (a) the level and frequency of monitoring and assessment required for inmates in segregation (mandatory vs. upon request); (b) programming to reduce mental health deterioration (the need for, and type of, intervention programs); and (c) the adequacy of current assessment strategies (what aspects of psychosocial functioning are important to assess, and which are less impacted by segregation). Since detrimental effects were not found, the policy implications are somewhat less significant than anticipated .

First, with regard to monitoring and assessment of segregated offenders, psychologists are required by policy to assess segregated offenders every 30 days, and health care workers and wardens are required to make daily visits to segregation units. Although this study revealed no evidence of detrimental effects, the 30-day requirement should be preserved, as well as the daily visits by health care workers and wardens. Arguably, reducing the few contacts segregated offenders currently enjoy could have negative consequences. It could be that regular contact itself is an important factor reducing the likelihood of deterioration. Moreover, this research only suggests that the possibility of negative effects is likely to be an exception rather than the norm. Since the 
findings of this study do not preclude in any way the possibility that some offenders may in fact be negatively affected by segregation, close monitoring should continue.

Due to their overall poorer mental health and psychological functioning, it may be appropriate as a "best practice" for psychologists to meet with all offenders placed in segregation. This could serve to establish a baseline for subsequent evaluations of mental health and psychological deterioration and to provide support for segregated inmates at times of crisis. In addition, since segregated offenders were found to have poorer mental health and psychological functioning, employees working with segregated offenders may benefit from special training on mental health issues.

Interestingly, the 30-day policy requirement also stipulates that psychologists must assess "inmates' capacity to remain in segregation". This criterion implicitly demands that psychologists predict future mental health deterioration. The findings of this research, as well as the existing literature on segregation, do not provide any information on what should be assessed or relied upon when making such a prediction. In fact, making such a prediction with any reasonable degree of accuracy may well be impossible at this time. The policy criterion is unrealistic and it may be more appropriate to limit the assessment of segregated inmates to their current mental heaith and psychological functioning. 
Second, it was expected that this research would provide specific areas of mental health and psychological functioning which needed particular attention when conducting assessment and monitoring of segregated offenders. But again, since this study did not detect detrimental effects, little can be said in the way of policy on what aspects of mental health and psychological functioning should be carefully scrutinized. However, some general comments can be made regarding psychological assessments.

Currently, psychologists utilize a standard form which highlights general mental health issues (e.g., risk of suicidal or self-injury, depression, anxiety, aggression, psychosis, mania) when completing their 30-day assessments. However, how to assess each component is left to the psychologist's discretion. Typically, psychologists conduct a brief semi-structured interview with the segregated offender. It may be appropriate as a "best practice" to conduct more elaborate assessment procedures to ensure that minor or perhaps less obvious deterioration can be detected and documented.

Finally, the findings of this study have programming implications for segregated offenders. Andrews, Zinger, Hoge, Bonta, Gendreau, and Cullen (1990) performed a meta-analysis, which is a quantitative and objective review of primary research (Cook \& Leviton, 1980), on the effectiveness of correctional programs. They found that treatment programs conducted in accordance with the following three empirically-based clinical principles of successful rehabilitation (Andrews, Bonta \& Hoge, 1990) significantly reduced recidivism rates: the 
risk principle, the need principle, and the responsivity principle. The risk principle involves matching levels of treatment with the risk level of the offender. Higher risk cases should receive more intensive services whereas lower risk cases should receive minimal services. Since segregated offenders were found to be higher risk cases than non-segregated offenders, programs delivered to segregated offenders should be intensive to maximize success.

The second principle, the need principle, requires programs which are intended to reduce recidivism to target empirically-based correlates of criminal behaviour. Andrews and Bonta (1994) have emphasized the importance of targeting variables such as antisocial attitudes, pro-criminal associates, and temperamental and personality factors. Although the primary concern with providing programs to segregated offenders is to facilitate their reintegration into the general inmate population, if such reintegration cannot occur quickly, intensive treatment programs that target variables that are known to be linked to criminal conduct should be introduced.

Lastly, the responsivity principle refers to the delivery of programs in a style and mode consistent with the learning ability and learning style of the offender (Andrews \& Bonta, 1994). Social learning and cognitive-behavioral approaches have been identified as the approaches which best reduce recidivism. Andrews et al. (1990) have demonstrated that these approaches have consistently generated better results. The distinct personality patterns of 
segregated offenders may be important to consider and assess when delivering treatment programs to them.

\section{Future Direction and Conclusion}

Because this study is one of the very few empirical longitudinal studies which has evaluated the effects of segregation, additional research is obviously needed. On a personal note, it is easy to understand why so little research of this kind has been completed. It is costly, time consuming and requires a great deal of dedication and collaboration from various actors. Support from the correctional authorities is required, and data collection necessitates a great deal of support from research assistants, psychologists, wardens, segregation unit managers and staff. Moreover, segregation units have typically insufficient interview and hearing rooms to accommodate everyone, let alone researchers. Segregation Review Boards, Independent Chairpersons and the National Parole Board often rely on space available in segregation units to hold hearings; psychologists need to conduct psychological assessments; parole officers (i.e., case management officers) are required to meet with segregated offenders to, inter alia, update correctional plans; and, lawyers must occasionally meet with segregated offenders. As well, staff managing segregation units need to ensure that segregated offenders get their showers and daily hour of exercise. This may seen trivial, but with limited staff managing large segregation units which house many "incompatible" offenders and which only possess one or two exercise yards and shower facilities, the level of activities in segregation units is 
surprising. Working around these priorities and under strict and elaborate security protocols makes this type of research venture quite difficult. To conduct further research in this area, correctional authorities should encourage their psychologists, who are already required to monitor and assess segregated offenders, to perform additional research. Correctional psychologists could easily conduct longitudinal segregation research if correctional authorities provide them with opportunities to pursue their research interest and some resources. A decentralized operational research function brings great benefits to correctional authorities.

It is obvious that research evaluating the effects of segregation beyond 60 days is also needed. Once again, it would be ill advised to attempt to extrapolate the findings of this study (a) beyond 60 days of administrative segregation, and (2) to other jurisdictions. For example, the findings of this study are somewhat irrelevant to current segregation practices in the United States where offenders can be segregated for years for disciplinary infractions with virtually no distractions, human contacts, services or programs.

The difference between the personality of segregated and nonsegregated offenders is an important finding. Although many have suggested that segregated offenders' psychological weaknesses and idiosyncratic behaviours were not well tolerated by the general inmate population (Carriere, 1989; Gendreau, Tellier, \& Wormith, 1985; Rold, 1992; Wormith, Tellier, \& Gendreau, 1988), the personality of segregated offenders had seldom been 
assessed. Whether a distinct personality profile may increase an offender's risk of being placed in administrative segregation should be further examined using more comprehensive measures of personality.

Although this research revealed no evidence that administrative segregation for periods of up to 60 days was damaging, the findings of this study should not be used to legitimize the practice of administrative segregation. As Johnston and Toch (1983) have remarked, "science is a hard game to play where policy implications are immediate and where we are concerned about the consequences of our findings" (p. 16). Administrative segregation remains a management tool which is grossly overused in Canadian penitentiaries. Regardless of whether offenders adapt and cope well with the segregation experience, it is not healthy for anyone to idle aimlessly in a cell for 23 out of 24 hours a day; it simply is not a constructive way of serving a sentence; and, it is likely to impede attempts to rehabilitate and safely reintegrate offenders into society.

Although it will always remain a legitimate management tool to effectively deal with problematic situations and individuals, its current use is perhaps symptomatic of the Correctional Service Canada's inability to reduce tensions and resolve conflicts in the prison context. Administrative segregation has clearly become the number one way of managing inmates and "doing business". Laplante (1998) reported that during the period between June 1, 1997 and May 31,1998 , out of an inmate population that averaged 13,504 offenders, 6,848 
placements in administrative segregation took place. Of these, $2534(37 \%)$ offenders were placed in segregation more than once during that same period, and a staggering $4314(63 \%)$ offenders were new placements. Such high reliance needs to be carefully examined. Moreover, the costs associated with processing these offenders in accordance to due process requirement are extraordinary (i.e., paperwork, enhanced security and staffing, and reviews by wardens, Segregation Review Boards and Regional Headquarters, etc.). It is time to rethink conflict resolution in Canada's penitentiaries.

Implementing alternative/appropriate dispute resolution processes on a large scale is the most promising initiative to reduce the disproportionate number of segregation cells and units in Canada's federal correctional system. Providing the tools to resolve conflicts and fostering a correctional environment respectful of human rights is the only way to breakdown this over-reliance on administrative segregation for managing offenders. Breaking the vicious cycle of relying on administrative segregation to reduce tensions and resolve conflicts should be the number one priority for the Correctional Service of Canada. 


\section{Appendix 1: Consent Form}

I , have been asked to take part in a study on the psychological effects of incarceration. I understand that this study is being conducted by the Research Branch of the Correctional Service of Canada coordinated by Ivan Zinger, Research Officer. The purpose and method of this study have been explained to me, and I understand the explanation. I have been given the opportunity to ask questions about the study, and am satisfied with the responses I was given.

I understand that participation in this study will include up to three sessions in which an interview will be conducted and questionnaires filled out. I have been made aware that these sessions will be about 60 to 90 minutes in length. Furthermore, I understand that I may refuse to continue with the study, or answer questions at any time.

There is no penalty if I choose not to participate, nor will participation be considered in any kind of release decision.

I understand that the information gathered in this study will be kept confidential. I also understand that my answers will be coded in such a way that I can not be identified in any report of the results. However, part of the study will include questions about my mental health, such as the presence of suicidal thoughts. If it becomes clear during the interview that you are suicidal, I understand that a psychologist will be notified. I also understand that I may be approached in the future concerning further evaluations of my psychological health.

This project has passed ethics approval boards both at Carleton University and Correctional Service of Canada (CSC). If you have any concerns regarding this project you may contact Ivan Zinger at CSC [(613) 947-4979] or Dr. Andrews at Carleton University [(613) 520-2662]. If you have ethical concerns about the study, you may also contact the Chair of the Psychology Department, Dr. Matheson [(613) 520-2600, ext. 7513] or the head of the Ethics Committee, Dr. Gick [(613) 520-2600, ext. 2664] at Carleton University.

I agree to take part in this research

(or)

I do not want to take part in this research

Signature of Participant

Date

I, the undersigned, have defined and fully explained the above to the participant in detail, and to the best of my knowledge, it was understood.

Signature of Researcher

Date 


\section{Appendix 2: Information Form}

The purpose of this study is to determine how inmates' in segregation and in the general population think and feel about many different areas of their lives. This study is being conducted at your institution for Correctional Service of Canada.

In this study, we will interview inmates, and ask them to fill out several questionnaires at three points in time. For segregated inmates, the initial session will occur shortly after placement in segregation. Two additional sessions will follow, one at 30 days and one at 60 days after placement. Not all inmates will be able to participate in all three sessions because many will be returned to the general population or transferred. For inmates in the general population, three sessions will be held, an initial one, and two other sessions at 30 and 60 days afterwards.

The purpose of this study is to collect information on the thoughts and feelings of inmates, and to examine how prisons may affect people. The findings from this study may be used later to determine how to improve the system. So if you decide to co-operate, not only will you be helping us, but you may be helping to shape changes in the prison system. At the same time, you need to be aware that we are only collecting information; we will have no power to help you with any problems you may have, and no ability to offer you treatment. You must go through accepted channels for those things. In addition, we can not offer you money, or rewards based on your participation. However, we can provide you with a copy of the results when the study is finished.

All answers provided by inmates will be strictly confidential, there will be no names attached to any of the answers. Your responses will not be shared with any persons other than those directly involved with the study (researchers), nor will they be used for purposes other than research without your further consent. This confidentially is guaranteed by the Canadian Human Rights Act, and it will be respected.

We would appreciate your co-operation in this study. If you agree to participate in this study, you may be approached in the future concerning further evaluations of your psychological health. This project has passed ethics approval boards both at Carleton University and Correctional Service of Canada (CSC). If you have any concerns regarding this project you may contact Ivan Zinger at CSC [(613) 947-4979] or Dr. Andrerws at Carleton University [(613) $520-2662]$. If you have ethical concerns about the study, you may contact the Chair of the Psychology Department, Dr. Matheson [(613) 520-2600, ext. 7513] or the head of the Ethics Committee, Dr. Gick [(613) 520-2600, ext. 2664] at Carleton University. 


\section{Appendix 3 Debriefing}

Over the last two months you have participated in a study concerned with the effects of long term segregation on inmates. This project came about for several reasons, the most important of which was that previous research has yielded conflicting findings regarding the impact of long-term segregation on inmates. Some authors report that segregation has minimal negative effect, yet others report that major mental health deterioration may occur with extended periods of segregation.

The purpose of this study was to explore the possible effects of segregation on psychological functioning in areas such as depression, suicide ideation, and interaction with others. We looked at changes in mental health and psychosocial functioning over a sixty day period. In order to determine if these changes were due to the experience of segregation, we also assessed the health of non-segregated inmates over the same period. A comparison between the two groups (segregated and non-segregated inmates) will provide us with a clearer understanding of the effects of long-term segregation.

Findings from this study may be used to guide programming, and the development of intervention strategies for inmates placed in segregation. It is hoped that this project will not only lead to reduced risk of disturbances in inmates' mental health, it will also function to increase CSC psychologists' provision of services to segregated inmates.

A research report will be available by Fall 1998. If you would like a copy of the report at that time, please contact the info Centre at CSC Research Branch [(613) 947-8871]. If you have any concerns regarding this project you may contact Ivan Zinger at CSC [(613) 947-4979] or Dr. Andrews at Carleton University [(613) 520-2662]. If you have ethical concerns about the study, you may contact the Chair of the Psychology Department, Dr. Matheson [(613) 5202600, ext. 7513] or the head of the Ethics Committee, Dr. Gick [(613) 520-2600, ext. 2664] at Carleton University. 
Appendix 4: Session 1 Interview: Segregated Inmates

Date of Interview (yy/mm/dd):

Subject Number:

Subject's Full Name:

Subject's FPS Number:

Date of Birth (yy/mm/dd):

Institution: Collin's Bay

Cell Type: Normal

Legal Grounds for Placement:
a. type:
voluntary
b. reason:
inmates own safety jeoperdized
involuntary
inmate jeopardizing safety of others
inmate may interfere with ongoing investigation

I want to ask you about a number of areas of your life today. We are going to be talking about how you feel about your life and circumstances. If at any point you feel uncomfortable answering a question you may refuse to answer. Before we begin, I need to tell you that although the information you provide today will be confidential, there are limits. I have an obligation to disclose any information you may provide if it's in regards to your safety or that of the institution. These areas include suicide plans, plans of escape, injury to others and the general security of the institution. Do you have any questions before we begin?

Let's start out with some general questions...

\section{General Well-Being}

1. On a scale of 1 to 10 with 1 being the very worst and 10 being the very best:

a. What is the very worst you have ever felt?

b. what is the very best you have ever felt?

c. how you are feeling today?

\section{Life on the Outside}

First I would like to talk about life on the outside, and ask you some general questions about your health. 


\section{Mental Health Functioning}

2. Have you ever been in a psychiatric hospital/ward for a long period of time (minimum of 1 month)? Yes No

if YES,

a. for what?

b. for how long (months)?

3. Have you ever seen a psychologist, psychiatrist, or counselor (other than for court)? Yes No

if YES

a. for what? (diagnosis or symptoms)

4. Have you ever been on any psychiatric medication?

if YES,

a. for what?

b. for how long (months)?

5. How many times have you ever had a head injury, lost consciousness or blacked out? Never \# of times

if HAS,

a. did you have to go to the hospital? Yes No

6. How far did you get in school (grade)?

if LESS than $\mathrm{Gr} .11$

a. how old were you when you quit?

7. Were you ever placed in special classes at school? Yes No if YES,

a. what for?

\section{Social Relationships}

I would like to talk about your relationships on the outside.

8. On a scale of 1 to 10 with 1 being extremely unimportant and 10 being extremely important, rate how important you think it is to have friends.

9. When you were on the outside, what were your living arrangements? Did you:

a. live with a spouse (include. common law)

b. live with a spouse and children

c. with other family members

d. live with friends

e. live alone

f. other (specify): 
10. How would you characterize your friendships when you were on the outside?

a. no friends

b. some casual friends

c. some casual and some close friends

d. many close friends

Casual friends are those who you do not spend a lot of time with, those with whom you have a passing acquaintance. These are the people you would stop and talk to on the street, but who you do not rely on or expect to be there for you.

Close friends on the other hand you see more often, they are the ones you would most prefer to spend your time with. You feel like you can trust them with private ideas and details, and who trust you too. Close friends know lots about each other, and can be counted on in a tight spot.

11. On a scale of 1 to 10 with one being extremely unhappy and dissatisfied and 10 being the happiest you could be, you wouldn't change a thing, how did you feel about your social relationships in general?

\section{Segregation Experiences}

I would like to talk about your experiences in prison. I am going to ask you questions about segregation, your treatment, and your life in general while incarcerated.

12. Have you ever been in segregation before? Yes No if YES,

a. how many times?

b. average number of days

13. What events or circumstances led to your placement in segregation this time? (specify)

14. On a scale of 1 to 10 with 1 being grossly unfair and 10 being extremely fair,

a. rate the fairness of the process by which you were placed in segregation

b. rate the fairness of the system 
15. On a 10 point scale, with 1 being much worse and 10 being much better,

a. generally, rate the way you are treated by staff now you are in segregation

b. generally, rate the way you were treated by staff when you were in the general population

16. How long do you think you'll be in here? (days)

\section{Suicide Ideation}

At different points in our lives, nearly everyone feels bad or thinks that things are going poorly. Sometimes these feelings are very strong, and may even lead people to consider whether or not they want to go on. I would like to ask you some questions about these kinds of feelings.

17(a) Have you ever been so down or depressed you've thought of hurting yourself? Yes No

17(b) Have you ever been so down or depressed you've thought of committing suicide? Yes No

if YES,

i. how often in the last year?

ii. rate the severity of these thoughts on a scale of 1 to 10 with 1 being a passing thought, briefly considered and 10 being a very serious thought - in which you had decided the method you would use and had made preparations.

iii. were you (usually) under the influence (alcohol/drugs) at the time? Yes No

18. Have you ever thought about how you would do it? (method)

19. Have you thought about committing suicide in the last week? Yes No if YES,

ii. rate the severity of these thoughts on a scale of 1 to 10 with 1 being a passing thought, briefly considered and 10 being a very serious thought in which you had decided the method you would use and had made preparations. method, note it) (if serious problem for method - if a realistic 
20. Have you ever attempted suicide? Yes No

if YES,

a. how many times?

b. were you under the influence (alcohol/drugs) at the time? Yes No

c. any recent attempts (i.e., last 6 months)? Yes No

d. how did you do it?(list methods)

e. why were you unsuccessful?

IF RECENT THOUGHTS OF SUICIDE WERE DISCLOSED, PLEASE NOTIFY THE SENIOR PSYCHOLOGIST IN WRITING AND BY TELEPHONE

\section{Life in Prison}

Now I want to talk a bit more specifically about your life in prison.

Social Relationships

21. How would you characterize your friendships in here?

a. no friends

b. some casual friends

c. some casual and some close friends

d. many close and casual friends

22. On a scale of 1 to 10 with one being extremely unhappy and dissatisfied and 10 being the happiest you could be, you wouldn't change a thing, how do you feel about your social relationships, in here?

Somatic Problems

23. For the following questions, I would like you use a 10 point rating scale to indicate possible problems in several areas. On a scale of 1 to 10 with one being no problem at all, and 10 being a very severe problem, do you have any problems with:? (specify)
a. sleeping:
b. anger:
c. concentration:
d. memory:
e. appetite:
f. interaction with others:
g. other: 
24. Aside from sleeping, how much time in the average week do you spend on:

a. School, or programs hours/week

b. Visits and writing letters hours/week

c. Watching TV, listening to radio or music? hours/week

d. Hobbycraft hours/week

e. Recreation: hours/week (describe)

f. Other hours/week (describe)

\section{Debriefing}

Thank you for your time and assistance with this project. If you experienced any distress as a result of your participation in this study, you may request to see a psychologist.

I want to remind you that the responses you provided to these questions today will be kept confidential and will not impact in any way on a release decision.

With this project, we hope to improve our understanding about the effects of long-term segregation. Although your particular comments will not be reported, they will help us in this endeavor.

If you are still in segregation when the next interview sessions are conducted, I very much hope you will agree to participate. Do you have any questions? 
Institution Name:

Date:

Filled out by:

A. Cell descriptions:

1. Typical Segregation Cell:

a. Dimensions

i. size: (approx. sq. ft.)

ceiling height:

ii. number of cells (in seg. unit):

iii. \% of cells currently double-bunked

iv. power outlets?:

Yes No

b. Window
i. size:
by
ii. able to open? Yes No

c. Door

i. double door? Yes No

ii. solid door? Yes No

iii. window in door? Yes No

if YES,

size:

by (in.)

\section{Other Types of Cells:}

\section{Dry Cells:}

a. Dimensions
i. size:
(approx. sq. ft.)
ii. ceiling height:
iii. number of cells:
iv. power outlets?: Yes No

b. Window

i. size:

by

c. Door
i. double door? Yes No
ii. solid door? Yes No
iii. window in door? Yes No if YES,
size: by (in.)

\section{Video-Monitored Cells:}

a. Dimensions
i. size:
(approx. sq. ft.)
ii. ceiling height:
iii. number of cells:
iv. power outlets?: Yes No

b. Window
i. size:
by (in.)
ii. able to open? Yes No

c. Door

i. double door? Yes No

ii. solid door? Yes No

iii. window in door? Yes No if YES, size: by _ (in.) 
B. Yard:

1. Size: (approx. sq. ft.)

2. Sides: Concrete Walls Fence Other:

3. Overhead: Partially Covered Open Comments:

C. General:

1. Common Area? Yes No

2. Number of : interview/visitor rooms:

3. Telephone in Cell? Yes No Comments: 

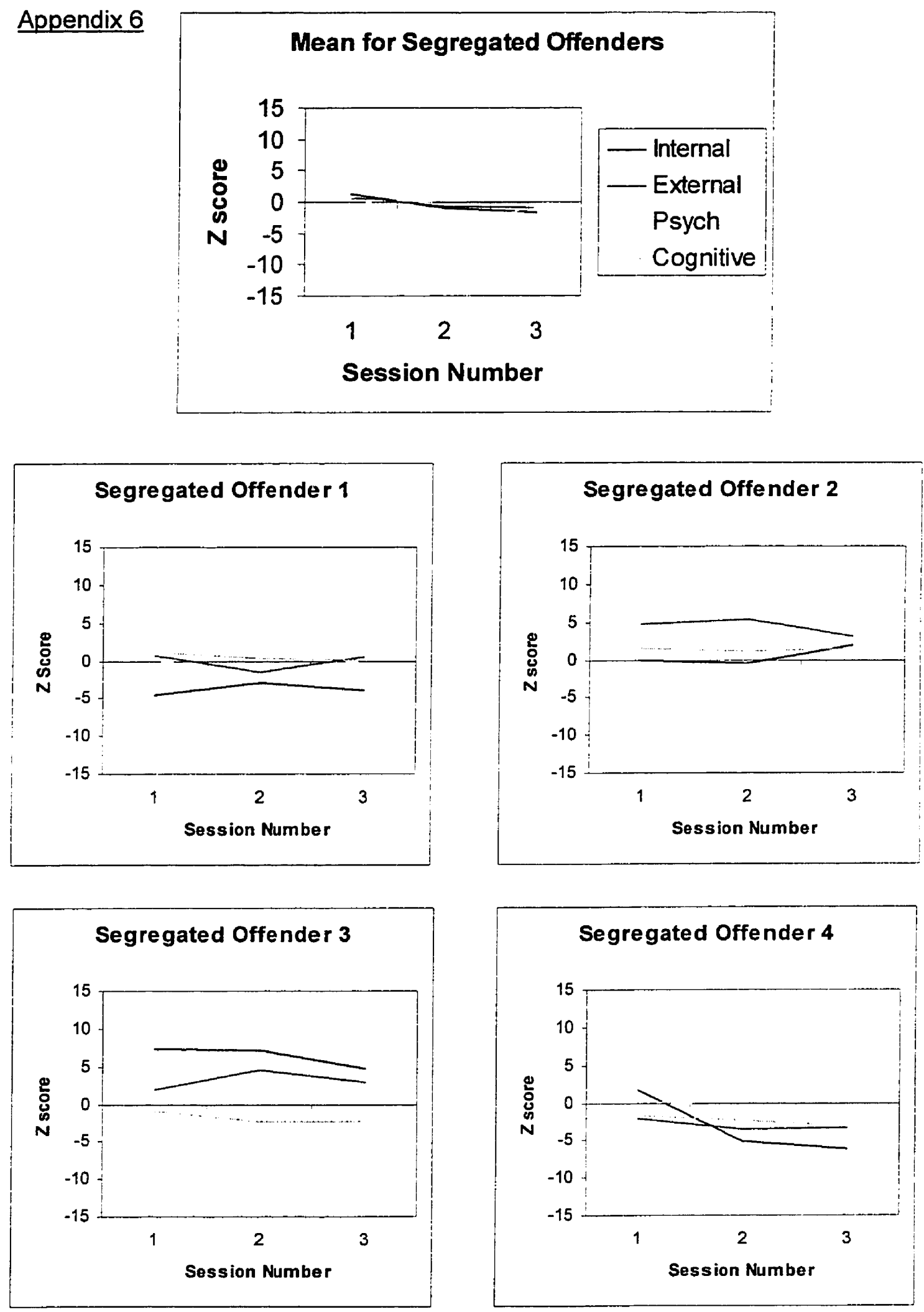
Effects of Segregation
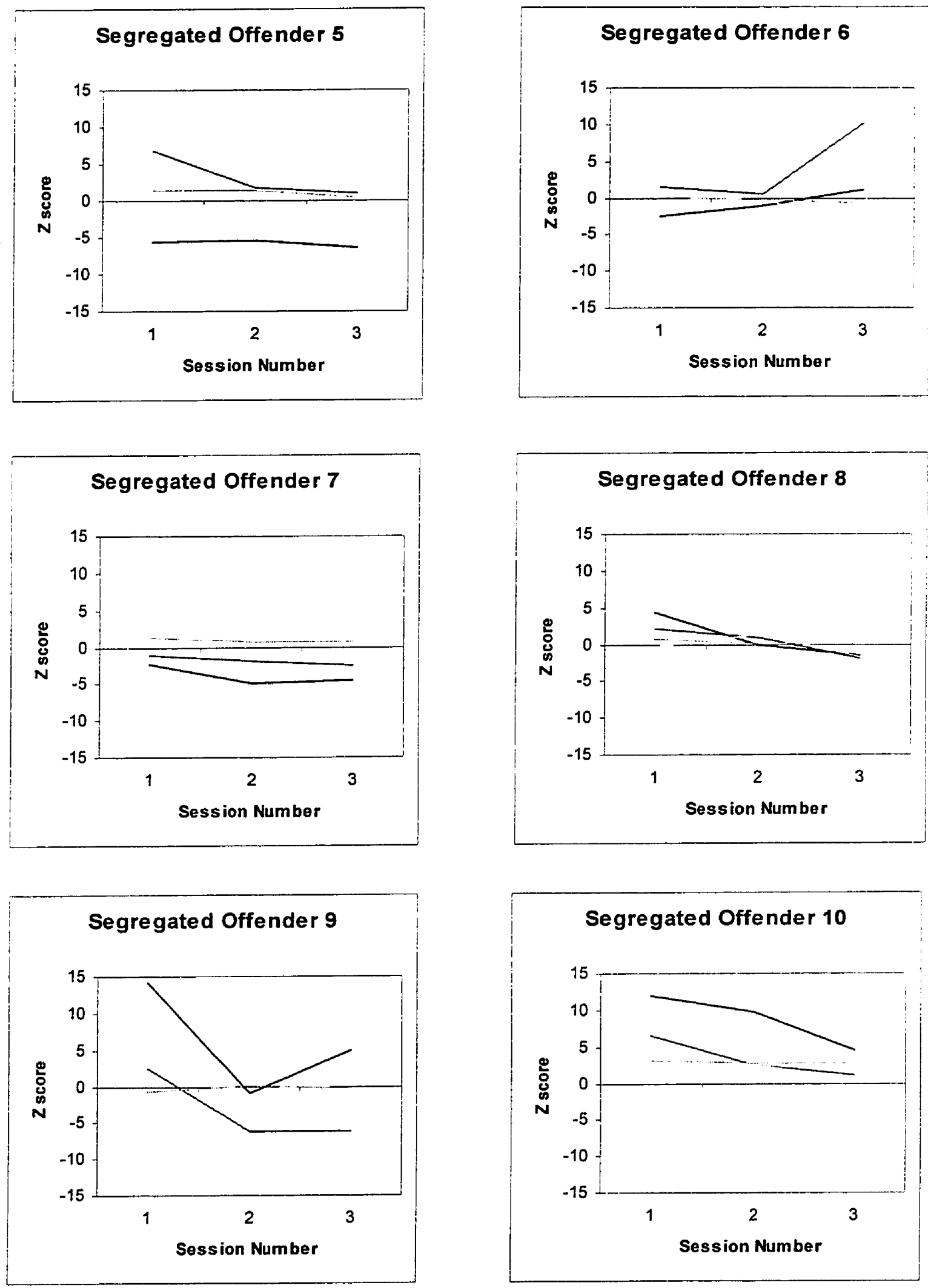

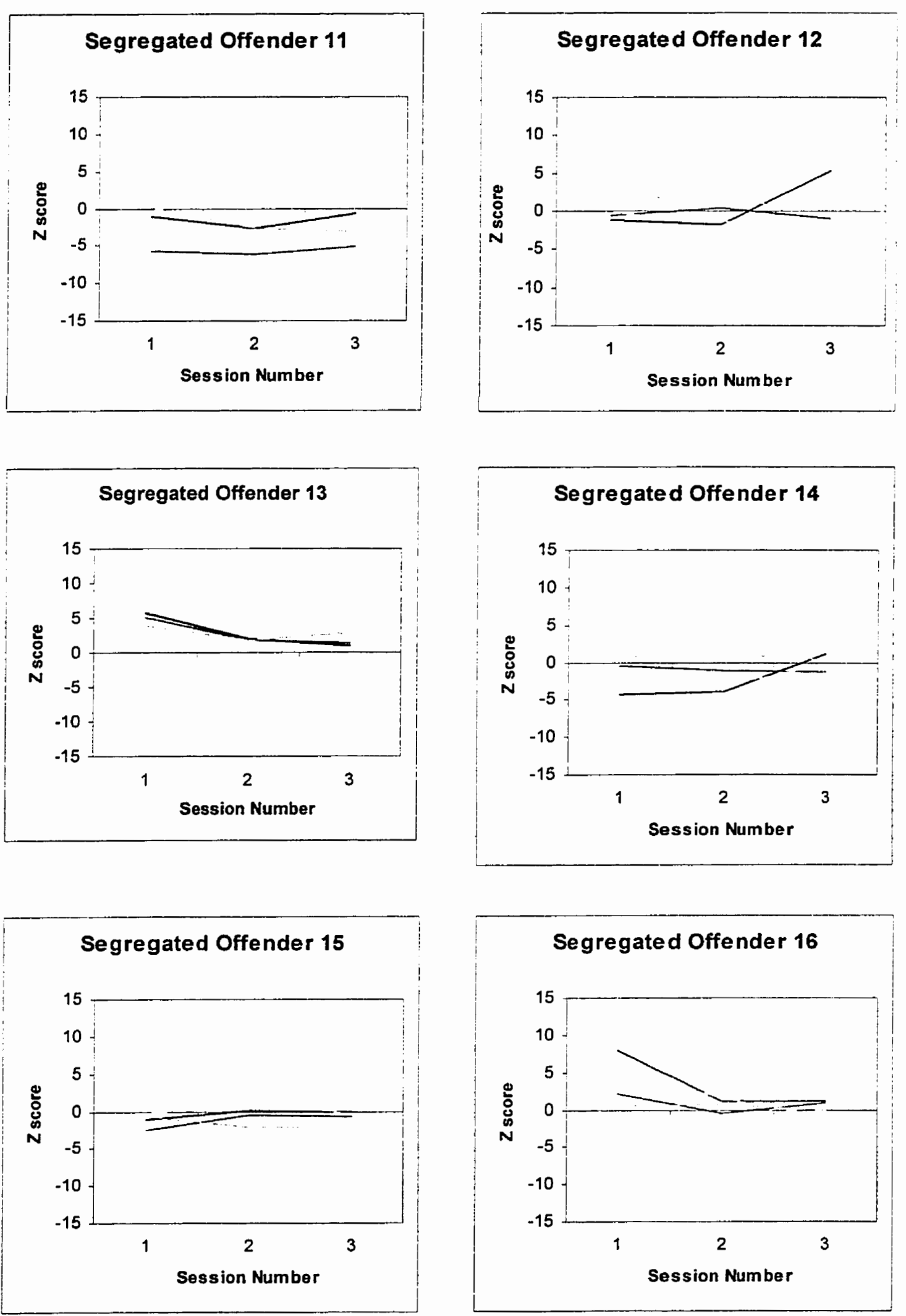

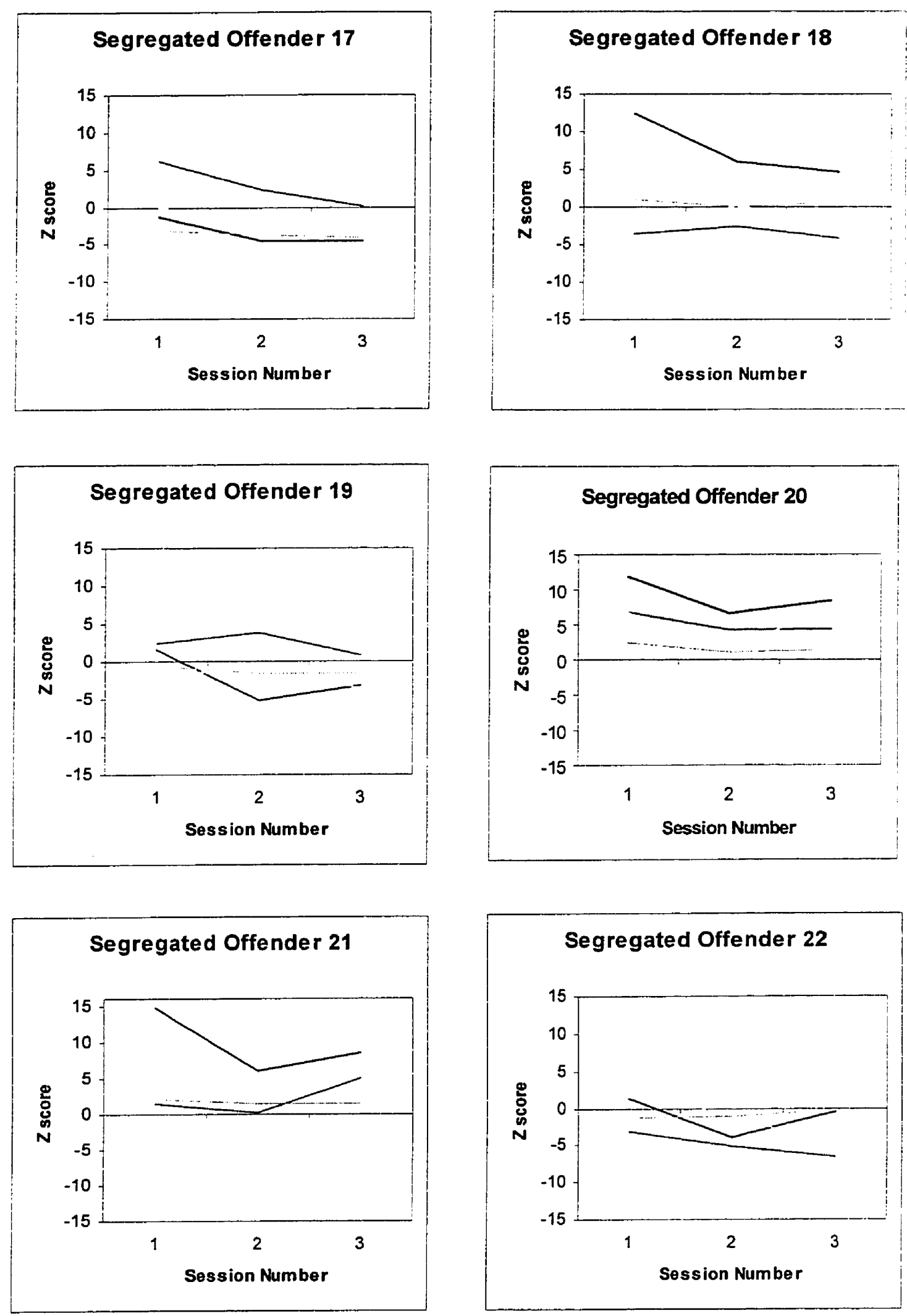
Effects of Segregation

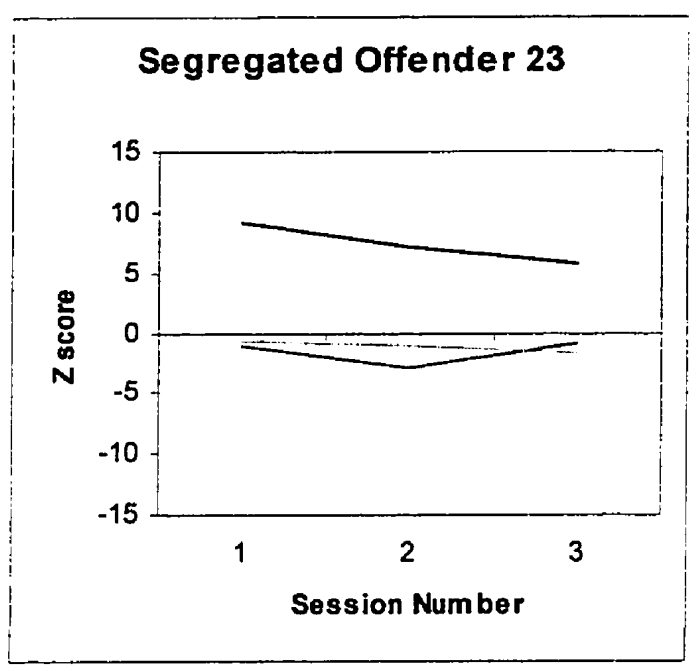



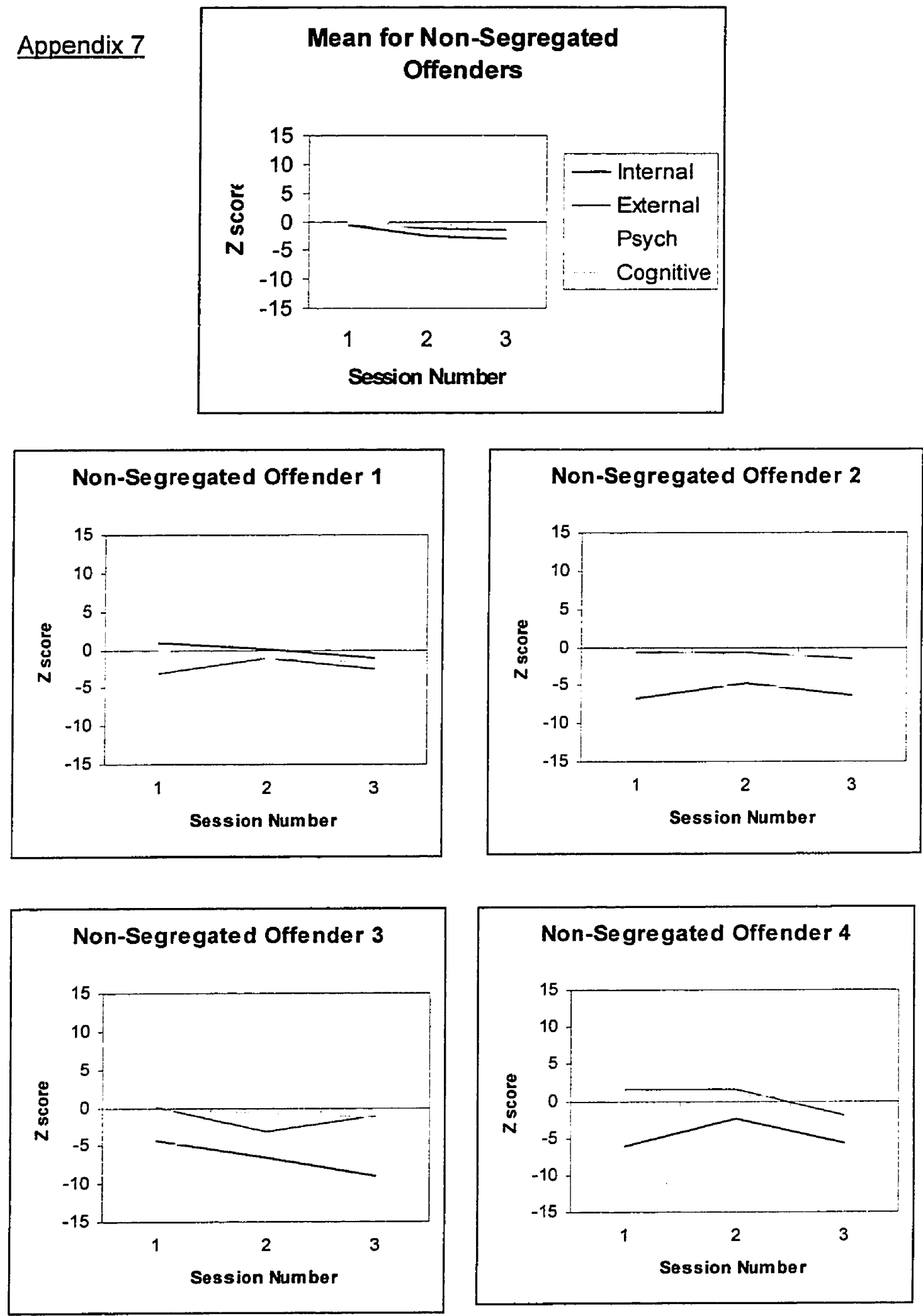

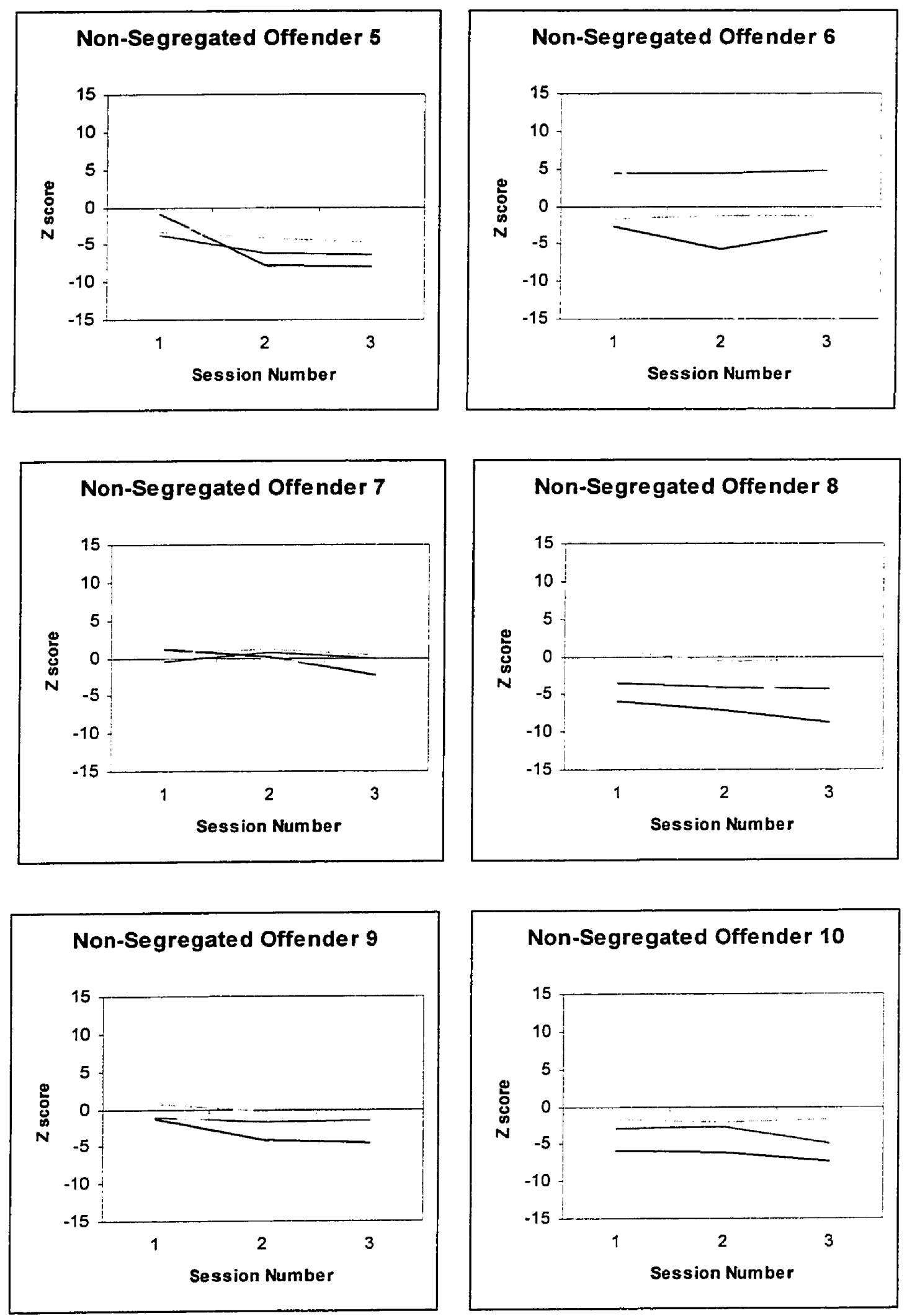
Effects of Segregation
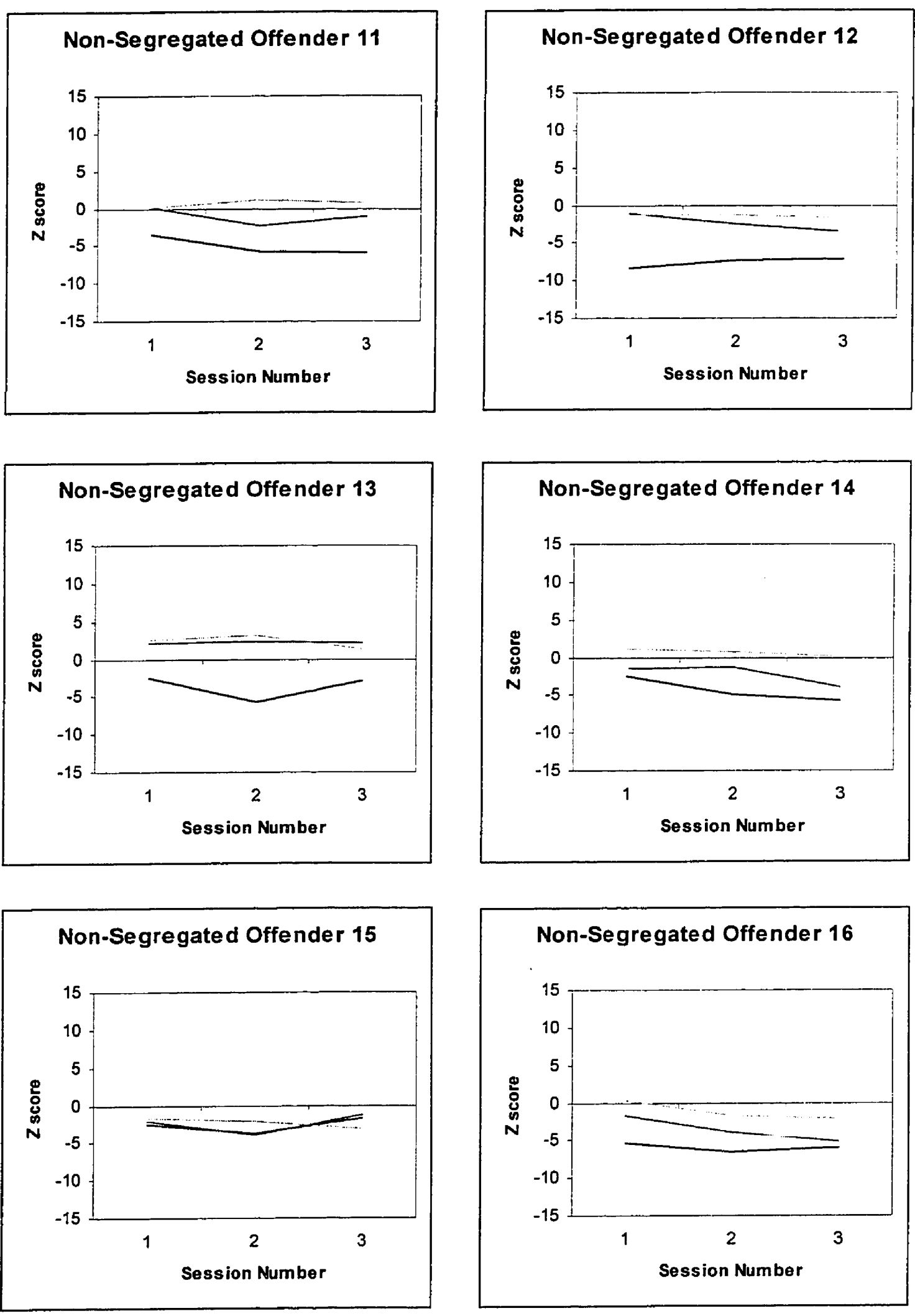

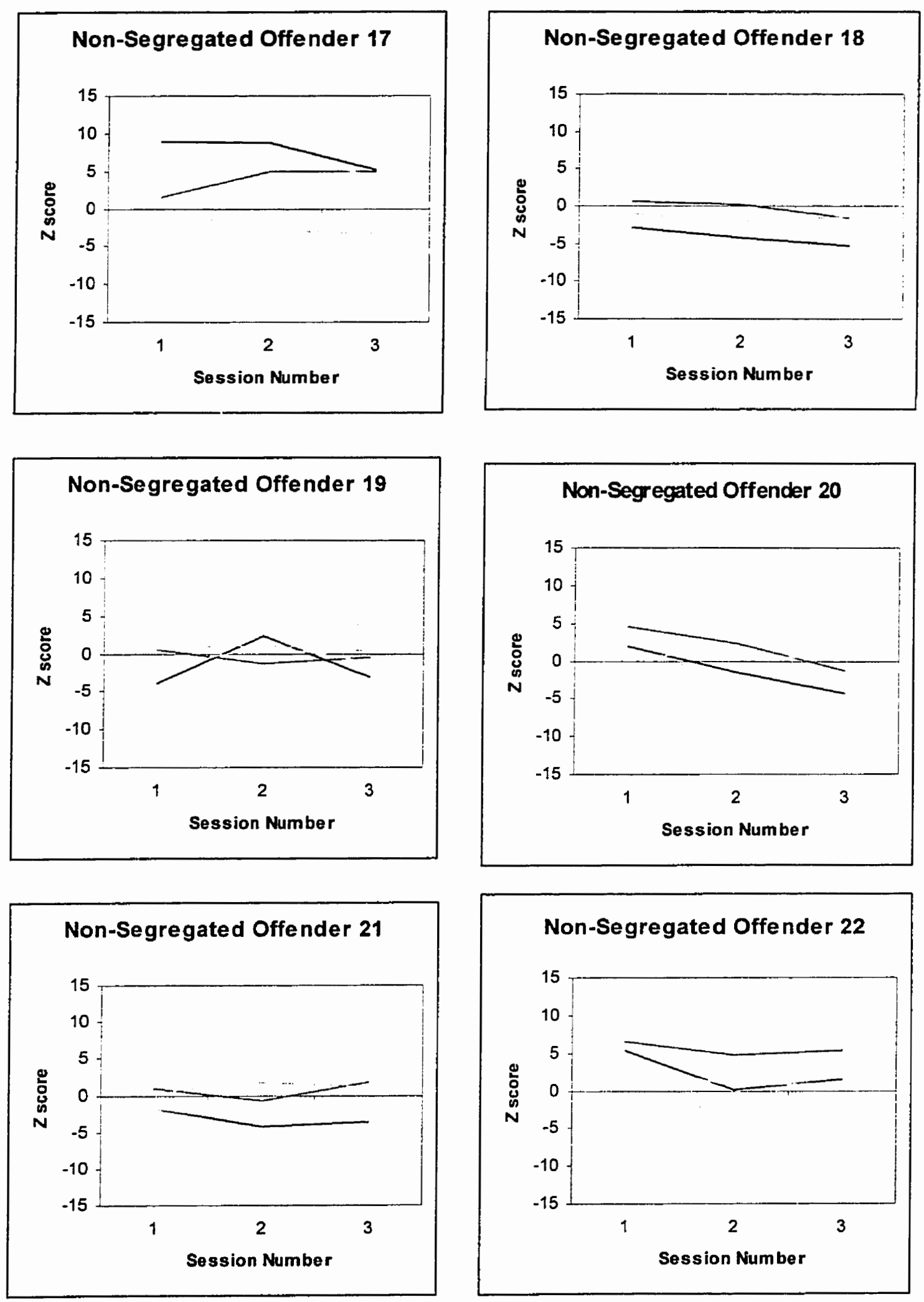

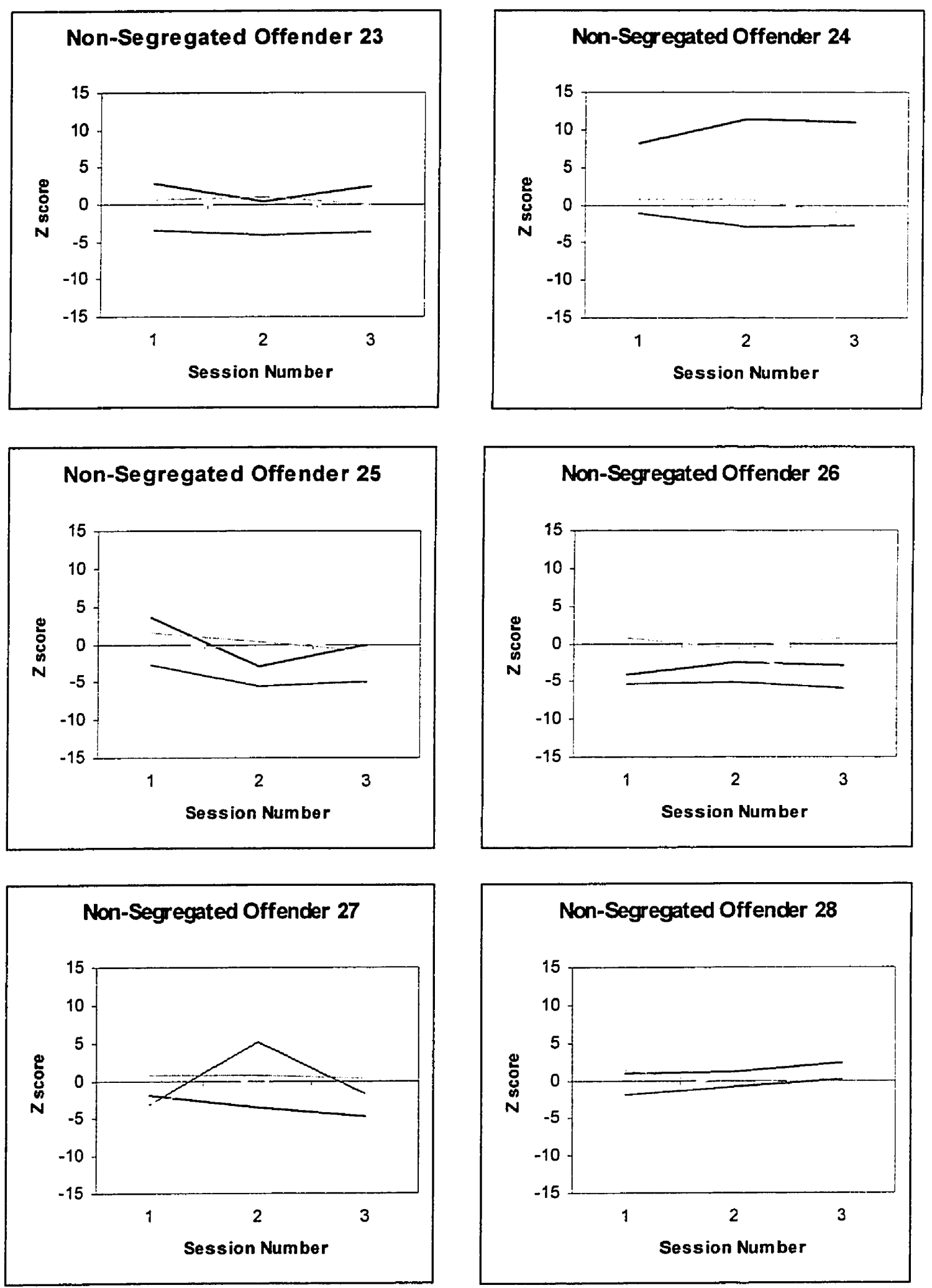

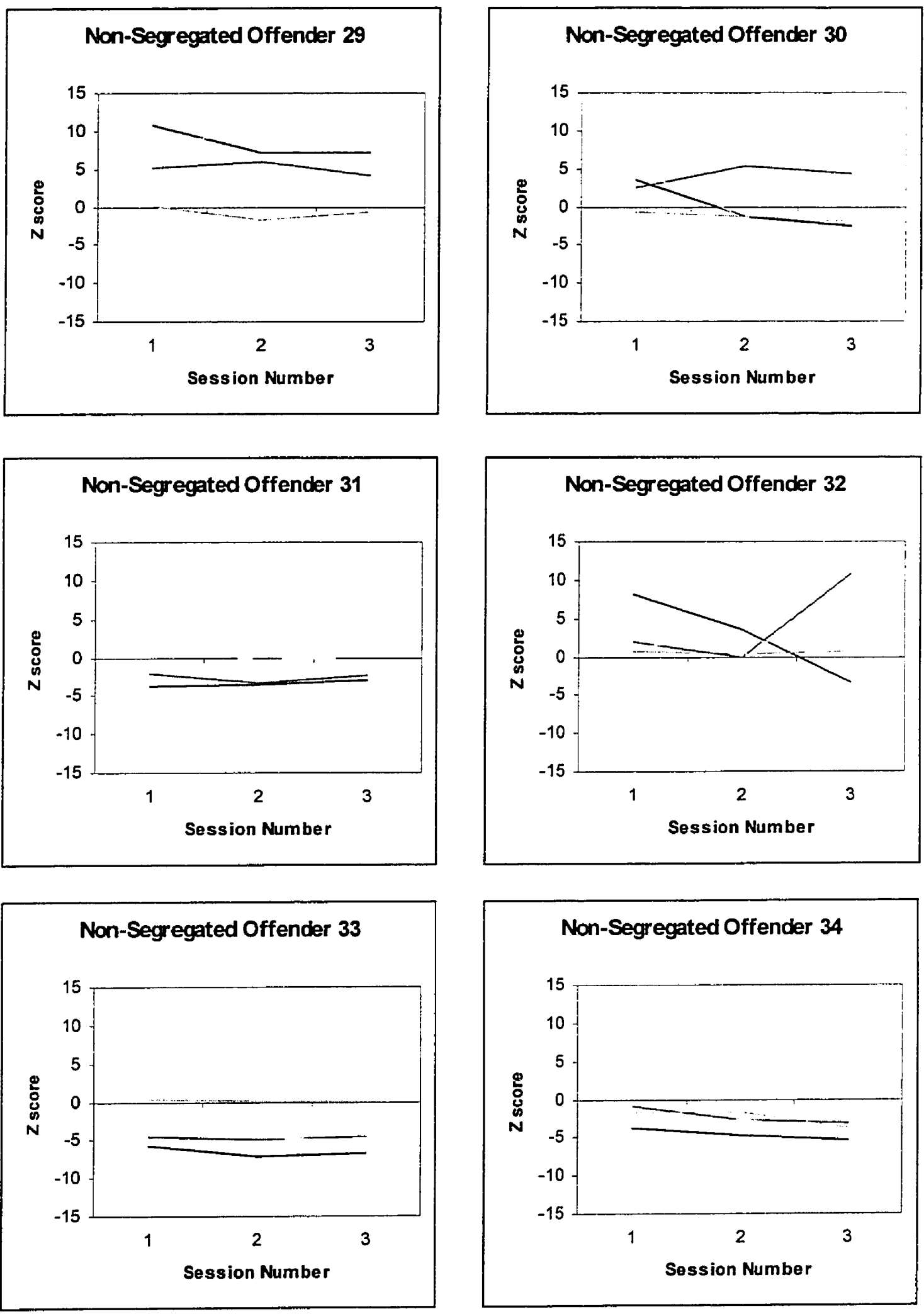
Effects of Segregation
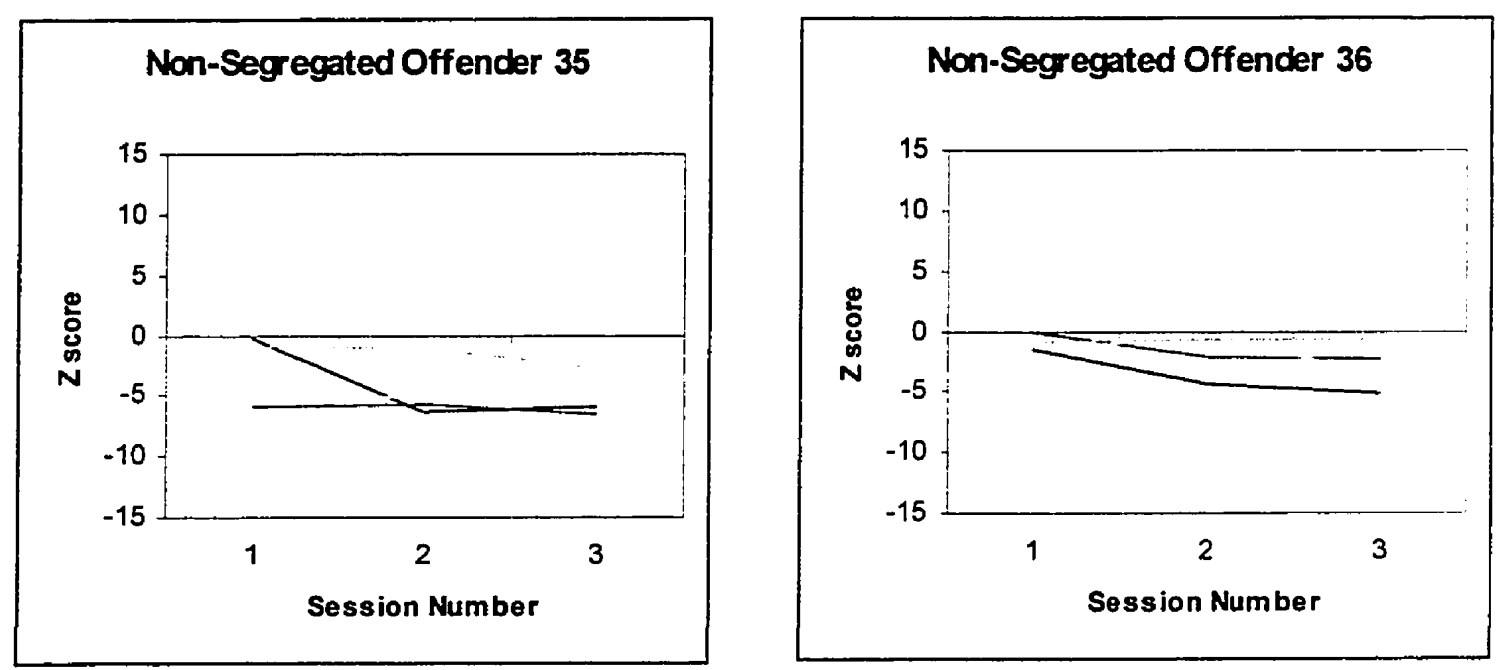

Non-Segre gated Offender 37

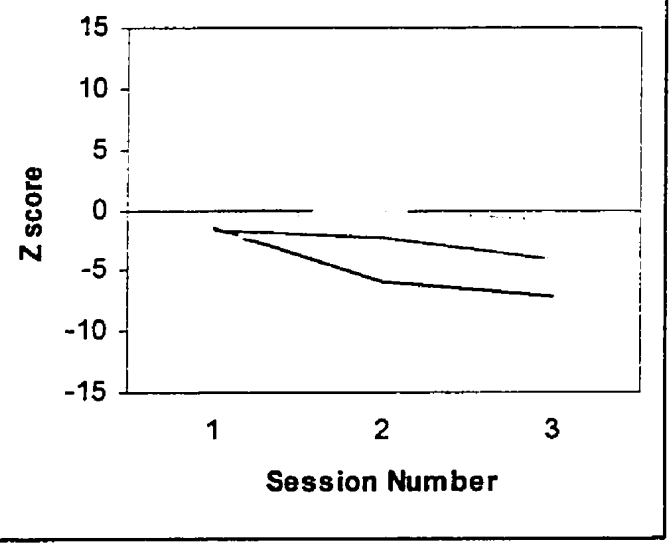




\section{$\underline{\text { References }}$}

Akers, R., Hayner, N.S., \& Gruinger, W. (1977). Prisonization in five countries: Type of prison and inmate characteristics. Criminology, 4, 527-554.

Alpert, G.P. (1979). Patterns of change in prisonization: A longitudinal analysis. Criminal Justice and Behaviour, 6, 159-174.

Andrews, D.A., \& Bonta, J. (1994). The Psychology of Criminal Conduct. Cincinnati: Anderson Publishing.

Andrews, D.A., Bonta, J., \& Hoge (1990). Classification for effective rehabilitation: Rediscovering psychology. Criminal Justice and Behavior, 17, 1952.

Andrews, D.A., Zinger, I., Hoge, R.D., Bonta, J., Gendreau, P., \& Cullen, F.T. (1990). Does correctional treatment work? A psychologically informed meta-analysis. Criminology, 28, 369-404.

Arbour L. (Commissioner), Commission of Inquiry into Certain Events at Prison for Women in Kingston (Ottawa: Queen's printer, April 1996).

Archer, J., Kilpatrick, G., \& Bramwell, R. (1995). Comparison of two aggression inventories. Aggressive Behavior, 21, 371-380.

Barak-Glantz, I.L. (1983). Who's in the "hole"? Criminal Justice Review, 8, 29-37.

Beck, A. T., \& Beamesdorfer, A. (1974). Assessment of depression: The depression inventory. Modem Problems in Pharmacopsychiatry, 7, 151-169. 
Beck, A. T., \& Beck, R. W. (1972). Screening depressed patients in family practice: A rapid technique. Postgraduate Medicine, 52, 81-85.

Beck, A. T., Rial, W. Y., \& Rickles, K. (1974). Short form of depression inventory: Cross-validation. Psychological Reports, 34, 1184-1186.

Beck, A. T., \& Steer, R. A. (1988). Manual for the Beck Hopelessness Scale. New York: Psychological Corporation.

Beck, A. T., Steer, R. A., \& Shaw, B. F. (1984). Hopelessness in an alcohol- and heroin-dependant women. Journal of Clinical Psychology, 40, 602-606.

Beck, A. T., Weissman, A., Lester, D., \& Trexler, L. (1974). The measurement of pessimism: The Hopelessness Scale. Journal of Consulting and Clinical Psychology, 42, 861-865.

Benjamin, T.B., \& Lux, K. (1977). Solitary confinement as punishment. California Westem Law Review, 13, 265-296.

Benjamin, T.B., \& Lux, K. (1975). Constitutional and psychological implications of the use of solitary confinement: Experience at the Maine State Prison. Clearinghouse Review, 9, 83-90.

Bertrand, M.-A. (1996). Women in prison, a comparative study. Caribbean Journal of Criminology and Social Psychology, 1(1), 38-58.

Bexton, W.H., Heron W., \& Scott, T.H. (1954). Effects of decreased variation in the sensory environment. Canadian Journal of Psychology, 8, 70-76.

Birkinshaw, P. (1981). The control unit regime: Law and order in prison. Howard Journal, 20, 69-80. 
Bonta, J., Harman, W.G., Hann, R.G., \& Cormier, R.B. (1996). The prediction of recidivism among federally sentenced offenders: A re-validation of the SIR scale. Canadian Journal of Criminology, Jan., 61-79.

Bonta, J., Pang, B., \& Wallace-Capretta, S. (1995). Predictors of recidivism among incarcerated female offenders. Prison Journal, 75:3, 277-294.

Bonta, J., \& Gendreau, P. (1995). Reexamining the cruel and unusual punishment of prison life. In T.J. Flanagan (Ed.), Long-term Imprisonment: Policy, Science, and Correctional Practice (pp. 75-94). Thousand Oaks, CA: Sage.

Boulet, J., \& Boss, M. W. (1991). Reliability and validity of the Brief Symptom Inventory. Psychological Assessment, 3, 433-437.

Broday, S. F., \& Mason, J. L. (1991). Internal consistency of the Brief Symptom Inventory for counseling-center clients. Psychological Reports, 68, 94.

Brodsky, S.L., \& Scogin, F.R. (1988). Inmates in protective custody: First data on emotional effects. Forensic Reports, 1, 267-280.

Buss, A. H., \& Perry, M. (1992). The aggression questionnaire. Journal of Personality and Social Psychology, 63, 452-459.

Carriere, K.D. (1989). Protective custody in Canada: A review of research and policy responses. Canadian Criminology Forum, 10, 17-25.

Clemmer, D. (1940). The Prison Community. Boston: Christoher. 
Coleman, E., Cesnik, J., Moore, A. M., \& Dwyer, S. M. (1992).

Exploratory study of the role of psychotropic medications in the treatment of sex offenders. Journal of Offender Rehabilitation, 18 (3-4), 75-88.

Cook, T.D., \& Leviton, L.C. (1980). Reviewing the literature: A comparison of traditional methods with meta-analysis. Journal of Personality, $48(4), 449-472$.

Costa, P. T., Jr., \& McCrae, R. R. (1989). The NEO-PI/NEO-FFI Manual Supplement. Odessa, FL: Psychological Assessment Resources.

Costa, P. T., Jr., \& McCrae, R. R. (1990). Personality disorders and the five-factor model of personality. Journal of Personality Disorders, 4, 362-371.

Costa, P. T., Jr., \& McCrae, R. R. (1992). Revised NEO Personality Inventory and NEO Five-factor Inventory Professional Manual. Odessa, FL: Psychological Assessment Resources.

Coyle, A.G. (1987). The management of dangerous and difficult prisoners. Howard Journal, 26, 139-152.

Day, A. (1993). Brief prescriptive psychotherapy for depression with an incarcerated young offender. Journal of Offender Rehabilitation, 19 (1-2), 75-87.

Derogatis, L. R. (1992). The Brief Symptom Inventory (BSI):

Administration, Scoring, and Procedures Manual II. Towson, MD: Clinical Psychometrics Research. 
Derogatis, L. R., \& Melisaratos, N. (1983). The Brief Symptom Inventory: An introductory report. Psychological Medicine, 13, 596-605.

Derogatis, L. R., \& Meyer, J. K. (1979). A psychological profile of the sexual dysfunctions. Archives of Sexual Behavior, 8, 201-223.

Derogatis, L. R. (1975). Brief Symptom Inventory. Baltimore: Clinical Psychometric Research.

Diagnostic and Statistical Manual of Mental Disorders (1994). (Washington: American Psychiatric Association).

Digman, J.M. (1990). Personality structure: Emergence of the five-factor model. Annual Review of Psychology, 41, 417-440.

Dowker, F., \& Good, G. (1993). The proliferation of control unit prisons in the United States. Journal of Prisoners on Prisons, 4, 95-110.

Dutton, D. G., \& Hemphill, K. J. (1992). Patterns of socially desirable responding among perpetrators and victims of wife assault. Violence and Victims, 7, 29-39.

Ecclestone, C.E.J., Gendreau, P., \& Knox, C. (1974). Solitary confinement of prisoners: An assessment of its effects on inmates' personal constructs and andrenocortical activity. Canadian Journal of Behavioral Science, $6,178-191$.

Ellis, J. (1993). Security officer's role in reducing inmate problem behaviors. Journal of Offender Rehabilitation, 20, 61-72. 
Endler N.S. (1997). Stress, anxiety and coping: The multidimentional interactional model. Canadian Psychology, 38:3, 137-153.

Endler N.S. (1993). Personality: An interaction perspective. In P.J. Hettema \& I.J. Deary (Eds.), Foundations of Personality, (pp. 251-168). Dordecht, Netherlands: Kuwer Academic.

Eyestone, L. L., \& Howell, R. J. (1994). An epidemiological study of attention-deficit hyperactivity disorder and major depression in a male prison population. Bulletin of the American Academy of Psychiatry and the Law, 22, 181-193.

Foelker, G. A., Shewchuk, R. M., Niederehe, G. (1987). Confirmatory factor analysis of the short form Beck Depression Inventory in elderly community samples. Journal of Clinical Psychology, 43, 111-118.

Fowles, G. P., \& Tunick, R. H. (1986). WAIS-R and Shipley estimated IQ correlations. Journal of Clinical Psychology, 42, 647-649.

Frisch, M. B., \& Jessop, N. S. (1989). Improving WAIS-R estimates with the Shipley-Hartford and Wonderlic Personell Tests: Need to control for reading ability. Psychological Reports, 65, 923-928

Frost, R. O., Krause, M. S., \& Steketee, G. (1996). Hoarding and obsessive-compulsive symptoms. Behavior Modification, 20, 116-132. 
Gavazzi, S. M., Julian, T. W., \& McKenry, P. C. (1996). Utilzation of the Brief Symptom Inventory to discriminate between violent and nonviolent male relationship partners. Psychological Reports, 79, 1047-1056.

Gendreau, P., \& Bonta, J. (1984). Solitary confinement is not cruel and unusual punishment: People sometimes are! Canadian Journal of Criminology, $26,467-478$.

Gendreau, P.E., Freedman, N., Wilde, G.J.S., \& Scott, G.D. (1968a). Stimulation seeking after seven days of perceptual deprivation. Perceptual and Motor Skills, 26, 547-550.

Gendreau, P.E., Freedman, N., Wilde, G.J.S., \& Scott, G.D. (1972). Changes in EEG alpha frequency and evoked response latency during solitary confinement. Abnormal Psychology, 79, 54-59.

Gendreau, P.E., Horton, J.G., Hooper, D.G., Freedman, G.J.S., \& Scott, G.D. (1968b). Perceptual deprivation and perceptual skills: Some methodological considerations. Perceptual and Motor Skills, 27, 57-58.

Gendreau, P., McLean, R., Parsons, T., Drake, R., \& Ecclestone, J. (1970). Effect of two days' monotonous confinement on conditioned eyelid frequency and topography. Perceptual and Motor Skills, 31, 291-293.

Gendreau, P., Tellier, M.-C., \& Wormith, J.S. (1985). Protective custody: The emerging crisis within our prisons. Federal Probation, 44, 55-63. 
Goldenberg, E., \& Cowden, J.E. (1977). An evaluation of intensive group therapy with male offenders in isolation units. Corrective and Social Psychiatry and Joumal of Behavior Technology, Methods, and Therapy, 23, 69-72.

Gould, J. (1982). A psychometric investigation on the standard and short from Beck Depression Inventory. Psychological Reports, 5, 1167-1170.

Grassian, S. (1983). Psychopathological effects of solitary confinement. American Journal of Psychiatry, 140, 1450-1454.

Groves, M. (1996). Administrative segregation of prisoners: Powers, principles of review and remedies. Melbourne University Law Review, 20,639689.

Gudjonsson, G. H. (1984). Attribution of blame for criminal acts and its relationship with personality. Personality and Individual Differences, 5, 53-58.

Haney, C. (1993). "Infamous punishment": The psychological consequences of isolation. National Prison Project Journal, 8, 3-7, 21.

Hann, R., \& Harman, W. (1989). Release Risk Prediction: A Test of the Nuffield Scoring System for Native and Female Inmates. Ottawa: Ministry of the Solicitor General of Canada.

Heinemann, A. W., Harper, R. G., Friedman, L. C., \& Whitney, J. (1985). The relative utility of the Shipley-Hartford Scale: Prediction of WAIS-R IQ. Journal of Clinical Psychology, 41, 547-551.

Henderson, J.D. (1992). Managing protective custody units. Federal Prisons Journals, 3, 42-47. 
Hodgins, S., \& Cote, G. (1991). The mental health of penitentiary inmates in isolation. Canadian Journal of Criminology, 33, 175-182.

Holden, R. R. (1991, June). Psychometric properties of the Holden Psychological Screening Inventory (HPSI). Paper presented at the annual convention of the Canadian Psychological Association, Calgary.

Holden, R. R. (1992). Associations between the Holden Psychological Screening Inventory and the NEO Five Factor Inventory in a non-clinical sample. Psychological Reports, 71, 1039-1042.

Holden, R. R., \& Fekken, G. C. (1988). Test-retest reliability of the hopelessness scale and its items in a university population. Journal of Clinical Psychology, 44, 40-43.

Holden, R. R., \& Fekken, G. C. (1994). The NEO five factor inventory in a Canadian context: Psychometric properties for a sample of university women. Personality and Individual Differences, 17, 441-444.

Holden, R. R. , \& Grigoriadis, S. (1995). Psychometric properties of the Holden Psychological Screening Inventory for a psychiatric offender sample. Journal of Clinical Psychology, 51, 811-819.

Holden, R. R., Mendonca, J. D., Mazmanian, D., \& Reddon, J. R. (1992). Clinical construct validity of the Holden Psychological Screening Inventory (HPSI). Journal of Clinical Psychology, 48, 627- 633. 
Hooper, F. A., \& Evans, R. G. (1984). Screening for disruptive behavior of institutionalized juvenile delinquents. Journal of Personality Assessment, 48, 159-161.

Immarigeon, R. (1992). The marionization of American prisons. National Prison Project Journal, 7, 1-5.

Ingram, J. C. et al., (1985). Recidivism, perceived problem-solving abilities, MMPI chars, and violence: A study of Black and White incarcerated male adult offenders. Journal of Clinical Psychology, 41, 425-432.

Ivanoff, A., \& Jang, S. J. (1991). The role of hopelessness and social desirability in predicting suicidal behavior: A study of prison inmates. Journal of Consulting and Clinical Psychology, 59, 394-399.

Jackson, M. (1988). Justice behind the Walls: A Report of the Canadian Bar Association Committee on Imprisonment and Release. Ottawa: Canadian Bar Association.

Jackson, M. (1983). Prisoners of isolation: Solitary confinement in Canada. Toronto: University of Toronto Press.

Johnson, R., \& Toch, H. (1983). Introduction. In R. Johnson, \& H. Toch. The Pains of Imprisonment. Beverly Hills: Sage Publications.

Jones, D.A. (1976). The health risks of imprisonment. Lexington, MA: Lexington Books.

Kane, D. (Chair) (1997). Commitment to Legal Compliance, Fair Decisions and Effective Results. Ottawa: Correctional Service Canada. 
Knight, R. G., Waal-Manning, H. J., \& Spears, G. F. (1983). Some norms and reliability data for the State-Trait Anxiety Inventory and the Zung Self-Rating Depression Scale. British Joumal of Clinical Psychology, 22, 245-249.

Korn (1988). The effects of confinement in the high security unit at Lexington. Social Justice, 15(1), 1-20.

Kroner, D. G., \& Weekes, J. R. (1996). Balanced Inventory of Desirable Responding: Factor structure, reliability, and validity with an offender sample. Personality and Individual Differences, 21, 323-333.

Laplante, J. (September, 1998). Paper presented at the Conference entitled The Reasonable Alternative. Kingston: Correctional service of Canada.

Lazarus, R.S., \& Folkman, S. (1984). Stress, Appraisal, and Coping. New York: Springer.

Leahne, G. K. (1994). The NEO-PI and the MCMI in the forensic evaluation of sex offenders. In P. T. Costa and T. A. Widiger (Eds.), Personality Disorders and the Five-factor Model of Personality (pp. 175-188). Washington, DC: American Psychological Association.

Leahy, J. M. (1992). Validity and reliability of the Beck Depression Inventory-short form in a group of adult bereaved females. Journal of Clinical Psychology, 48, 64-68. 
Lennings, C. J. (1992). Suicide and time perspective: An examination of Beck and Yufit's suicide-risk indicators. Joumal of Clinical Psychology, 48, 510516.

Lepore, S.J., \& Evans, G.W. (1996). Coping with multiple stressors in the environment. In M. Zeidner \& N.S. Endler (Eds.), Handbook of Coping: Theory, Research, Applications. New York: John Wiley.

Luise (1989). Solitary confinement: Legal and psychological considerations. Criminal and Civil Confinement, 15, 301-324.

Lutz, S. J. (1990). Effect of relaxation training on sleep, state anxiety and, and sick call in a jail population. Journal of Prison and Jail Health, 9, 55-71.

MacGuigan J. (Chair) (1977). Report to Parliament: The Sub-Committee on the Penitentiary System in Canada. Ottawa: Queen's Printer.

Magnussen, D., \& Endler, N.S. (1977). Personality at a Crossroads: Current Issues in Interactional Psychology. Hillsdale, N.J.: Lawrence Erlbaum Associates.

Manson, A. (1996). Scrutiny from the outside: The Arbour Commission, the Prison for Women and the Correctional Service of Canada. Canadian Criminal Law Review, 1, 321-337.

Manson, A. (1990). Solitary confinement, remission and prison discipline. Criminal Reports, 75 (3ed.), 356-364. 
Matreau, T. M., \& Bekker, H. (1992). The development of a six-item short-form of the state scale of the Spielberger State-Trait Anxiety Inventory (STAI). British Journal of Clinical Psychology, 31, 301-306.

Maxwell, W.W. (1987). Educating segregated inmates. Corrections Today, 2, 106, 108, 110, 112.

McGuire, J., Broomfield, D., Robinson, C., \& Rowson, B. (1995). Shortterm effects on probation programs: An evaluative study. International Journal of Offender Therapy and Comparative Criminology, 39, 23-42.

Metzger, R. L. (1976). A reliability and validity study of the State-Trait Anxiety Inventory. Journal of Clinical Psychology, 32, 276-278.

Miller, H. A. (1994). Reexamining psychological distress in the current consitions of segregation. Journal of Correctional Health Care, 1, 39-53.

Miller, H. A., \& Young, G.R. (1997). Prison segregation: administrative detention remedy or mental health problem. Criminal Behaviour and Mental Health, 7, 85-94.

Motiuk, L.L., \& Blanchette, K. (1997). Case Characteristics of Segregated Offenders in Federal Corrections. Ottawa, ON: Correctional Service of Canada.

Motiuk, L.L., \& Porporino, F. (1989). Offender Risk/needs Assessment: A Study of Conditional Releases. Ottawa, ON: Correctional Service of Canada. 
Nielson, A. C., \& Williams, T. W. (1980). Depression in ambulatory medical patients: Prevalence by self-report questionnaire and recognition by nonpsychiatric physicians. Archives of General Psychiatry, 37, 399.

Nixon, G. F., \& Steffeck, J. C. (1977). Reliability of the state-trait anxiety inventory. Psychological Reports, 40, 357-358.

Novy, D. M., Nelson, D. V., Goodwin, J., \& Rowzee, D. (1993).

Psychometric comparability of the State-trait anxiety inventory for different ethnic subpopulations. Psychological Assessment, 5, 343-349.

Osman, A., Barrios, F. X., Aukes, D., Osman, J. R., \& Markway, K. (1993). The Beck Anxiety Inventoyr: Psychometric properties in a community population. Journal of Psychopathology and Behavioral Assessment, 15, 287-297.

Osman, A., Besett, T. M., Osman, J. R., Troutman, J. A., \& Grittman, L. (1995). Systematic evaluation of psychometric properties of the Cognition Checklist with college students. Psychological Reports, 76, 523-528.

Paulhus, D. L. (1984). Two-component models of socially desirable responding. Journal of Personality and Social Psychology, 46, 598-609.

Pedhazur, E.J. (1982). Multiple Regression in Behavioral Research. New York: Harcourt Brace College Publishers.

Piersma, H. L., Reaume, W. M., \& Boes, J. L. (1994). The Brief Symptom Inventory (BSI) as an outcome measure for adult psychiatric inpatients. Journal of Clinical Psychology, 50, 555-563. 
Pierson, T.A. (1988). Use of protective custody: How different systems respond. Corrections Today, 50, 150, 152, 154.

Power, K. G., \& Beveridge, L. (1990). The effects of custody in a Scottish detention centre on inmates' self-esteem. International Journal of Offender Therapy and Comparative Criminology, 34(3), 177-186.

Reddon, J. R., Pope, G. A., Friel, J. P., Sinha, B. K. (1996). Leisure motivation in relation to psychosocial adjustment and personality in young offenders and high school samples. Journal of Clinical Psychology, 52, 679-685.

Retzlaff, P., Slicner, N., \& Gibertini, M. (1986). Predicting WAIS-R scores from the Shipley Institute of Living Scale in a homogeneous sample. Journal of Clinical Psychology, 42, 357-359.

Reynolds, W. M., \& Gould, J. W. (1981). A psychometric investigation of the standard and short form Beck Depression Inventory. Journal of Consulting and Clinical Psychology, 49, 306-307.

Rold, W.J. (1992). Consideration of mental health factors in inmate discipline. Journal of Prison and Jail Health, 11, 41-49.

Ruiz, R. A., \& Krauss, H. H. (1967). Test-retest reliability and practice effect with the Shipley-Institute of Living Scale. Psychological Reports, 20, 10851086.

Russell, G. W. (1995). Personalities in the crowd: Those who would escalate a sports riot. Aggressive Behavior, 21, 91-100. 
Russell, G. W., \& Arms, R. L. (1995). False consensus effects, physical aggression, anger, and willingness to escalate a disturbance. Aggressive Behavior, 21, 381-386.

Scogin, F., Beutler, L., Corbishley, A., \& Hamblin, D. (1988). Reliability and validity of the short form Beck Depression Inventory with older adults. Journal of Clinical Psychology, 44, 853-856.

Scott, G.D., \& Gendreau, P. (1969). Psychiatric implications of sensory deprivation a maximum security prison. Canadian Psychiatric Association Journal, 14, 337-340.

Segal, B, Hobfoll, S. S., \& Cromer, F. (1984). Alcohol use by juvenile offenders. International Journal of the Addictions, 19, 541-549.

Sheldon, K. M. (1994). Emotionality differences between artists and scientists. Joumal of Research in Personality, 28, 481-491.

Shipley, W. C. (1940). A self-administering scale for measuring intellectual impairment and deterioration. Joumal of Psychology, 9, 371-377.

Singer, M. I., Bussey, J., Song, L. Y., \& Lunghofer, L. (1995). The psychological issues of women serving time in jail. Social Work, 40, 103-113.

Skyes, G.M., \& Messinger, S.L. The inmate social system. In R. Cloward et al. (Eds.), Theoretical Studies in Social Organization of the Prison. New York: Social Science Research Council, 1960. 
Smyth, N. J., Ivanoff, A., \& Jang, S. J. (1994). Changes in psychological maladaptation among inmate parasuicides. Criminal Justice and Behavior, 21, 357-365.

Spielberger, C. D. (1983). Manual for the State-Trait Anxiety Inventory STAI (Form Y). Palo Alto, CA: Consulting Psychologist Press.

Steer, R. A., Beck, A. T., Brown, G. K., \& Beck, J. S. (1993). Classification of suicidal and nonsuicidal outpatients: A cluster-analytic approach. Journal of Clinical Psychology, 49, 603-614.

Stukenberg, K. W., Dura, J. R., \& Kiecolt-Glaser, J. K. (1990). Depression screening scale validation in an elderly, community dwelling population. Psychological Assessment, 2, 134-138.

Suedfeld, P., \& Roy, C. (1974). Using social isolation to change the behaviour of disruptive inmates. International Journal of Offender Therapy, 19, 90-99.

Suedfeld, P., Ramirez, C, Deaton, J., \& Baker-Brown, G. (1982). Reactions and attributes of prisoners in solitary confinement. Criminal Justice and Behavior, 9:3, 303-340.

Sutker, P. B., \& Moan, C. E. (1973). Prediction of socially maladaptive behavior within a state prison system. Journal of Community Psychology, 1, 7478. 
Tellier, C., Wormith, S., \& Gendreau, P. (1989). Protective Custody: The Emerging Crisis Within the Prison System (Working Paper). Ottawa: Solicitor General Canada.

The Editors (1986). Note: Prisoner segregation. Administrative Law Journal, 2, 62-68.

Toch, H. (1992). Living in Prison: The Ecology of Survival. Washington: American Psychological Association.

Toch, H., \& Adams, K. (1989). Coping: Maladaptation in Prisons. New Brunswick, N.J.: Transaction Books.

Thomas, C.W. (1977). Theoretical perspectives on prisonization: A comparison of the importation and deprivation models. Joumal of Criminal Law \& Criminology, 68, 135-145.

Thomas, C.W., \& Poole, E.D. (1975). The consequences of incompatible goal structures in correctional settings. International Journal of Criminology and Penology, 3, 27-42.

Vantour, J.A. (1975). Report of the Study Group on Dissociation. Ottawa: Solicitor General Canada.

Verkasalo, M., \& Lindeman, M. (1994). Personal ideals and socially desirable responding. European Journal of Personality, 8, 385-393.

Volk, R. J., Pace, T. M., \& Parchman, M. L. (1993). Screening for depression in primary care patients: Dimensionality of the short form of the Beck Depression Inventory. Psychological Assessment, 5, 173-181. 
Vredenberg, K., Krames, L., \& Flett, G. L., (1985). Re-examining the Beck Depression Inventory: The long and the short of it. Psychological Reports, $56,767-778$.

Wadeson, H., \& Carpenter, W.T. (1976). Impact of seclusion room experience. Journal of Nervous Mental Disease, 163, 318-328.

Walters, R.H., Callagan, J.E., \& Newman, A.F. (1963). Effect of solitary confinement on prisoners. American Journal of Psychiatry, 119, 771-773.

Watson, C. G., Plemel, D., Schaefer, A., Raden, M., Alfano, A. M., Anderson, P. E. D., Thomas, D., \& Anderson, D. (1992). The comparative concurrent validities of the Shipley Institute of Living Scale and the HemmonNelson Tests of Mental Ability. Journal of Clinical Psychology, 47, 233-239.

Weinberg, M.M. (1967). Effects of Partial Sensory Deprivation on Involuntary Subjects. Unpublished doctoral dissertation, Michigan State University.

Weiss, J. L., \& Schell, R. E. (1991). Estimating WAIS-R IQ from the Shipley Institute of Living Scale: A replication. Journal of Clinical Psychology, $47,558-561$

Williams, T. Y., Boyd, J. C., Cascardi, M. A., Poythress, N. (1996). Factor structure and convergent validity of the Aggression Questionnaire in an offender population. Psychological Assessment, 8, 398-403. 
Wood, R. W., Conn, D. C., \& Harrison, H. D. (1977). The efficacy of using Shipley-Hartford scores to predict to predict WAIS IQ in a penal population. Quarterly Joumal of Corrections, 1, 39-41.

Wormith. J.S., Tellier, M.-C., \& Gendreau, P. (1988). Characteristics of protective custody offenders in a provincial correctional centre. Canadian Joumal of Criminology, 30, 39-58.

Zamble, E. (1992). Behavior and adaptation in long-term prison inmates: Descriptive longitudinal results. Criminal Justice and Behavior, 19:4, 409-425.

Zamble, E., \& Poporino, F.J. (1988). Coping, Behavior, and Adaptation in Prison Inmates. New York: Springer-Verlag.

Zamble E., \& Poporino, F.J. (1990). Coping, imprisonment, and rehabilitation: Some data and their implications. Criminal Justice and Behavior, $17,53-70$.

Zamble, E., Poporino, F.J., \& Kalotay, J. (1984). An Analysis of Coping in Prison Inmates. Programs Branch User Report no. 1984-77. Ottawa: Ministry of the Solicitor General of Canada.

Zubek, J.P., Bayer, L, \& Shephard, J.M. (1969). Relative effects of prolonged social isolation and confinement: Behavioral and EEG changes. Journal of Abnormal Psychology, 74, 625-631. 

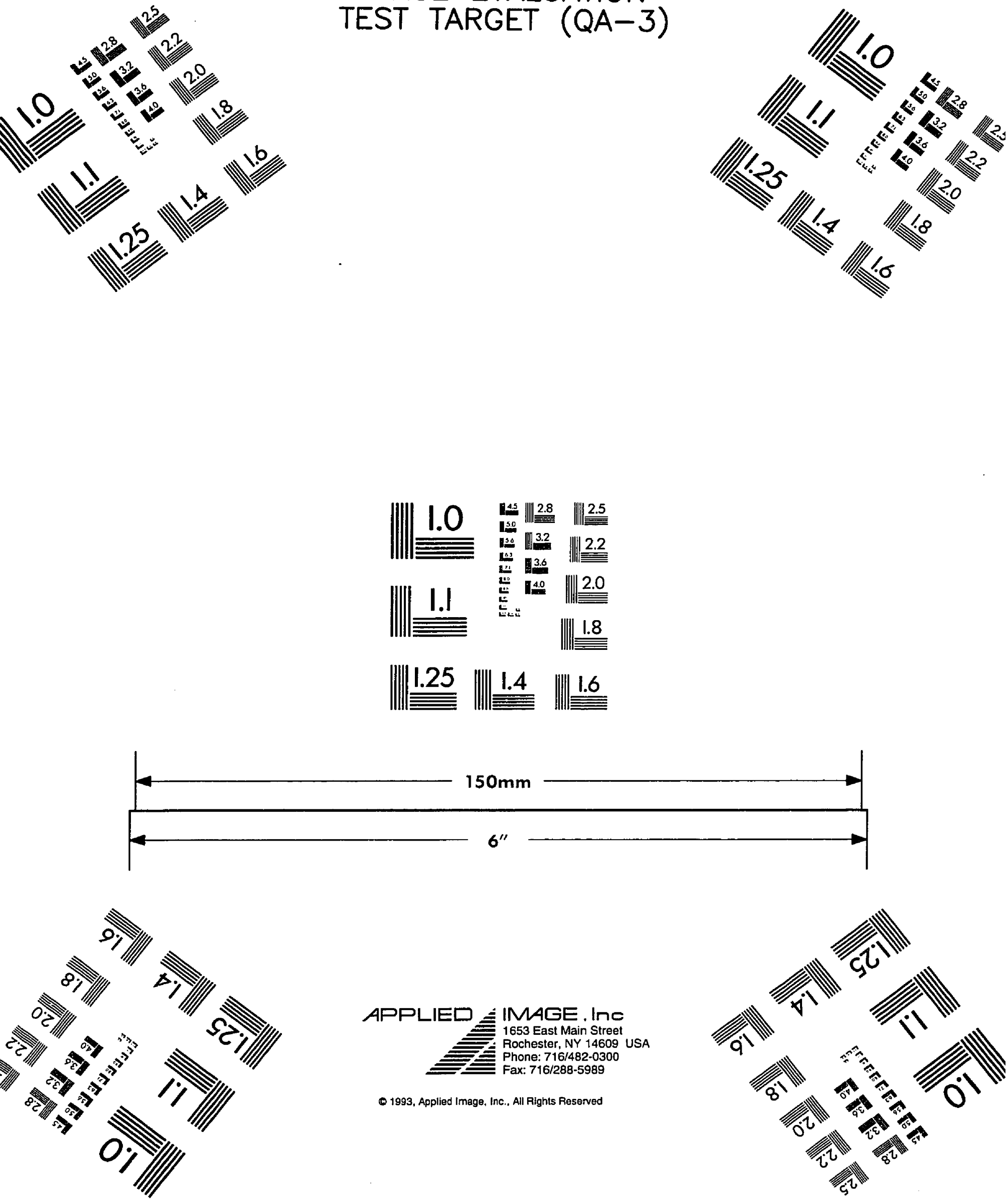